NBER WORKING PAPER SERIES THE DEMAND FOR INSURANCE AND RATIONALE FOR A MANDATE:
EVIDENCE FROM WORKERS' COMPENSATION INSURANCE

\author{
Marika Cabral \\ Can Cui \\ Michael Dworsky \\ Working Paper 26103 \\ http://www.nber.org/papers/w26103 \\ NATIONAL BUREAU OF ECONOMIC RESEARCH \\ 1050 Massachusetts Avenue \\ Cambridge, MA 02138 \\ July 2019, Revised January 2022
}

For providing helpful comments, we thank the editor Henrik Kleven, four anonymous referees, James Anderson, Mark Duggan, Liran Einav, Itzik Fadlon, Alex Gelber, Josh Gottlieb, Jonathan Gruber, Adriana Lleras-Muney, Seth Seabury, and seminar participants at BU/Harvard/MIT Health Economics, Cornell University, Ohio State University, Stanford University, the University of California Davis, the University of California Los Angeles, the University of California San Diego, the University of Michigan, the University of Texas at Austin, the University of Wisconsin Madison, the American Society of Health Economists Annual Conference 2018, the National Tax Association Annual Meeting 2018, and the Austin-Bergen Applied Microeconomics Conference 2018. Additionally, we thank several employees of the Texas Department of Insurance for helpful discussions about the institutional details and data. We thank Andriy Bega, David Beheshti, Bokyung Kim, Frank Martin-Buck, Seth Neller, and Jinyeong Son for their excellent research assistance. This research has undergone IRB review and obtained approval at the NBER. The authors gratefully acknowledge the RAND Institute for Civil Justice for financial support. Cabral gratefully acknowledges financial support from the National Science Foundation CAREER Award (1845190). The views expressed herein are those of the authors and do not necessarily reflect the views of the National Bureau of Economic Research.

NBER working papers are circulated for discussion and comment purposes. They have not been peer-reviewed or been subject to the review by the NBER Board of Directors that accompanies official NBER publications.

(C) 2019 by Marika Cabral, Can Cui, and Michael Dworsky. All rights reserved. Short sections of text, not to exceed two paragraphs, may be quoted without explicit permission provided that full credit, including $\odot$ notice, is given to the source. 
The Demand for Insurance and Rationale for a Mandate: Evidence from Workers' Compensation Insurance Marika Cabral, Can Cui, and Michael Dworsky

NBER Working Paper No. 26103

July 2019, Revised January 2022

JEL No. H0,I1,I13,I18,J38

\begin{abstract}
This paper analyzes the demand for insurance and the potential rationale for coverage mandates in the context of workers' compensation insurance. Workers' compensation is a state-regulated insurance program that provides employers with liability protection and employees with defined income and medical benefits in the event of work-related injuries or illnesses. Nearly all states have mandated workers' compensation insurance coverage; the sole exception is Texas. Using administrative data from the unique voluntary Texas workers' compensation insurance system, we estimate the demand for workers' compensation insurance leveraging idiosyncratic regulatory updates to relative premiums across industry-occupation classifications. The difference-indifferences estimates indicate that the demand for workers' compensation coverage is pricesensitive, with a $1 \%$ increase in premiums leading to approximately a $0.3 \%$ decline in coverage. Drawing upon these estimates and additional data on costs, we analyze potential justifications for government intervention to increase coverage through subsidies or a mandate. This analysis suggests that some common market failure justifications for government intervention in insurance markets-adverse selection, market power, and externalities-may not be compelling justifications for a mandate in this setting.
\end{abstract}

Marika Cabral

Department of Economics

University of Texas at Austin

2225 Speedway

BRB 1.116, C3100

Austin, TX 78712

and NBER

marika.cabral@utexas.edu

Can Cui

Department of Economics

University of Texas at Austin

2225 Speedway

BRB 1.116, C3100

Austin, TX 78712

cindycuican@gmail.com
Michael Dworsky

RAND Corporation

1776 Main Street

P.O. Box 2138

Santa Monica, CA 90407

mdworsky@rand.org 
Workers' compensation insurance is one of the first examples of large-scale social insurance in the United States, with the earliest state workers' compensation insurance programs established in the 1910s. Workers' compensation insurance provides covered employers protection from workplace injury liability and their associated employees with income and medical benefits in the event of work-related injuries or illnesses in exchange for forgoing the right to sue their employer for compensation for these workplace injuries. ${ }^{1}$ Workers' compensation insurance paid $\$ 62$ billion in benefits nationally in 2016, which was nearly double the $\$ 32$ billion paid in unemployment insurance benefits that year and was roughly equivalent to the amount paid that year through the Earned Income Tax Credit program and through the Supplemental Nutrition Assistance Program. ${ }^{2}$ Despite the substantial size and importance of workers' compensation insurance, little is known about the demand for workers' compensation insurance or the effects of government intervention in this market.

While many state workers' compensation markets initially allowed for voluntary participation, by the mid-1970s almost all states passed legislation mandating that employers purchase workers' compensation insurance. The sole remaining state without a workers' compensation coverage mandate is Texas, leaving employers in Texas free to choose whether or not to participate in the state-regulated workers' compensation system. A worker who suffers an on-the-job injury at a participating employer (i.e., an employer that participates in the state workers' compensation system) receives workers' compensation benefits as defined by statute. In contrast, there are no statutorily defined benefits for a worker who suffers an on-the-job injury at a non-participating employer (i.e., an employer that has chosen not to participate in the state workers' compensation system), and such employers may be exposed to tort liability for workplace injuries. In Texas, the total payroll covered by workers' compensation insurance policies was $\$ 257$ billion annually in the period 2006-2011, which represented roughly $74 \%$ of total Texas private industry payroll. ${ }^{3}$

Recently, lawmakers in several states have been debating repealing coverage mandates in favor of a regulated private market for voluntary workers' compensation insurance, based on the Texas model. In 2013, Oklahoma enacted a law intended to allow employers to opt out of the state workers' compensation system, though the law was overturned by the Oklahoma supreme court in 2015. ${ }^{4}$ Similar laws have recently been proposed in state legislatures in Tennessee, Florida, South Carolina, and Arkansas. These recent legislative proposals are part of an ongoing policy debate over the appropriate role of government regulation: should the government allow consumers to choose whether or not to purchase insurance, or should the government

\footnotetext{
${ }^{1}$ For convenience, we use workplace injury to refer to both workplace injuries and illnesses.

${ }^{2}$ Aggregating across the United States, workers' compensation insurance paid out $\$ 61.9$ billion dollars of benefits in 2016 (Elaine Weiss and Boden, 2019). In comparison, unemployment insurance paid \$31.7 billion in benefits in 2016 (DOL, 2019), the federal Earned Income Tax Credit paid \$66.7 billion in benefits in 2016 (IRS, 2020), and the Supplemental Nutrition Assistance Program paid \$66.5 billion in benefits in 2016 (USDA, 2020).

${ }^{3}$ Authors' calculations are based on data from the Texas Department of Insurance and the Quarterly Census of Employment and Wages published by the Bureau of Labor Statistics.

${ }^{4}$ See Sengupta, Baldwin and Reno (2014).
} 
mandate the purchase of private insurance? Proponents of coverage mandates often argue that they are necessary to address market failures such as adverse selection or externalities. Opponents of coverage mandates argue that allowing consumers to decide whether or not to purchase insurance while guaranteeing access to insurance (through, for example, regulating the form of coverage and pricing) is a better solution that respects choice while overcoming the main inefficiencies that can arise in a private insurance market.

In this paper, we estimate the demand for workers' compensation insurance in the absence of a coverage mandate and use these demand estimates to explore the empirical relevance of some common market failure justifications for coverage mandates. The Texas workers' compensation system provides a unique opportunity to study the demand for workers' compensation insurance. First, employers in Texas can choose whether to purchase workers' compensation insurance, making it possible to analyze the demand for coverage. Second, while coverage is voluntary, other aspects of the state-regulated workers' compensation system are very similar to the workers' compensation systems in other states. ${ }^{5}$ Thus, Texas provides a useful case study of an otherwise typical workers' compensation system that exists in the absence of a coverage mandate. Third, there exists extensive, plausibly exogenous variation in premiums and rich administrative data on coverage, costs, and premiums. Fourth, Texas is a large state-the second most populous, with an estimated population of more than 28 million. ${ }^{6}$ The findings in this paper are directly relevant for this large workers' compensation insurance market, and the findings may inform policy debates in states considering repealing coverage mandates.

Using administrative data on workers' compensation coverage, we exploit variation in insurance premiums resulting from regulatory updates to estimate the demand for workers' compensation insurance. Like other state workers' compensation systems, workers' compensation insurance in Texas is heavily regulated by the state, both in terms of the form of policies and the premiums insurers can charge. In particular, the structure of relative premiums across industry-occupation classifications is set by the government. We leverage idiosyncratic regulatory updates to these industry-occupation relative premiums in a difference-in-differences framework to estimate demand. These regulatory updates induce large changes in premiums within classification, over time: the mean absolute premium update is $9.3 \%$, and the interquartile range of updates is 15.3\%. Exploiting this variation, our baseline demand estimates suggest that a $1 \%$ increase in the premium results in approximately a $0.3 \%$ decline in coverage. The demand estimates are statistically precise and robust to the inclusion of more flexible controls, alternative event study specifications, and alternative specifications leveraging non-linearities in the update algorithm.

\footnotetext{
${ }^{5}$ The basic structure of benefits is common across all states: complete coverage for medical expenses associated with the workplace injury, partial wage replacement for temporary impairments, and additional cash benefits for permanent impairments or workplace fatalities. Experience rating formulas are very similar across states. See NCCI (2019) for more information about the basics of experience rating in state workers' compensation programs.

${ }^{6}$ According to the United States Census in April 2010, the population of Texas was 25,145,561. As of July 2018, the Census estimates the population in Texas to be $28,701,845$.
} 
Motivated by the near ubiquity of coverage mandates in the setting of workers' compensation insurance, we then use the demand estimates-along with administrative cost data-to investigate some common justifications for government intervention to increase coverage through a mandate and/or subsidies in this market. Specifically, we consider three classic market failure justifications for government intervention to increase coverage: adverse selection, market power, and externalities. Following the approach outlined by Einav and Finkelstein (2011) and Einav, Finkelstein and Cullen (2010), we employ administrative cost data to investigate the degree of selection in this market, leveraging the premium variation used to estimate demand. We find no evidence of adverse selection in this setting. We then explore market power as a potential alternative justification for government intervention through a series of welfare counterfactuals. In this analysis, we interpret the estimated demand for workers' compensation as representing the combined surplus of employers and employees, as they jointly make up the consumers in this market. This analysis suggests that there is little welfare at stake comparing the status quo to a perfectly competitive market and that market power is not a compelling justification for a coverage mandate in this setting. Lastly, we present additional back-of-the-envelope welfare analysis suggesting that potential externalities on external health care payers (e.g., health insurers, charity care providers) do not appear to be a compelling justification for mandating coverage in this market.

Overall, our analysis suggests that the market failure justifications we examine-adverse selection, market power, and externalities on external health care payers-may not justify mandating workers' compensation insurance coverage. We conclude by discussing two possible interpretations. One interpretation of this evidence is that a workers' compensation insurance coverage mandate may not improve welfare relative to a regulated voluntary market for this coverage. Another interpretation of the evidence is that there may be alternative justifications for a coverage mandate, such as underinsurance driven by behavioral biases or labor market frictions, that go beyond the classic market failure rationale we investigate in the revealed preference welfare analysis. Our empirical strategy does not allow us to rule out (or rule in) either of these interpretations, though we briefly discuss the plausibility of these interpretations in light of prior studies on workers' compensation insurance and discuss areas where future work is needed to inform policy.

Beyond addressing an important policy question, our research contributes to several distinct areas of the economics literature. This paper contributes to the recent growing literature investigating asymmetric information in private insurance markets and the welfare implications of government intervention. Some recent empirical papers have analyzed welfare in settings such as health insurance (e.g., Hackmann, Kolstad and Kowalski (2015), Einav, Finkelstein and Cullen (2010), Bundorf, Levin and Mahoney (2012), Finkelstein, Hendren and Shepard (2019)), annuities (e.g., Einav, Finkelstein and Schrimpf (2010), Finkelstein and Poterba (2004)), disability insurance (e.g., Cabral and Cullen (2019)), and unemployment insurance (e.g., Hendren 
(2017), Landais et al. (2021)). ${ }^{7}$ Our paper contributes to this literature in two key ways. First, our study is the first to investigate adverse selection and the efficiency consequences of government intervention to increase coverage in the setting of workers' compensation insurance. Workers' compensation insurance is a large and important insurance market, and there is active policy debate concerning government intervention to increase coverage in this setting. Second, while several studies in this literature analyze welfare using data from one employer or one insurer, this study is among only a handful of studies that investigate the welfare effects of government intervention in a large market that is particularly relevant for current policy debates.

Our paper also contributes to the broader literature on workers' compensation insurance. Much of the prior literature on workers' compensation insurance focuses on the incentive effects of program features (e.g., Cabral and Dillender (2020); Krueger (1990a,b); Meyer, Viscusi and Durbin (1995); Neuhauser and Raphael (2004)), the impact of the generosity of medical benefits (e.g., Powell and Seabury (2018)), and the incidence of the program or changes within the program (e.g., Fishback and Kantor (1995); Gruber and Krueger (1991)). This paper contributes to this literature by being the first study to investigate a voluntary workers' compensation market to estimate the demand for workers' compensation insurance and to analyze the potential efficiency implications of government intervention to increase coverage, providing evidence pertinent to the ongoing policy debate surrounding workers' compensation mandates. ${ }^{8}$ Lastly, this paper contributes to the literature on the demand for employment-linked insurance. While much of the prior work on the demand for employment-linked insurance focuses on contexts such as health insurance (e.g., Finkelstein (2002); Gruber and Lettau (2004); Kolstad and Kowalski (2016)) and long-term care insurance (e.g., Courtemanche and He (2009)), our paper is the first to provide evidence on the demand for workers' compensation insurance.

This paper proceeds as follows. Section 1 provides details on the institutional setting and the data. Section 2 outlines the empirical strategy, and Section 3 presents the demand estimates. Section 4 considers potential justifications for government intervention to increase coverage, presenting supplemental evidence and welfare analysis. Lastly, Section 5 concludes.

\section{Background and Data}

In this section, we begin by providing background information on the structure of the Texas workers' compensation system and workers' compensation systems more broadly. We then describe the data sources we use and present descriptive statistics.

\footnotetext{
${ }^{7}$ For a more comprehensive review of this literature, see Einav, Finkelstein and Levin (2010) and Chetty and Finkelstein (2013).

${ }^{8}$ Our work is also related to a few prior descriptive studies on employers opting out of the Texas workers' compensation system. Butler (1996) finds that safety conditions-as proxied by workplace fatalities-are not systematically different across participating and non-participating employers, though reported sprains and strains are lower among firms opting out of workers' compensation insurance. Morantz (2010) conducts and summarizes an employer survey assessing the compensation for work-related injuries at large non-participating employers, and Morantz (2016) summarizes detailed data on compensation offered to injured employees at select employers opting out of the workers' compensation insurance system.
} 


\subsection{Background}

Workers' Compensation Insurance Workers' compensation is frequently characterized as a "grand bargain" between workers and employers: relative to the status quo that preceded the enactment of workers' compensation statutes in the early 20th century, workers gained a reliable source of no-fault compensation for on-the-job accidents while employers gained protection from tort liability resulting from on-the-job accidents. Each of the 50 states and the District of Columbia has its own workers' compensation program.

Institutionally, the way this market functions is that employers purchase workers' compensation coverage. This coverage provides employers with liability protection against workplace injuries and provides employees with medical and income benefits in the event of workplace injuries. Workers' compensation insurance is effectively mandatory for employers in all states other than Texas. In contrast, employers in Texas can choose whether or not to provide workers' compensation insurance coverage to their employees. ${ }^{9}$ Although coverage mandates in 15 other states have exemptions for very small businesses and many states have additional exemptions for specific classes of workers such as agricultural or domestic workers, Texas is the only state where a substantial portion of the workforce is outside the workers' compensation system. In 2014, an estimated $20 \%$ of non-federal workers in Texas were not covered by workers' compensation, while an estimated $1.4 \%$ of non-federal workers in other states were not covered by workers' compensation insurance (Baldwin and McLaren, 2016).

Interestingly, workers' compensation coverage mandates have not always been the norm. Until the early 1970s, more than a third of state workers' compensation systems were voluntary. ${ }^{10}$ In 1972 , the National Commission on State Workmen's Compensation Laws recommended that workers' compensation coverage be made compulsory, and by the mid-1970s almost all states had passed amendments mandating that employers provide workers' compensation insurance. ${ }^{11}$ South Carolina enacted a coverage mandate in 1997, leaving Texas as the only remaining state with a voluntary workers' compensation insurance program. Recently, several states have begun to consider rolling back their coverage mandates to revert to a voluntary workers' compensation insurance system.

Most workers' compensation coverage is provided through insurance policies purchased by employers from workers' compensation insurers, either private insurers or public/quasi-public insurers (also known as state funds), which have considerable market share in many states. ${ }^{12}$ The majority of the Texas workforce that is covered by workers' compensation obtains this coverage through a policy purchased from a workers' compensation insurer. The Texas workers' compensation insurance market is fairly concentrated: the top

\footnotetext{
${ }^{9}$ Government agencies and public institutions are required to provide workers' compensation insurance.

${ }^{10}$ For more detail on the history of workers' compensation insurance mandates, see Howard (2002); Morantz (2010); Larson (19511952); National Commission on State Workmen's Compensation Laws (1972).

${ }^{11}$ See National Commission on State Workmen's Compensation Laws (1972).

${ }^{12}$ In four states, a state fund is the only provider of workers' compensation insurance.
} 
10 insurance companies in 2015 served 79\% of the market, and the largest insurer, Texas Mutual Insurance Company, served $40 \%$ of the market (TDI WCREG, 2016b). Texas Mutual is a quasi-public insurer created by the Texas Legislature in 1991 to serve as a competitive force in the marketplace and to guarantee the availability of affordable workers' compensation insurance.

While most employers obtain workers' compensation coverage through purchasing a workers' compensation policy from an insurer, some large employers have the option to become a certified self-insured employer. Certified self-insured employers are required to provide the same regulated benefits to employees in the event of workplace injury or illness in exchange for protection from tort liability. Texas imposes strict requirements on certified self-insured employers, effectively limiting this option to very large firms that can demonstrate substantial reserves for paying out future claims. ${ }^{13}$ Perhaps because of these strict requirements, only 95 employers were certified self-insured in Texas at any point during our period of analysis, 2006-2011, and these firms collectively employ approximately $5 \%$ of Texas private sector workers. ${ }^{14}$

The evidence in this paper is directly relevant for the Texas workers' compensation insurance market, a large and important market and a setting in which mandates are the subject of ongoing policy debate. We may also be interested in the broader applicability of these findings. Appendix Table A1 provides some context by comparing workers in Texas and broader populations using data from the Current Population Survey (CPS) Annual Social and Economic Supplement 2007-2012 (representing years 2006-2011) (Flood et al. (2021)). Workers in Texas, in states recently considering mandate repeal, and in the broader U.S. look similar to one another on demographic characteristics and earnings. Industry composition looks broadly similar across these groups, though a somewhat larger share of Texans work in mining, utilities, construction. Overall, it is important to emphasize that the population of workers in Texas is not representative of a broader population of workers, so one should exercise appropriate caution in extrapolating from our estimates. However, along the lines of observable attributes, Texas workers look broadly similar both to workers in states recently debating mandate repeal and workers nationwide.

Consequences of Non-Participation When an employer participates in the workers' compensation system, legal recourse for workplace injury is replaced by a no-fault system of defined benefits for workplace injury. Workers' compensation serves as the exclusive remedy available to covered workers for workplace injuries, meaning that workers covered by workers' compensation cannot sue their employers for negligence. When

\footnotetext{
${ }^{13}$ Since 1993, employers who meet certain safety and financial requirements may apply to be a certified self-insured employer in Texas. Self-insurance allows an employer to assume the risk for the vast majority of its workers' compensation liability and purchase some form of excess or stop-loss coverage to protect the employer from catastrophic losses. To be eligible for the certified self-insured program, private employers need to have an estimated unmodified manual insurance premium of at least $\$ 500,000$ in Texas, or at least $\$ 10,000,000$ nationwide, and meet other qualifications. As of January 1, 2016, there were about 130 employers who are self-insured in Texas. A detailed list of certified self-insured employers can be found here: http://www.tdi.texas.gov/wc/si/documents/ selfinsurlist.pdf.

${ }^{14}$ For this study, we obtained data on the 95 firms ever self-insured during the analysis period, 2006-2011 (TDI (2016a)). Based on the administrative data provided by the Texas Department of Insurance (TDI), these firms collectively employ approximately 450,000 workers, or roughly $5 \%$ of Texas private sector workers.
} 
employers opt out of the workers' compensation system, they forgo the protections afforded by the exclusive remedy feature of workers' compensation and assume the risk of liability for negligence.

Employers value workers' compensation insurance, as it offers liability protection for workplace injuries. From an employee's perspective, workers' compensation insurance and the outside option of recourse through the tort system are horizontally differentiated sources of effective coverage for workplace injuries. Workers' compensation insurance provides defined benefits for all workplace injuries, including injuries for which recovery through the tort system is unlikely (e.g., minor injuries, injuries with no case for employer negligence). However, in comparison to a successful lawsuit or legal settlement, workers' compensation limits the amount of compensation available to workers: earnings losses are not fully insured by workers' compensation, and workers' compensation does not allow workers to recover non-economic damages (i.e., pain and suffering or punitive damages) that may be compensated in a lawsuit. ${ }^{15}$

Employers outside the workers' compensation system manage legal settlements for work-related injuries and illnesses in a variety of ways. For instance, roughly a third of non-participating employers design a formal or informal occupational benefit plan to offer workers after they suffer a work-related injury (TDI WCREG, 2014). In contrast to workers' compensation insurance, the existence of an alternative occupational benefit plan does not shield an employer from tort liability. ${ }^{16}$ One way to think about these plans is as a standardized form of settlement offered to employees after suffering a common work-related injury, where these benefit packages reduce the transaction costs associated with addressing injuries through the legal system. Based on a survey of large non-participating employers, Morantz (2010) reports that these plans typically offer medical and wage replacement benefits for temporary impairments and that it is common for non-participating employers with these plans to still reach legal settlements outside the scope of these plans, particularly for cases involving permanently impaired workers. ${ }^{17,18}$

Importantly, workers' compensation coverage may increase the joint surplus of employers and employees for several reasons. The existence of workers' compensation insurance may reduce the legal costs borne

\footnotetext{
${ }^{15}$ While no systematic data exist on lawsuits and legal settlements, our discussions with individuals in the workers' compensation legal industry in Texas suggest that lawsuits involving injured employees at non-participating employers typically conclude with an out-of-court settlement (instead of proceeding to trial).

${ }^{16}$ State law prohibits non-participating employers from contracting with an employee to waive his or her rights to negligence claims before an injury takes place. See Texas Labor Code Sec. 406.033(e).

${ }^{17}$ According to Morantz (2010), in some ways non-participating employer occupational benefit plans on average appear more generous than statutory benefits in the workers' compensation system: these plans typically do not have a waiting period, do not cap the weekly wage replacement benefits for temporary impairments, and have a longer eligible duration for wage replacement benefits for temporary impairments. In other ways, these alternative plans appear less generous: most alternative plans have an end-of-shift or 24-hour reporting deadline (as compared to 30-day deadline in the workers' compensation system), do not cover permanent partial or total disability, limit medical benefits to about two years, and impose per-person or per-event caps on total benefits. See Morantz (2010), Morantz (2016), and Butler (1996) for a more in-depth comparison of compensation for work-related injuries at large non-participating employers relative to benefits within the workers' compensation system.

${ }^{18}$ Morantz (2010) reports that non-participating employers commonly state that an advantage of opting out is the ability to control the design of benefits available to injured workers. Given prior evidence suggesting there is substantial scope for moral hazard in workers' compensation insurance (e.g., Cabral and Dillender (2020), Krueger (1990b), Krueger (1990a), Meyer, Viscusi and Durbin (1995)), it is perhaps not surprising that some employers would try to innovate over the standard workers' compensation benefit package given the opportunity. The impact of the particular alternative risk management techniques adopted by non-participating employers is an important topic for future research.
} 
by employers and employees relative to the outside option of recourse through the tort system. Further, employers and employees may value the statutorily defined benefits of workers' compensation insurance over the uncertainty involved with recourse through the tort system. The delays and uncertainty involved in pursuing compensation through the tort system were an important motivation for the establishment of workers' compensation systems (Fishback and Kantor, 1998).

Of course, the value of workers' compensation insurance may vary across employers and employees. While some employers and employees may place a large value on workers' compensation insurance over the outside option of legal recourse, others may place little value on workers' compensation insurance relative to the outside option. Heterogeneous values for workers' compensation may reflect differences in the attractiveness of the outside option. For instance, there may be heterogeneity in the transaction costs associated with reaching settlements for workplace injuries in the absence of workers' compensation insurance, in employee opportunities for pursuing legal recourse for injuries outside of the workers' compensation insurance system, or in the ability to manage moral hazard within the outside option relative to the workers' compensation insurance system. There may also be heterogeneity in the effective coverage provided by the outside option. For example, some small employers with few assets may have de facto limited liability. ${ }^{19}$ The crux of the argument made by proponents of voluntary workers' compensation insurance is that a one-size-fitsall coverage mandate may hurt employers and employees alike as it does not accommodate heterogeneous preferences for workers' compensation coverage compared to the outside option.

While employers decide whether to purchase workers' compensation insurance, the consumer in the workers' compensation market may more accurately be thought of as some combination of employers and employees. As will become clear below, the empirical strategy and data used in this paper do not allow us to investigate the division of surplus among consumers in this market (i.e., between employers and employees). Instead, we have two primary aims in this paper. First, we estimate the demand for workers' compensation insurance using regulatory variation in premiums. Second, we analyze some common market failure justifications for coverage mandates using these demand estimates. For some of this latter analysis, we interpret the demand curve as representing the joint value of workers' compensation insurance to both employers and employees. This interpretation is valid if employers account for employee preferences, as well as their own

\footnotetext{
${ }^{19}$ Relative to hypothetical unlimited liability, the impact of limited liability on the demand for workers' compensation is unclear, given limited liability may depress employer values of workers' compensation and may inflate employee values of workers' compensation (under the assumption that workers have rational expectations and understand that small employers have de facto limited liability). Our revealed preference welfare analysis assumes: (i) employer decisions reflect both employer and employee values and (ii) employers and employees accurately value workers' compensation insurance relative to the outside option. Within this framework, limited liability is not an obvious source of externalities that would justify government intervention, as limited liability primarily affects consumers (employers and employees) rather than external parties. We discuss two related important points in Section 4.3. First, a failure of these assumptions-for example, if employers or employees had inaccurate information about compensation through the tort system-could provide an alternative justification for government intervention. Second, while our welfare analysis holds fixed the attributes of workers' compensation insurance and the outside option, broader government reform to re-design the workers' compensation insurance system or the tort system may improve welfare.
} 
preferences, when purchasing workers' compensation insurance. Section 4 presents a simple, stylized model to motivate this interpretation and discusses the robustness of our findings to relaxing this interpretation.

Regulation of Premiums and Benefits Like other state workers' compensation programs, Texas regulates both the form of workers' compensation insurance policies and the pricing of these policies. The policies sold by workers' compensation insurers guarantee the same stated benefits in terms of wage replacement and medical coverage in the event of injury. The basic structure of premiums per $\$ 100$ of covered payroll charged to employer $j$ by insurer $i$ in time period $t$ for plan type $p$ can be described by the following expression:

$$
\text { premium }_{j i t p}=b_{t}\left(c_{j}\right) \times r_{t}\left(e_{j t}\right) \times d_{i p} \times f_{i t} .
$$

There are several components to this premium. The base rate, $b_{t}\left(c_{j}\right)$, depends on an employer's workers' compensation industry-occupation classification, $c_{j}$. TDI sets these classification base rates for 360 distinct industry-occupation classifications. As discussed further below, our empirical strategy exploits regulatory updates to these classification base rates, which induce classification-specific idiosyncratic shocks to the relative premium for obtaining workers' compensation coverage. Another component of the premium is an experience rating modifier, $r_{t}\left(e_{j t}\right)$, which is a function of employer $j^{\prime}$ 's prior experienced claim history, $e_{j t}$. Like the classification base rates, the experience rating modifier function is set by the regulator. Additionally, there is a regulated plan type multiplicative discount $\left(d_{i p}\right)$ for plans that deviate from the standard coverage by including features such as employer deductibles or more restricted health care provider networks. ${ }^{20}$ Lastly, each insurer can choose its multiplier, $f_{i t}$, which gives the insurer the ability to set the overall price level charged for its policies even though insurers cannot set relative prices across classifications or loss experience groups.

Insurance policies in the market are written for a period of one year, and the base rate in effect at policy origination applies for the duration of the policy. When we aggregate data over time for our analysis, we aggregate coverage and loss information based on policy effective dates to correspond with the timing of applicable base rates. While most employers have payroll concentrated within one classification, employers may have multiple associated industry-occupation classifications if they have a large, diverse workforce. According to discussions with the Texas Department of Insurance (TDI) actuarial office, large firms with multiple classifications typically have a primary classification—often referred to as the governing classification—which accounts for $80-90 \%$ of payroll, with adjustments for the remaining $10-20 \%$ of payroll attributable to other classifications, most commonly clerical or sales services. Actual premiums paid are adjusted to account for the fraction of the employer's workforce dedicated to other categories, and the percent of payroll allocated to

\footnotetext{
${ }^{20}$ In practice, the most common plan type discount is an employer deductible discount, and the allowable deductible discounts are set by the regulator. Historically, approximately $17 \%$ of premiums were written for policies that included a deductible discount (TDI WCREG, 2016b). For smaller discounts (e.g., network discounts), the insurer has some discretion in setting the multiplicative discount rate applicable for policies sold of that plan type.
} 
each classification is subject to verification with ex post payroll auditing. ${ }^{21}$ Because premium adjustments for secondary classifications are concentrated in clerical and sales-classifications that are low risk with low base rates, these adjustments typically account for a very small share of premiums for employers with multiple classifications. ${ }^{22}$ While our data does not allow us to investigate the prevalence of firms with multiple classifications, Appendix Section D.2 presents conservative back-of-the-envelope analysis which suggests that this data limitation has little potential impact on the demand estimation. Specifically, this analysis illustrates that percent changes in employer governing classification base rates would translate nearly one-for-one into percent changes in employer overall mean base rates and premiums, even if adjustments for secondary classifications were more prevalent than indicated by TDI. Further, robustness analysis in Appendix Table A8 Panel B illustrates that the demand estimates are similar when excluding classifications that represent common adjustments for secondary classifications.

\subsection{Data}

Data Sources We have compiled a unique dataset for this study drawing on several administrative data sources. We obtained publicly available data from TDI on industry-occupation classification base rates and several inputs used in the regulatory rate update algorithm (TDI (2016b)). Through an open records request, we obtained unique actuarial data covering every workers' compensation insurance policy sold in Texas, including information on: industry-occupation classification code, coverage dates, covered payroll, premiums, experience rating modifiers, and data on each associated claim (TDI (2019)). A limitation of these data is that they do not allow us to consistently link covered payroll and claims to the associated employers. To complement analysis based on the actuarial data, we also obtained unique administrative data on all covered employers in Texas through a separate open records request. These employer-level data include employer identifiers, the employer's governing industry-occupation classification code, North American Industry Classification System (NAICS) industry code, and policy coverage dates (TDI (2014)). Additionally, we obtained supplemental administrative data on each certified self-insured employer in the state of Texas for our analysis period through a third open records request; these data include employer identifiers, number of covered employees, and coverage effective dates (TDI (2016a)). We augment the administrative data on the Texas workers' compensation system with public data on employment from the Quarterly Census of Employment and Wages (QCEW) (U.S. Bureau of Labor Statistics (2014)). Finally, we supplement these data with data reported by TDI on insurer combined loss ratios (TDI WCREG (2016c), TDI WCREG (2010a)). The main difference-in-differences analysis uses data from 2006 to 2011, as all of the key variables are available

\footnotetext{
${ }^{21}$ Throughout, we treat an employer's payroll classification(s) as exogenous. In Appendix Section D.1, we illustrate that it is uncommon for employers to change governing classifications, and changes in governing classifications are not systematically related to the rate updates we leverage for identification.

${ }^{22}$ For instance, the most common clerical classification (classification 8810 ) has a classification base rate that is 0.17 times the mean classification base rate in the baseline year 2006.
} 
for this period and the regulatory environment is otherwise stable during this period. ${ }^{23}$ Some supplemental analysis leverages additional available data from earlier or later years. See Appendix Section A for more detail on data sources.

While we have rich administrative data on employers and payroll insured within the Texas workers' compensation system, there does not exist comparable data on employers that opt out of the workers' compensation insurance system. In addition, there is no data on the universe of eligible firms and eligible payroll within each classification. Thus, it is not possible to estimate demand using firm-level data, and it is not feasible to estimate demand in terms of the fraction of firms insured or the fraction of payroll insured. Given these data constraints, the difference-in-differences regression analysis focuses on estimating the impact of premium base rate updates on the natural logarithm of coverage measures aggregated to the classification-year (or governing classification-year) level. To interpret the estimates as reflecting the demand for insurance, a key assumption is that the eligible population of firms and payroll in each classification is not changing in response to the identifying premium variation. In Section 2, we describe this assumption in more depth within the context of the estimating equations and discuss supplemental evidence supporting this assumption.

Analytical Dataset and Key Measures The analysis is conducted on data aggregated to the classificationyear level, where these data represent coverage and loss information for policies initiated within that year. The demand estimation focuses on two measures of coverage: the number of covered employers and total covered payroll. The number of covered employers is constructed based on aggregating the number of distinct covered employers within a classification, based on the employer's governing classification. The measure of covered payroll is constructed by aggregating all covered payroll within a classification, where payroll is precisely allocated to the associated classification.

We use premium data to verify that legislated base rate updates were implemented and shifted premiums as expected. This analysis focuses on mean premiums per unit of risk-adjusted payroll: total premiums associated with a classification divided by total risk-adjusted payroll covered within that classification, where we define risk-adjusted payroll as payroll scaled by the associated experience rating modifier. The premium data exclude any later plan type multiplicative discounts ( $d_{i p}$ in the notation above). Shifts in mean premiums per unit of risk-adjusted payroll $\left(b_{t}\left(c_{j}\right) \times f_{i t}\right.$ in the notation above) reflect shifts in the premium faced by a given employer, holding all else constant. We also report mean premiums per unit of payroll $\left(b_{t}\left(c_{j}\right) \times f_{i t} \times\right.$ $r_{t}\left(e_{j t}\right)$ in the notation above).

To measure mean claim costs, we aggregate data on all incurred medical and indemnity losses to the

\footnotetext{
${ }^{23}$ We exclude rate updates after 2011, as insurers were no longer required to use classification base rates-also known as relativitiesfor workers' compensation insurance rate determination after this period. Currently, insurers have the option to set rates based on TDI relativities or loss costs rates filed by the National Council on Compensation Insurance. We exclude rate updates prior to 2006 due to the limited earlier availability of some variables and to avoid spanning the period of the enactment of House Bill 7 in 2005 , a major legislative reform affecting Texas workers' compensation insurance.
} 
classification-year level and divide by the associated risk-adjusted (or unadjusted) payroll. The data on losses are valued at the $42^{\text {nd }}$ month after the policy effective date, and incurred losses include both insurer losses and employer out-of-pocket losses (e.g., due to policy deductibles). While most costs related to claims have been reported by 42 months after the policy effective date, we scale these losses to account for expected future reported costs related to these claims using category-specific loss development factors reported by TDI, where categories reflect claim types: major indemnity, minor indemnity, and medical only (TDI (2011)). To limit the impact of outlier events on the selection analysis, the mean cost measure in the selection analysis draws on underlying claim data that are winsorized at the $99^{\text {th }}$ percentile of claim costs. In robustness analysis, we illustrate that the findings in the selection analysis are very similar when considering alternative cost measures (e.g., unwinsorized losses, varying the winsorizing threshold, undeveloped losses, etc.).

The analysis focuses on classification codes that consistently appear in Texas throughout our analysis period and that have at least five million dollars of insured payroll in aggregate over the analysis period. Throughout, our analysis focuses on private sector employees, as government employees are insured through a separate system. Our baseline analysis excludes certified self-insured employers and associated employee payroll. We make this exclusion for two key reasons: (i) our identification strategy leverages variation in the premiums for coverage purchased from workers' compensation insurance providers, and (ii) the administrative data on covered payroll and claims are only available for the payroll covered through policies purchased from a workers' compensation insurance provider. While in principle the regulatory updates to premiums could have induced substitution between the market for purchased policies and certified self-insurance, in practice we find no such substitution. Further, using administrative data on both the number of employers with purchased policies and the number of certified self-insured employers, we illustrate that the demand analysis in terms of the number of covered employers is qualitatively and quantitatively very similar regardless of whether we exclude the certified self-insured. See Appendix D.3 for this supplemental analysis.

Summary Statistics Table 1 displays the mean and standard deviation of statewide annual aggregates describing workers' compensation take-up among private industry employers in Texas. Panel A describes statewide annual aggregates from the administrative data used in this paper from the years 2006 to 2011. Across the analysis period, approximately $\$ 257$ billion of payroll is annually insured through the Texas workers' compensation system, comprising approximately $74 \%$ of private sector Texas payroll. ${ }^{24,25}$ Panel B describes annual aggregates from a biennial employer survey commissioned by the Texas Department of Insurance (TDI) investigating the prevalence of employer participation in the Texas workers' compensation

\footnotetext{
${ }^{24}$ As noted in Table 1, dollar quantities are CPI-U adjusted to be 2006 dollars.

${ }^{25}$ We calculate that the covered payroll in the Texas workers' compensation market comprises approximately $74 \%$ of private sector Texas payroll by comparing TDI administrative covered payroll data to total private sector payroll data from the QCEW 2006-2011. In this calculation, we exclude the estimated fraction of payroll attributable to certified self-insured employers from the denominator to be consistent with the exclusion of these data from the numerator.
} 
system. ${ }^{26}$ According to these survey data, workers' compensation insurance coverage is held by approximately $66 \%$ of Texas private sector employers, employing roughly $78 \%$ of employees statewide. There are a few notable dimensions of heterogeneity in coverage rates. First, the fraction of participating employers increases with employer size: employers with fewer than five employees are nearly twice as likely to opt out of workers' compensation insurance relative to firms with more than 500 employees. The pattern of increasing participation with employer size is not monotonic, with very large firms with more than 500 employees being more likely to opt out of the workers' compensation system than slightly smaller firms with 100-499 employees. Second, employer participation rates are higher in the high-risk goods-producing industries and lower in service sectors. However, the participation rate varies within a fairly narrow range across the aggregated industry groups, with the highest participation rate $(77 \%)$ in mining/utilities/construction and the lowest participation rate (54\%) in arts/entertainment/accommodation/food services.

Appendix Table A5 displays summary statistics describing the baseline estimation dataset: classificationyear-level data covering 2006-2011. All reported mean values are market-level averages of the underlying classification-year level data weighted by the payroll insured within the associated classification. All dollar quantities are CPI-U adjusted to be 2006 dollars. Appendix Table A5 summarizes mean premiums and claim costs both in terms of dollars per $\$ 100$ of payroll and dollars per $\$ 100$ of risk-adjusted payroll. The number of claims per $\$ 100$ of covered payroll is $6.13 \times 10^{-5}$, representing an annual mean claim probability of roughly $3.1 \%$ for workers earning $\$ 50,000$ annually (roughly the mean annual earnings in this population). The mean premium for policies sold is $\$ 1.81$ per $\$ 100$ of payroll. The mean total claim cost associated with workplace illness and injury for covered employees is $\$ 0.69$ per $\$ 100$ of covered payroll, with roughly $60 \%$ of costs attributable to medical spending and $40 \%$ to cash benefits.

Note that we cannot understand insurer profit margins by comparing mean premiums and claim costs. The claim cost data exclude insurer administrative and operating expenses, and these expenses are considerable in this market, as TDI estimates that between $45 \%$ and $50 \%$ of insurer costs are attributable to administrative and operating expenses (TDI WCREG (2016c), TDI WCREG (2010a)). To account for these costs in the welfare analysis, we bring in additional data on insurer profit margins reported by TDI. Specifically, the welfare analysis in Section 4 uses claim cost data to trace out the slope of the insurer average cost curve, under the assumption that insurer costs are proportional to claim costs. We then use data on market-wide insurer combined loss ratios reported by TDI, which account for both insurer claim costs and administrative costs, to identify the level of insurer profit margins (the distance between the average cost and demand curves at the observed quantity).

\footnotetext{
${ }^{26}$ This phone survey takes place every other year, and these descriptive statistics summarize data from the 2006, 2008, and 2010 surveys. Aggregate data from these surveys were obtained from TDI WCREG (2016a). Choi (2011) presents an in-depth discussion of the strengths and limitations of these survey data.
} 


\section{Empirical Strategy}

\subsection{Variation}

Our strategy to estimate the demand for workers' compensation coverage is to isolate plausibly exogenous variation in premiums arising from regulatory updates to base rates across industry-occupation classifications. As described in the prior section, premiums (per dollar of covered payroll) are a multiplicative function, where classification base rates are multiplied by other components. Since all further adjustments to premiums are multiplicative and orthogonal to base rates, a $1 \%$ increase in the classification base rate leads to a $1 \%$ increase in premiums all else equal. Below, we use data on premiums to confirm that base rate updates were implemented and shifted premiums one-for-one in percent terms. Given the multiplicative structure of premiums, the primary difference-in-differences analysis focuses on regressing the natural logarithm of the quantity insured on the natural logarithm of the base rate, where we interpret the coefficient on the natural logarithm of the base rate as the price elasticity of demand.

Premiums are heavily regulated in this market, and the Texas Department of Insurance (TDI) is charged with setting the relative premiums across roughly 360 industry-occupation groups through setting the corresponding classification base rates employed in this market. Prior to 2009, TDI updated base rates on an annual basis, while in more recent years base rates are updated every other year. There were four total base rate updates during our analysis period, in each of the following years: 2007, 2008, 2009, and 2011. Below, we provide a brief outline of the regulators' algorithm for updating base rates, and then we summarize a few key features of the algorithm. A basic outline of the steps of the update algorithm is as follows:

1. Input current base rates and raw claim loss experience within a classification from a five-year window, lagged by four years (e.g., for 2007 base rate, input is raw losses from 1999-2003).

2. Raw losses are adjusted to exclude all amounts in excess of per-claim or per-accident caps (e.g., $\$ 350,000$ per claim, \$700,000 per accident).

3. These limited losses are adjusted for loss development and scaled so that the mean equals the mean of the current base rates.

4. Take the weighted average of the experienced rate (the average adjusted losses from the prior step) and the current rate, where weights depend on the number of claims ("credibility weighting").

5. Scale rates from the prior step to have the same mean as the current base rates, cap each change to be at most $+/-25 \%$ of the current base rate, and re-scale the resulting rates to have the same mean as the current base rates.

6. (Some Years) Across-the-board multiplicative adjustment to the proposed base rates (the rates from the prior step). 
The inputs into the update algorithm are: (i) historical classification claims experience (specifically, a fiveyear moving average of claims experience with a four-year lag) and (ii) current classification base rates. The algorithm determines the weight to place on this claims experience versus the current classification base rate through an assessment of the noise in this experience measure. The algorithm then caps any changes at $+/$ $25 \%$ of the current classification base rate. Appendix Section B presents a full description of the rate update algorithm. As described further below, we exploit some mechanical features of this algorithm to investigate the robustness of our findings.

The final output of the algorithm is an updated set of base rates, where these rates are normalized so that the weighted mean of the base rates is unaltered by this update process. There are three updates during our period that are exceptions: 2008, 2009, and 2011. During these updates, TDI made an across-the-board downward multiplicative adjustment in base rates as a final step in the update process (step 6 above). ${ }^{27}$ Because insurers are free to set the level of premiums overall (as described in Section 1.1), insurers can effectively undo the effect of any across-the-board adjustment in the level of base rates on premiums. Additionally, all of our analysis includes time effects, allowing us to focus on updates in the relative base rates across classifications (as opposed to the level of base rates). Thus, the discussion of the identifying variation below focuses on the updates to the proposed base rates (the output from step 5) before any across-the-board adjustments, not the final adopted base rates. ${ }^{28}$

Figure 1 displays a histogram depicting the updates to the classification base rates as a percentage of the current base rates. ${ }^{29}$ This figure displays these updates pooling across all updates during the analysis period, while Appendix Figure A1 displays histograms of the updates year by year. There are a few things worth noting about this figure. First, the figure illustrates that the typical updates in classification base rates are large in relative terms. The mean absolute percent change in the base rate is $9.3 \%$, and the interquartile range of percent changes in base rates is $15.3 \%$. Second, as discussed above, the figure clearly depicts that the base rate updates are capped at $+/-25 \%$ change relative to the current classification base rate level. Pooling across the updates during the analysis period, the cap is binding for approximately $7.6 \%$ of classification updates. Appendix Figure A3 presents another illustration of this cap feature of the base rate update algorithm, illustrating that some classifications would have received much larger updates (in absolute value) if not for the cap feature.

Our empirical strategy leverages all of the idiosyncratic updates to base rates in a difference-in-differences framework to estimate the demand for workers' compensation coverage. A potential concern with this strat-

\footnotetext{
${ }^{27}$ In 2008, 2009, and 2011, classification base rates were decreased across the board by $7.7 \%, 10 \%$, and $7.4 \%$, respectively.

${ }^{28}$ Each table and figure clearly indicates which base rate is being described. Appendix Section B describes the update algorithm step-by-step and describes the role of each of the interim and final base rates we discuss in the text.

${ }^{29}$ This histogram describes the distribution of classification proposed base rate updates prior to any across-the-board adjustments to the level of base rates in the years in which this occurs $(2008,2009,2011)$. For comparison, Appendix Figure A2 separately plots the histograms of final base rate updates year-by-year inclusive of any applicable across-the-board adjustments.
} 
egy is that the base rate updates rely on historical cost data from the classification, and thus these updates could reflect broader trends in the classification, which could have an independent effect on the demand for coverage. We have three broad strategies to address this concern, and we discuss each of these strategies in more detail below in the context of our estimating equations.

\subsection{Econometric Model}

Let $j$ represent workers' compensation industry-occupation classification and $t$ represent time period. The main regression we estimate can be written as:

$$
\ln \left(y_{j t}\right)=\alpha+\beta \ln \left(b_{j t}\right)+\delta_{j}+\theta_{t}+\epsilon_{j t},
$$

where $\ln \left(y_{j t}\right)$ is the dependent variable, and $\ln \left(b_{j t}\right)$ is the natural logarithm of the classification base rate. The specification includes time period fixed effects $\left(\theta_{t}\right)$ and classification fixed effects $\left(\delta_{j}\right)$. We focus on two coverage measures as dependent variables: (i) the natural logarithm of the total covered employers with governing classification $j$ and for policies originating in time period $t$, and (ii) the natural logarithm of the total covered payroll associated with classification $j$ and for policies originating in time period $t$.

The baseline demand estimation uses classification-year-level data, where the key independent variable, $\ln \left(b_{j t}\right)$, is the natural logarithm of the average classification base rate applicable for policies associated with classification $j$ and originated in year $t^{30}$ Because some of the base rate updates occur mid-year, we also present complementary difference-in-differences event study analysis which illustrates how coverage changes over time relative to the exact month each base rate update was implemented. The event study analysis yields estimates very similar to the baseline annual difference-in-differences analysis.

The key identification assumption behind the specification above is that changes in base rates are uncorrelated with other determinants of the take-up of workers' compensation insurance, conditional on the included controls. A potential concern with the baseline identification strategy is that the base rate updates could be correlated with broader trends in the industry-occupational classification which could have an independent effect on coverage rates. We have three broad strategies to address this concern and assess the validity of the baseline identifying assumption.

Our first strategy is to include classification-specific time trends:

$$
\ln \left(y_{j t}\right)=\alpha+\beta \ln \left(b_{j t}\right)+\delta_{j}+\theta_{t}+\lambda_{j} t+\epsilon_{j t},
$$

where $\lambda_{j} t$ represents a classification-specific time trend. Due to power considerations, we include these classification-specific trends at the two-digit classification level given our limited analysis period. In the Texas workers' compensation insurance system, there are approximately 360 distinct four-digit classification codes, which are grouped into roughly 70 distinct two-digit classification codes. These specifications relax the

\footnotetext{
${ }^{30}$ Because some years span a base rate update, the average base rate used in this analysis is the average base rate applicable to policies originated in that year weighted by the months the base rate was in effect.
} 
identification assumption by focusing on base rate updates that cause deviations in workers' compensation take-up after accounting for long-run trends among classifications with similar risk experience.

Our second strategy is to estimate alternative specifications investigating the robustness of our findings using two types of non-linearities in the regulator's rate update algorithm. The first of these alternative specifications builds on the window of historical costs which enters the regulatory update algorithm. If, contrary to the identification assumption, changes in cost inputs have an independent effect on workers' compensation take-up, then we would expect to see that changes in workers' compensation take-up pre-date the regulatory rate updates. To assess if this is the case, we estimate regressions of the following form:

$$
\ln \left(y_{j t}\right)=\alpha+\beta \ln \left(b_{j t}\right)+\phi \ln \left(b_{j t+2}\right)+\delta_{j}+\theta_{t}+\epsilon_{j t},
$$

where $\ln \left(b_{j t+2}\right)$ represents the natural logarithm of classification base rates to be implemented two years into the future. Given that lagged historical costs enter the update algorithm, $b_{j t+2}$ is arguably more relevant than $b_{j t}$ for capturing the expected costs in classification $j$ in time $t$, though $b_{j t+2}$ does not affect pricing at time $t$ after controlling for the current base rate, $b_{j t}$. If our baseline identification assumption holds, we would expect to see no relationship between workers' compensation take-up and this additional term, and the estimated coefficient on the actual base rate $(\beta)$ is not sensitive to the inclusion of this additional term. ${ }^{31}$ A second robustness test builds on the algorithm feature which caps base rate updates to be no greater than $+/-25 \%$ of the current classification rate. If, contrary to the baseline identification assumption, the inputs to the regulatory formula have an independent relationship with take-up above and beyond their role in rate determination, then we would expect to see that hypothetical uncapped base rates would be correlated with take-up after conditioning on the ultimately adopted capped base rates. To test whether this is the case, we estimate specifications of the following form:

$$
\ln \left(y_{j t}\right)=\alpha+\beta \ln \left(b_{j t}\right)+\pi\left[\ln \left(\tilde{b}_{j t}\right) * \mathbb{1}\left(\operatorname{capBinding}_{j}\right)\right]+\delta_{j}+\theta_{t}+\epsilon_{j t},
$$

where $\ln \left(\tilde{b}_{j t}\right)$ represents the natural logarithm of the hypothetical uncapped base rate for classification $j$ in year $t$, and $\mathbb{1}\left(\right.$ capBinding $\left._{j}\right)$ indicates that the $+/-25 \%$ cap was binding for the base rate for classification $j$ at some point during the analysis period. If our baseline identification assumption holds, we would expect to see no relationship between workers' compensation take-up and the hypothetical uncapped base rate for classifications for which the cap was binding, and the estimated coefficient on the actual base rate $(\beta)$ is not sensitive to the inclusion of this additional term.

Our final strategy is to use a complementary difference-in-differences event study approach to analyze the impact of rate updates on coverage. For each update used in the difference-in-differences analysis, we

\footnotetext{
${ }^{31}$ We focus on base rates two years into the future for this robustness analysis because these base rates are unrelated to the price of workers' compensation this year, after controlling for this year's base rates. As discussed above, these regressions use classification-yearlevel data, where base rates in classification $j$ in year $t$ are the average base rates in effect for policies purchased in that calendar year. Because the average base rate one year into the future may contain information about base rates relevant for purchase decisions at the end of the current year, base rates two years in advance provide a clearer robustness test.
} 
construct a balanced panel that includes data from policies initiated in the two to three years directly preceding and following the index rate update, where we aggregate information about policies to the yearly level where years are defined relative to the update month. ${ }^{32}$ Let $\tau$ index event time, $j$ index classification, and $p$ index each update panel. Combining the data from these update panels, we estimate specifications of the following form:

$$
\ln \left(y_{\tau j p}\right)=\alpha+\sum_{\tau} \beta_{\tau} \mathbb{1}_{\tau}\left[\ln \left(b_{1 j p}\right)-\ln \left(b_{0 j p}\right)\right]+\delta_{j}+\theta_{\tau p}+f\left(X_{\tau j p}\right)+\epsilon_{\tau j p},
$$

where $\left[\ln \left(b_{1 j p}\right)-\ln \left(b_{0 j p}\right)\right]$ represents the index base rate update between event time 0 and 1 , and the specification includes classification fixed effects $\left(\delta_{j}\right)$ and event-time by panel fixed effects $\left(\theta_{\tau p}\right)$. To address any potential serial correlation between the reference base rate update and other rate updates, we include additional flexible controls $\left(f\left(X_{\tau j p}\right)\right)$ which interact event time with prior and subsequent rate updates. ${ }^{33}$ Robust standard errors are clustered at the classification level. ${ }^{34}$ The $\beta_{\tau}$ 's are the coefficients of interest. We normalize $\beta_{0}=0$, so these estimates can be interpreted as changes relative to year directly prior to the update. We plot the $\beta_{\tau}$ estimates by time relative to update, allowing us to visually determine whether there is evidence of spurious correlated pre-existing trends and to assess any anticipatory or delayed effects of rate updates.

We use data on premiums to verify that the legislated base rates updates were implemented and shifted premiums as expected. Table 2 displays estimates for the difference-in-differences specifications outlined in equations 2 through 5 above, replacing the dependent variable with mean premiums per unit of risk-adjusted (experience-rated) payroll. Given the multiplicative structure of premiums, this measure of premiums allows us to assess how the profile of premiums shifts for a given employer, holding all else constant. Each column in Table 2 displays estimates from a separate regression, where the included controls are as indicated in the table. There are two important take-aways. First, as expected, a 1\% increase in statutory base rates causes a $1 \%$ increase in premiums and this relationship is very precisely estimated (with a standard error no bigger than $0.030 \%$ ). Second, there is no significant association between premiums and the additional terms included in specifications 2 through 4 .

Figure 2 displays estimates from the event study specification outlined in equation 6 replacing the dependent variable with the statutory base rate (panel A) or mean premiums per unit of risk-adjusted payroll

\footnotetext{
${ }^{32}$ For this event study analysis, we augment our main analysis data by including additional pre- and post-update data when available. Data is available from 2004 to 2014 for all variables aside from covered employers, for which data is available from 2005 to 2014 Q1.

${ }^{33}$ The included flexible controls for prior and subsequent rate updates parallel the treatment of the index rate update in the event study specification. Using the notation in equation 6 , the included controls can be expressed as:

$$
f\left(X_{\tau j p}\right) \equiv \sum_{s=-2}^{-1} \sum_{\tau} \gamma_{\tau}^{s} \mathbb{1}_{\tau}\left[\ln \left(b_{s j p}\right)-\ln \left(b_{0 j p}\right)\right]+\sum_{s=2}^{3} \sum_{\tau} \gamma_{\tau}^{s} \mathbb{1}_{\tau}\left[\ln \left(b_{s j p}\right)-\ln \left(b_{1 j p}\right)\right]
$$

where $b_{0 j p}$ and $b_{1 j p}$ are the base rates in effect just before and just after the index rate update, respectively, and $b_{s j p}$ is the mean base rate in effect during event time $s \neq 0,1$. In practice, there is limited serial correlation in rate updates, and we obtain qualitatively similar estimates when omitting these controls. See Appendix Figure A4 for estimates from additional specifications omitting these controls.

${ }^{34}$ Note that the construction of the data used in this event study approach will result in the same classification appearing multiple times. Clustering standard errors at the classification level accounts for the repeated appearances of classifications.
} 
(panel B). The capped vertical bars indicate 95\% confidence intervals. Figure 2 Panel A illustrates the legislated change in statutory base rates between event years 0 and 1 isolated by the event study specification, and Figure 2 Panel B illustrates that this change in statutory base rates translates to a one-for-one percent change in mean premiums. This figure demonstrates the event study specification isolates variation from the index rate update which causes a sharp and persistent change in statutory base rates-and a one-for-one change in premiums-spanning the remainder of the event window (three years). In summary, Table 2 and Figure 2 confirm that a one percent increase in base rates is reflected one-for-one in premiums, this relationship is precisely estimated, and the first stage of the event study specification is one. Based on this evidence, in the remainder of the paper, we interpret the reduced form effects of base rates on outcomes as resulting from a one-for-one percent change in premiums.

The dependent variables in the demand estimation (the natural logarithm of covered employers and the natural logarithm of covered payroll) rely solely on the administrative data. As discussed in Section 1.2, there is no administrative data on the universe of eligible firms and eligible payroll within each classification, so it is not possible to estimate demand in terms of the fraction of firms insured or the fraction of payroll insured. ${ }^{35}$ Thus, to interpret the estimates as reflecting the demand for insurance, a key assumption is that the eligible population of firms and payroll in each classification is not changing in response to the identifying variation. ${ }^{36}$ While the lack of classification-level data on the eligible population prevents us from testing this directly, we present some supporting evidence for this assumption by using North American Industry Classification System (NAICS) industry-year-level data on the Texas workforce from the Quarterly Census of Employment and Wages (QCEW). We relate the QCEW industry-year data on industry size to the classification-year-level variation in workers' compensation premiums by constructing a unique weighted crosswalk between workers' compensation classifications and NAICS industry codes from the administrative data on employers covered by workers' compensation insurance. Appendix Section D.4 describes this supplemental analysis in detail. Based on this analysis, there is no evidence that the aggregate number of firms or the aggregate number of workers in an industry are correlated with the premium variation within the associated classifications, building confidence in our interpretation of the primary regressions as reflecting the demand for insurance.

\section{Demand Estimates}

Table 3 displays the demand estimates. Columns 1 through 4 present results in terms of covered employers, while columns 5 through 8 present results in terms of covered payroll. All specifications include both year

\footnotetext{
${ }^{35}$ While the Quarterly Census of Employment and Wages (QCEW) reports the total number of firms and payroll in the state of Texas, the workers' compensation classification information is not available for non-participating employers in either public or administrative data.

${ }^{36}$ See Appendix Section D.4 for a more detailed description of the assumption needed to address this econometric challenge and supporting evidence for this assumption.
} 
fixed effects and industry-occupation classification fixed effects. Columns 1 and 5 present the results of the baseline difference-in-differences specification for covered employers and covered payroll, respectively. The estimates indicate that an increase in workers' compensation premiums leads to a decline in workers' compensation coverage. Drawing on the baseline estimates, a $1 \%$ increase in premiums leads to a $0.38 \%$ decline in covered employers and a $0.29 \%$ decline in covered payroll. Based on the $95 \%$ confidence interval of these estimates, we can rule out an elasticity less than -0.21 or more than -0.54 in terms of covered employers (and less than -0.05 or more than -0.54 in terms of covered payroll). The results are similar when including two-digit classification-specific time trends (columns 2 and 6).

Figure 3 graphically depicts the baseline regressions through binned mean residual plots. Each dot in these figures represents $5 \%$ of the classification-year observations in the baseline analysis data, where observations are binned by the values on the horizontal axis. ${ }^{37}$ The horizontal axis displays bins of residuals from a regression of the base rate on the controls included in the baseline specification, while the vertical axis displays the within-bin mean of residuals from a regression of the dependent variable on the baseline controls. Panel A displays the results for covered employers (analogous to the estimates in Table 3 column 1), and Panel B displays the results for covered payroll (analogous to the estimates in Table 3 column 5). These plots confirm the strong relationship between base rates and workers' compensation coverage.

Next, we investigate the robustness of these demand estimates through estimating alternative specifications. Columns 3 and 7 present the results from alternative specifications that include future base rates two years in advance of their implementation (from equation 4). If, contrary to the identification assumption, changes in the algorithm's historical cost inputs have an independent effect on workers' compensation take-up, then we would expect to see that changes in workers' compensation take-up pre-date the regulatory rate updates. However, in these specifications, the coefficient estimates on the future base rate are not statistically distinguishable from zero, and the estimated coefficients on the contemporary base rate are largely unchanged. Thus, the pattern of these estimates builds confidence in the identification assumption and the robustness of the baseline demand estimates.

Columns 4 and 8 estimate the alternative specification described in equation 5 . This alternative specification assesses the plausibility of the identification assumption by including a term representing hypothetical base rate updates that would have been implemented absent the $+/-25 \%$ cap on rate adjustments within the regulator's update algorithm. If, contrary to the baseline identification assumption, the inputs to the regulatory formula have an independent relationship with workers' compensation take-up above and beyond their role in rate determination, then we would expect to see that hypothetical uncapped base rates would be correlated with take-up after conditioning on the ultimately adopted base rates. However, the co-

\footnotetext{
${ }^{37}$ Appendix Figure A5 displays analogous residual plots without binning data and these plots illustrate similar patterns.
} 
efficient estimates on the hypothetical uncapped base rate are statistically indistinguishable from zero, while the coefficient estimates on the actual base rate are largely unaffected. These results support the baseline identification assumption and the robustness of the baseline estimates.

Figure 4 displays estimates from the complementary event study approach outlined in equation 6 . The figure displays estimates and $95 \%$ confidence intervals for the coefficients on the interaction of the reference base rate update and event time. Panels A and B display the results for covered employers and covered payroll, respectively. Appendix Table A7 displays the associated coefficient estimates, standard errors, and p-values. Note that the event study analysis focuses on a balanced panel of classification-time observations, where data availability on covered employers for years before and beyond our main analysis period constrains the event window to two years pre- and post- rate update when considering covered employers as an outcome. ${ }^{38}$ The figure shows no evidence of a trend in coverage prior to the rate update, providing support for our parallel trends identification assumption. In the year following the implementation of the rate update, we see that a $1 \%$ increase in the base rate leads to a $0.26 \%$ decline in covered employers (p-value 0.002 ) and $0.27 \%$ decline in covered payroll ( $\mathrm{p}$-value 0.031 ). We note that the effect appears in the year immediately following the rate update and persists for the duration of the event window, which suggests it may be reasonable to interpret the demand estimates as a medium-run or long-run elasticity. Overall, the event study estimates closely correspond to the baseline difference-in-differences estimates and provide further support for the identification assumption.

Beyond the primary robustness analysis presented above, Appendix Section D.5 presents additional specifications where we further probe the robustness of the demand estimates with respect to a few additional potential concerns. We present three additional sets of robustness analysis. First, we consider the potential impact of endogenous wage adjustment on the covered payroll demand estimates. To analyze this, we repeat the covered payroll regression analysis under various assumptions on the fraction of premiums passed through to employees in the form of reduced wages. The demand estimates are very similar across the range of possible assumptions on the division of premiums between employees and employers. Second, we illustrate the demand estimates are similar when focusing on a subset of classifications-either excluding small classifications or excluding clerical and sales classifications (classifications that are the most common secondary classifications). Lastly, we illustrate the robustness of the demand estimates to weighting. While the baseline demand analysis is unweighted, we obtain similar estimates in alternative specifications where we weight the regressions using available proxies for eligible payroll within each classification: covered payroll, risk-adjusted covered payroll, and premiums paid in the first year of the analysis period. ${ }^{39}$

\footnotetext{
${ }^{38}$ While the main event study specifications focus on a balanced panel, Appendix Figure A6 illustrates the results are similar when estimating an alternative specification when considering covered employers as an outcome which uses an unbalanced panel spanning three years pre- and post- rate update excluding years with incomplete data.

${ }^{39}$ While the descriptive statistics throughout represent market-level aggregates weighted by the payroll insured within each classifi-
} 


\section{Welfare Framework and Empirical Evidence}

Drawing upon the demand estimates and additional administrative cost data, we investigate some potential justifications for government intervention to increase coverage. Motivated by the near ubiquity of coverage mandates in the setting of workers' compensation insurance, we begin by discussing some potential market failure justifications for mandating workers' compensation coverage through the lens of a standard welfare framework in insurance settings. We then present empirical evidence on these potential justifications and present counterfactual analysis of the impact of interventions such as a mandate or subsidy. Lastly, we discuss the interpretation of this evidence and potential alternative justifications for mandating coverage.

\subsection{Welfare Framework}

We consider the welfare impact of market failures and potential government interventions in this setting, holding fixed the attributes of workers' compensation insurance and the outside option of tort liability. In this analysis, we interpret the demand curve as representing the value of this insurance to marginal consumers, noting that marginal consumers are jointly composed of marginal employers and employees in the setting of workers' compensation insurance. Before turning to our discussion of potential justifications for a mandate, we provide more motivation for this interpretation of demand.

Interpretation of Demand While the decision to purchase workers' compensation insurance is made by employers, the welfare analysis relies on the assumption that employer decisions reflect both employer and employee preferences. Many models suggest employer workers' compensation insurance purchase decisions reflect both employer and employee values of workers' compensation insurance. We describe one simple model that provides sufficient conditions for demand to reflect both employer and worker values of workers' compensation insurance. Appendix Section E presents a more detailed description of this model and discusses an alternative model that yields the same result.

We apply the model of equalizing differentials outlined in Rosen (1986) to the setting of a labor market where firms choose wages and whether to purchase workers' compensation insurance over the outside option of settling workplace injuries through the tort system. ${ }^{40}$ The intuition behind this model is simple. Labor markets link two transactions: workers sell their labor services to firms and buy a set of job attributes from firms, while firms buy labor from workers and sell a set of job attributes to workers. In this way, the labor market induces sorting of workers across firms, and job attributes reflect worker preferences and firm costs.

cation, the baseline regressions estimating the causal effect of rates on coverage are unweighted. There are two reasons for this. First, it is not clear whether unweighted or weighted regressions are preferred when estimating causal effects (Solon, Haider and Wooldridge, 2015). Second, data is not available to construct the most natural weights for the demand estimation in this setting: total eligible payroll or total eligible employers within each classification.

${ }^{40}$ We apply the simple model of equalizing differentials in Rosen (1986), which considers the case where firms make a binary decision over a particular job attribute. See Rosen (1974) for a more general model considering firm decisions over a continuous measure of a job attribute. 
Consider a competitive labor market where workers have homogeneous productivity and firms choose whether to offer jobs with workers' compensation insurance $(I=1)$ or jobs without workers' compensation insurance $(I=0)$. Let $\alpha_{j}$ represent employer $j$ 's per-worker expected costs of tort liability. The expected costs of tort liability are weakly positive $\left(\alpha_{j} \geq 0\right)$, and this represents the per-worker cost savings (or value) to the firm from purchasing workers' compensation insurance. While firms face the same price for workers' compensation insurance, firms may differ in the cost savings they get from avoiding tort liability $\left(\alpha_{j}\right)$. For instance, there may be variation across firms in the transaction costs and legal fees associated with injury settlements in the outside option. Let $\beta_{i}$ represent worker $i$ 's value of a job with workers' compensation insurance relative to a job with the outside option of tort liability (i.e., the worker's compensating differential for $I=0$ compared to $I=1$ ). There may be heterogeneity in employee values, and employee values may be either positive or negative $\left(\beta_{i} \lessgtr 0\right)$, as workers' compensation insurance and recourse through the tort system are horizontally differentiated from a worker's perspective. ${ }^{41}$

Suppose the number of jobs in the economy and the number of workers employed are fixed. Firms choose which type of job to offer, and workers choose which type of job to apply to. Both workers and firms make rational, privately optimal decisions. Define $\Delta w \equiv w_{0}-w_{1}$, where $w_{I}$ indicates the wage in job type $I$. Worker $i$ chooses to apply to a job with workers' compensation insurance if and only if $\beta_{i} \geq \Delta w$. Define $p$ as the per-worker premium for workers' compensation insurance. Firm $j$ will purchase workers' compensation insurance if and only if $p \leq \Delta w+\alpha_{j}$, or equivalently when $\alpha_{j} \geq p-\Delta w$. Let $G$ represent the distribution of $\beta$ in the worker population, and let $F$ represent the distribution of $\alpha$ across jobs at firms. ${ }^{42}$ In this notation, the labor supply in each market segment is simply the fraction of workers applying to jobs of that type: $L_{1}^{s}(\Delta w)=1-G(\Delta w)$ and $L_{0}^{s}(\Delta w)=G(\Delta w)$. Labor demand in each market segment is the fraction of jobs of each type that are offered: $L_{1}^{d}(p-\Delta w)=1-F(p-\Delta w)$ and $L_{0}^{d}(p-\Delta w)=F(p-\Delta w)$. In equilibrium, labor supply equals labor demand in each segment of the market: $L_{1}^{d}(p-\Delta w)=L_{1}^{s}(\Delta w)$ (or equivalently, $\left.L_{0}^{d}(p-\Delta w)=L_{0}^{s}(\Delta w)\right)$. This equilibrium condition can be represented as: $1-F(p-\Delta w)=1-G(\Delta w)$.

In equilibrium, the sum of the per-worker value of this coverage to the marginal firm and the value of this coverage to the marginal worker equals the price of workers' compensation insurance. ${ }^{43}$ At any given price, the share of the workforce covered by workers' compensation insurance is the share of the workforce for which the sum of the per-worker employer value and the employee value exceeds the price. Thus, the

\footnotetext{
${ }^{41}$ See Section 1 for further discussion of factors that may influence employer and employee values of workers' compensation insurance.

${ }^{42}$ This distribution incorporates the size of each firm as well as production technology, meaning $F(\alpha)$ indicates the fraction of potential jobs in the economy for which the expected per-worker costs from tort liability are less than or equal to $\alpha$.

${ }^{43}$ To see this, let $\Delta w^{*}$ represent the equilibrium wage differential. The marginal worker $i^{\prime}$ is indifferent between working at a job with and without workers' compensation insurance, $\beta_{i^{\prime}}=\Delta w^{*}$. The marginal firm $j^{\prime}$ is indifferent between purchasing workers' compensation insurance or not, $p=\alpha_{j^{\prime}}+\Delta w^{*}$. Combining these expressions, we see that in equilibrium, the sum of the per-worker value of this coverage to the marginal firm and the value of this coverage to the marginal worker equals the price of workers' compensation insurance, $p=\alpha_{j^{\prime}}+\beta_{i^{\prime}}$. Hence, at any given price, the share of the workforce covered by workers' compensation insurance is the share of the workforce for which the sum of the per-worker employer value and the employee value exceeds the price.
} 
demand for workers' compensation insurance reflects the value of this coverage to marginal employers and employees. ${ }^{44}$ This prediction is not unique to this model, as there are other models employing different assumptions that produce the same result: the demand for workers' compensation insurance reflects the value of this coverage to marginal employers and employees. For instance, the same basic finding arises in an alternative simple model, outlined in Appendix Section E, in which worker-firm matches are taken as exogenous, firms know worker values of workers' compensation insurance, and firms choose the allocation of compensation-across wage and non-wage job attributes—that minimizes firm costs.

The welfare analysis relies on interpreting the demand curve as representing the value of workers' compensation insurance to the marginal consumers-the marginal employers and employees. Throughout the welfare analysis, we maintain this interpretation of the demand curve. Section 4.3 discusses which of our findings are robust to relaxing this interpretation.

Potential Rationale for Mandate Classic economic theory provides some potential explanations for why a private market would under-provide insurance relative to the first best, including: adverse selection, market power, and (positive) externalities. Figure 5 illustrates the intuition behind each potential explanation through a graphical example in the spirit of Einav and Finkelstein (2011). Each panel of this figure plots the demand, marginal cost curve, and average cost curve associated with an insurance market, where the horizontal axis represents the fraction with insurance and the vertical axis is measured in dollars. In this graphical illustration (and in the empirical welfare calculations below), we abstract from insurer-level and market-level economies of scale and focus on market-level demand and cost curves. Abstracting from economies of scale allows us to extrapolate from the selection estimates based on claim costs to estimate how average (and marginal) costs vary with the quantity insured. Following much of the prior empirical literature on insurance markets, our welfare analysis of potential government interventions within the workers' compensation insurance market abstracts from general equilibrium impacts in this market or related markets. ${ }^{45,46}$

\footnotetext{
${ }^{44}$ The notion that employer decisions regarding wage and non-wage job characteristics reflect employee preferences is in line with a rich theoretical literature on equalizing wage differentials and mandated benefits (e.g., Rosen (1974), Summers (1989)) and prior empirical work documenting wage offsets when employee benefits change in workers' compensation insurance (e.g., Gruber and Krueger (1991), Fishback and Kantor (1995)) and other settings (e.g., Gruber (1994), Gruber (1997)). While many factors may influence employer benefit offerings, it has been challenging for researchers to directly test the theory that employers set employee benefits in equilibrium to reflect worker preferences. Several empirical papers have shown, however, that employer benefit offerings and benefit design are responsive to employee characteristics (Bundorf, 2002) and variation in employees' valuation of fringe benefits (Dranove, Spier and Baker, 2000).

${ }^{45}$ The welfare analysis considering a coverage mandate abstracts from general equilibrium impacts of a coverage mandate. For example, it is possible that mandating workers' compensation insurance improves information available to regulators and employer incentives, which could impact the efficiency of existing regulations (e.g., experience rating regulations) and may create opportunities for improving regulation. While in principle workers' compensation regulators could take a different approach to regulation depending on whether a mandate is in place, we note that in practice the basic regulations in the setting of workers' compensation insurance (e.g., the experience rating formula, the structure of benefits) are very similar in Texas—the sole state without a mandate-and other states.

${ }^{46}$ Any counterfactual government intervention to increase coverage (e.g., a subsidy or mandate) may induce general equilibrium adjustments in related markets (e.g., labor markets, the associated markets for goods/services, etc.) that are not captured by this simple partial equilibrium welfare analysis. For this partial equilibrium analysis, we treat the maximum quantity insured as fixed with respect to the back-of-the-envelope welfare counterfactuals we analyze. Though coverage mandates could theoretically cause the quantity of labor employed to fall, prior empirical work finds no employment effects associated with changes in the actuarial value and cost of mandated workers' compensation benefits (Gruber and Krueger (1991)).
} 
Motivated by the widespread use of coverage mandates in this setting, our discussion of the graphical example focuses on the impact of a coverage mandate implemented with full compliance. Figure 5 Panel A describes a competitive market that is adversely selected (as depicted in the figure by the downward sloping cost curves). In a perfectly competitive market, firms earn zero profits, and the equilibrium is defined by the intersection of the demand and the average cost curves (point B). The efficient provision of insurance occurs at the quantity described by the intersection of the demand and the marginal cost curve (point A). Thus, in an adversely selected setting, a competitive market under-provides insurance, where the deadweight loss in this figure is described by area $\mathrm{ABC}$. Though adverse selection may justify a mandate, whether a mandate will improve welfare is an empirical question that will depend on the relative magnitude of the welfare gain among those inefficiently uninsured without a mandate (area $\mathrm{ABC}$ ) and the welfare loss among those efficiently uninsured without a mandate (area ADE).

Market power may lead to under-insurance and provide a motivation for government intervention. To illustrate this point, Figure 5 Panel B presents a simple example of a market served by a monopolist insurer with no selection (as depicted in the figure by the flat marginal/average cost curve). The monopolist sets prices such that marginal revenue equals marginal costs, so the market equilibrium is depicted by point $B$. The efficient provision of insurance occurs in a competitive market with average cost pricing, at the intersection of the demand and the marginal/average cost curve (point A). Thus, insurance is under-provided and the welfare loss of this under-provision is depicted in this figure by area ABC. Whether it is welfare-improving to mandate the purchase of insurance will depend on the relative magnitude of the welfare gained for those inefficiently uninsured without a mandate (area $A B C$ ) and the welfare lost for those efficiently uninsured without a mandate (area ADE). The intuition in this graphical illustration extends to a more general imperfectly competitive market where insurers provide symmetric insurance products, and imperfect competition among insurers results in a symmetric equilibrium where the market price exceeds the average cost among the insured. Applying this framework to the empirical setting, we measure the impact of market power by comparing the observed market allocation to a competitive equilibrium characterized by zero profits. ${ }^{47}$

Figure 5 Panel $\mathrm{C}$ describes a market with no selection and a positive externality associated with insurance. For example, a positive externality associated with insurance arises if some of the costs covered by the insurer would have been paid by external parties outside of the consumers/producers in the absence of insurance. Panel C illustrates the case of a constant positive externality. In this case, the efficient provision of insurance occurs at the point at which the social marginal cost (SMC) curve intersects the demand curve (point $\mathrm{A}$ ). However, a competitive private market would provide insurance at the point at which the private marginal

\footnotetext{
${ }^{47}$ Because this welfare framework considers a fixed product space, our analysis within this framework abstracts from any potential impact of market power on product attributes beyond price. This abstraction may be fairly reasonable in this application, as insurance products are highly standardized by the regulator in the setting of workers' compensation insurance.
} 
cost (PMC) curve intersects the demand curve (point B). Thus, a competitive private market would underprovide insurance, where the welfare loss of this under-provision is depicted by area ABC. In the case of a

positive externality, whether a mandate will improve welfare is an empirical question that will depend on the relative magnitude of the welfare gain among those inefficiently uninsured without a mandate (area $A B C$ ) and the welfare loss among those efficiently uninsured without a mandate (area ADE).

There are a few key take-aways from this simple graphical example. First, adverse selection, market power, and positive externalities may each contribute to the under-provision of insurance relative to the first best and are potential justifications for mandating coverage. Second, the existence of adverse selection, market power, and/or positive externalities is not sufficient for justifying a coverage mandate. Within this framework, whether a mandate will improve welfare will depend on the empirical demand and cost curves.

\subsection{Empirical Evidence}

Selection Next, we look to the data for evidence relating to these potential justifications. Leveraging the same price variation used to estimate demand, we test for the presence of selection following the approach outlined by Einav and Finkelstein (2011) and Einav, Finkelstein and Cullen (2010). Specifically, we estimate the baseline empirical specification outlined in equation 2, replacing the dependent variable with applicable measures of costs. In this analysis, we assume that marginal costs are monotonic in the quantity insured, so that the sign of the relationship between average costs and quantity is informative as to the degree of selection (as measured by the sign of the slope of the marginal cost curve).

Table 4 Panel A reports the results of this analysis. Each column corresponds to a separate regression, where the corresponding dependent variable is indicated at the top of the column. One challenge with estimating selection is that a few classifications have no claims in some years, so the natural logarithm of the average cost for such observations is undefined. Table 4 Panel A presents the results for the baseline specification that uses all classification-year observations in the demand estimation and an inverse hyperbolic sine transformation to include observations with zero costs. In the discussion below, we interpret the inverse hyperbolic sine transformation as an approximation of the natural logarithm. We obtain qualitatively similar findings in alternative specifications where we investigate alternative transformations- a $\ln (x)$ transformation or a $\ln (x+1)$ transformation—of the cost measure. See Appendix Table A9 for these estimates.

Because insurers in this setting are allowed to risk-adjust premiums (through a multiplicative experience rating modifier, as described in Section 1.1), assessing whether there is welfare-relevant selection in this setting requires analyzing whether insurer expected risk-adjusted costs vary with the quantity insured. Table 4 Panel A column 1 reports the results relating a feasible proxy for insurer expected risk-adjusted costs- ex post realized mean claim costs per $\$ 10 \mathrm{~K}$ of risk-adjusted payroll-to the base rate variation. The coefficient 
estimate on the base rate is quantitatively small and statistically indistinguishable from zero. Scaling this cost estimate by the appropriate demand estimate in terms of risk-adjusted payroll (from Table 4 Panel A column 2 ), the estimate suggests that a $1 \%$ increase in risk-adjusted covered payroll induces a $0.06 \%$ decrease in mean risk-adjusted claim costs. ${ }^{48}$

To see the magnitude of the point estimates graphically, Appendix Figure A7 Panels A and B plot the implied demand and cost curves based on the risk-adjusted cost elasticity estimate, market-level aggregate data (on premiums, costs, and quantity), and a linear or constant elasticity extrapolation, respectively. ${ }^{49}$ This figure illustrates that the implied risk-adjusted marginal/average costs based on the point estimates in Table 4 Panel A are very close to constant in the quantity insured. Further, Table 4 Panel B displays the implied welfare cost of selection using the implied cost curves based on extrapolating from these statistically insignificant point estimates. Panel B also reports standard errors calculated using a block bootstrap estimation procedure based on 1,000 iterations, clustering at the classification level, where demand and cost regressions are estimated within each bootstrap iteration. ${ }^{50}$ The point estimates from Panel A based on a constant elasticity extrapolation indicate an implied welfare cost from adverse selection of $\$ 0.001$ per $\$ 100$ of risk-adjusted payroll, with a 95\% confidence interval allowing us to rule out a welfare cost in excess of $\$ 0.24$ per $\$ 100$ of risk-adjusted payroll. Benchmarking this by the size of the market in terms of mean premiums, the point estimate indicates the welfare cost from adverse selection is $0.04 \%$ of mean premiums in the market, and the associated confidence interval allows us to rule out that the welfare cost of adverse or advantageous selection exceeds $10.9 \%$ of mean premiums in the market. Overall, the calculations in Table 4 Panel B indicate that the implied welfare cost of selection based on the point estimates is economically small and statistically indistinguishable from zero.

Based on the estimates above, there is no evidence of adverse selection in this setting. We probe the robustness of this qualitative finding in a variety of ways. First, Appendix Table A9 presents estimates from additional specifications with alternative transformations of the cost measure and alternative cost measures. The results reported in Appendix Table A9 illustrate that these additional specifications yield similar findings. Second, Appendix Figure A8 depicts a binned mean residual plot to graphically illustrate the baseline selection estimates. While the cost regression estimates are nosier than the demand estimates, these plots show no evidence of selection. Third, Appendix Figure A9 displays estimates from the complementary event

\footnotetext{
${ }^{48}$ These estimates correspond to the elasticity of the average cost curve with respect to the quantity insured (in terms of risk-adjusted payroll) using a constant elasticity extrapolation based on the demand and cost regression estimates. See Appendix Section $\mathrm{C}$ and Appendix Table A10 for more detail on these estimates.

${ }^{49}$ For a more detailed explanation of the welfare calculations, see below and Appendix Section C.

${ }^{50}$ Note that we need to rely on parametric extrapolation to recover the marginal cost curve from the estimated average cost and demand curves. Given the limited range of quantities spanned by the identifying premium variation, estimates of the deadweight loss from selection may be sensitive to the chosen parametric form used for extrapolation and should be interpreted with appropriate caution. In practice, we obtain very similar estimates of the deadweight loss from selection using either a linear or constant elasticity extrapolation.
} 
study approach outlined in equation 6, with mean claim costs (Panel A) and risk-adjusted payroll (Panel B) as outcomes. This figure shows no evidence of selection and no evidence of pre-existing trends.

We note that it may not be surprising that we find no evidence of adverse selection in this setting. Workers' compensation insurance is a very heavily risk-adjusted market compared to many other insurance markets (e.g., individual health insurance, individual annuities, etc.). Thus, one possible explanation for the lack of evidence of adverse selection is that the extensive risk adjustment in this setting-through industryoccupation rating and experience rating-may reduce the scope for private information and may be effective at addressing selection. Further, employer workers' compensation insurance purchase decisions reflect employer and employee preferences over horizontally differentiated options for settling workplace injuries (workers' compensation insurance or tort liability), and these decisions likely reflect many factors beyond expected workers' compensation insurance claim costs. For example, heterogeneity in the value of workers' compensation insurance may reflect variation in preferences or variation in the transaction costs associated with settling workplace injuries outside the workers' compensation insurance system.

Market Power To investigate the potential quantitative importance of market power, we conduct backof-the-envelope welfare calculations using our demand elasticity estimates along with market-level data on mean premiums and insurer combined loss ratios. While the selection analysis focuses on estimating the slope of the average and marginal cost curves using data on claim costs, we rely on data on market-wide mean premiums and insurer-reported combined loss ratios to infer the level of the average cost curve (and the profit margin) at the observed market quantity. This broader market-level measure of mean costs based on insurer combined loss ratios is more comprehensive than claim costs, as it also accounts for insurer administrative and operating expenses. ${ }^{51}$ The mean insurer combined loss ratio over the analysis period is $84 \%$.

We then employ a few parametric assumptions to extrapolate from our estimated demand elasticity and conduct several back-of-the-envelope calculations projecting welfare under various hypothetical government interventions. As described in Section 1.1, insurers in this market only choose the overall price level; relative prices across industry-occupation groups and across experience-rating groups are fixed by regulation. Thus, for the purpose of this calculation, we model this as a single market where we measure the quantity insured as the fraction of risk-adjusted payroll that is insured. To obtain the aggregate risk-adjusted payroll in the population, we extrapolate based on the estimated relationship between the mean experience rating modi-

\footnotetext{
${ }^{51}$ We use the mean insurer combined loss ratio from 2006-2011 from reports published by the Texas Department of Insurance (TDI) (TDI WCREG (2016c) and TDI WCREG (2010a)). According to TDI WCREG (2010b) pg. 7, the combined loss ratio "combines the loss ratio with the expense ratio to gauge overall profitability, before consideration of the investment earnings of insurance companies.... A combined ratio of less than 100 percent indicates that the insurance company earned a profit on its insurance operations (also called an underwriting profit)." The first component of this calculation is the loss ratio which "equals the projected direct ultimate incurred losses divided by the direct earned premium." The second component in this calculation is the expense ratio which "includes loss adjustment expenses, other types of expenses, and policyholder dividends. Loss adjustment expenses are those costs incurred in processing, investigating, and settling claims. Other types of expenses include insurance company administrative overhead, commissions, and taxes, licenses, and fees. Policyholder dividends may be thought of as profit-sharing in the form of a return of a percentage of the premiums to policyholders."
} 
fier and the quantity of payroll insured. ${ }^{52}$ To measure the universe of possible payroll insured, we obtain aggregate Texas payroll data from the Quarterly Census of Employment and Wages (QCEW). Specifically, we define the relevant population for this market to be all private sector payroll in the state of Texas, excluding the fraction of payroll attributable to certified self-insured firms, as described further in Section 1.2 and Appendix D.3. Based on the empirical analysis described above which finds no evidence of selection, we do these calculations under the assumption of no selection, meaning that there is a flat market-level average/marginal (risk-adjusted) cost curve. ${ }^{53}$ Appendix Table A11 illustrates that the welfare estimates are similar if instead we employ the small (and statistically indistinguishable from zero) risk-adjusted cost elasticity estimates reported in Table 4 . In the following calculations, we ignore potential externalities. We revisit the role of externalities further below.

Table 5 Panel A displays the welfare calculations, while Panel B reports the underlying point estimates and corresponding demand curve. The counterfactuals are conducted using two alternative parametric extrapolations from the demand estimates: linear demand (displayed in columns 1 and 2) and constant elasticity demand (displayed in columns 3 and 4). In addition to the reported estimates in Table 5, Figure 6 Panel A displays the linear and constant elasticity demand curves graphically, along with mean costs. The figure indicates the observed quantity insured and the optimal quantity insured. Dashed vertical reference lines indicate the range of the identifying variation: the implied range in quantity based on a constant elasticity specification and the observed range of premium variation spanning a $+/-25 \%$ price change. Note that the identifying variation spans the relevant range of quantities for the analysis comparing the observed quantity insured to the optimal quantity, and so the fitted linear and constant elasticity demand curves closely correspond to one another in this range. The counterfactuals related to an insurance mandate are outside of the range of the identifying variation. Thus, these counterfactuals will naturally be more sensitive to the chosen functional form for demand, and one should interpret the precise magnitudes with the appropriate caution.

Table 5 reports welfare measured in dollars per $\$ 100$ of risk-adjusted payroll. In addition, we also report two scaled measures of welfare to ease interpretation. The table reports welfare as a percent of mean premiums in this market, a measure of the "maximum money at stake" in this setting (Einav, Finkelstein and Schrimpf, 2010). To contextualize the relative estimates in terms of annual dollars, the table also reports welfare measures scaled by $\$ 50 \mathrm{~K}$, approximately the mean annual earnings for Texas workers in $2011 .{ }^{54}$

\footnotetext{
${ }^{52}$ See Appendix Section $\mathrm{C}$ for more details.

${ }^{53}$ While the selection regression analysis in Table 4 Panel A uses claim cost data to measure the slope of the average cost curve with respect to the quantity insured, the welfare calculations employ a more comprehensive measure of aggregate costs inclusive of both claim costs and administrative costs to identify the level of average costs relative to premiums. If total insured costs (inclusive of claim and administrative costs) are proportional to claim costs, the cost elasticities estimated in Table 4 Panel A are informative about the slope of the average cost curve using a more comprehensive definition of costs.

${ }^{54}$ Based on the authors' calculations, the mean earnings of Texas workers in the QCEW data for 2011 is roughly $\$ 50 \mathrm{~K}$. Note that this is simply a convenient way to contextualize the magnitude of the estimates rather than a statement regarding the incidence of workers' compensation surplus among employees/employers.
} 
First, let us consider the optimal allocation in this market. In the absence of selection, a perfectly competitive market yields the optimal allocation. According to our estimates, the optimal allocation in this setting is attained when $67.3 \%$ of risk-adjusted payroll is insured in the linear specification $(67.9 \%$ in the constant elasticity extrapolation), a roughly 5 percentage point increase over the status quo quantity insured of $62.8 \% .^{55}$ Focusing on the linear demand specification, relative to the imperfectly competitive status quo, moving to the perfectly competitive optimal allocation would increase welfare by $\$ 0.0078$ per $\$ 100$ of risk-adjusted payroll, with a $95 \%$ confidence interval allowing us to rule out an increase less than $\$ 0.0038$ or more than $\$ 0.0118$ per $\$ 100$ of risk-adjusted payroll. Scaling this by $\$ 50 \mathrm{~K}$ (roughly the mean annual earnings), these estimates imply a welfare increase of $\$ 3.91$ annually per worker in a perfectly competitive optimum relative to the status quo, which is approximately $0.4 \%$ of the analogous mean premium in this market. We obtain very similar welfare estimates in the alternative specification with constant elasticity demand (reported in columns 3 and 4).

The small magnitude of these estimates indicates that there is very little welfare at stake when considering a move from the imperfectly competitive status quo to the perfectly competitive optimum. This analysis suggests government intervention to increase coverage would at best generate a small amount of surplus and at worse be welfare-detrimental. Consider a government subsidy to move the market from the status quo to the optimal allocation. If there is no deadweight loss of taxation to fund this subsidy, the subsidy would increase welfare by approximately $\$ 4$ per worker annually. However, more realistically, there is likely some deadweight loss associated with raising tax revenue to cover the cost of the subsidy. If we assume the marginal deadweight loss associated with taxation is $25 \%$ and the subsidy is fully passed through to consumers, then the subsidy needed to implement the optimal allocation would reduce welfare relative to the status quo, where the estimates indicate a welfare reduction of $\$ 0.051$ per $\$ 100$ of risk-adjusted payroll—or approximately $\$ 26$ per worker annually. In fact, a subsidy to implement the optimal allocation will be welfaredetrimental provided that the marginal deadweight loss associated with taxation per dollar of subsidy is greater than $1 \%$. Overall, this evidence suggests that market power does not present a compelling justification for government intervention to further increase insurance enrollment through a subsidy in this setting.

Motivated by the prevalence of workers' compensation mandates, we next consider a hypothetical insurance mandate in the Texas workers' compensation insurance market. Because this counterfactual is further outside of the variation we use to estimate demand, naturally these estimates will be more sensitive to the parametric specification of the demand curve, and one should be more cautious in interpreting the estimates. With that caveat in mind, our estimates indicate that an insurance mandate would substantially decrease wel-

\footnotetext{
${ }^{55}$ Pooling the data over our analysis period, $74 \%$ of private industry payroll is insured (as reported in Table 1), and $62.8 \%$ of riskadjusted private industry payroll is insured. As discussed above, we obtain risk-adjusted payroll using data on experience rating and extrapolating from the estimated reduced form relationship between the mean experience rating factor and base rates. An implication of these estimates is that inframarginal insured employers have lower experience modifiers (and hence risk-adjusted premiums per unit of covered payroll) than marginal employers. See Appendix Section C for more details.
} 
fare. The precise magnitude of the reduction in welfare relative to the status quo depends on the specification: the linear specification indicates a decline of $\$ 0.41$ per $\$ 100$ of risk-adjusted payroll, while the constant elasticity specification indicates a decline of $\$ 0.20$ per $\$ 100$ of risk-adjusted payroll. Scaling this by $\$ 50 \mathrm{~K}$, these estimates imply that a mandate would decrease welfare by approximately $\$ 206$ annually per worker based on the linear specification or $\$ 100$ annually per worker based on the constant elasticity specification. The welfare loss from a mandate amounts to $18.8 \%$ of mean premiums based on the linear specification and $9.1 \%$ of mean premiums based on the constant elasticity specification.

Externalities Next we turn to another traditional market failure justification for government intervention to expand coverage: positive externalities. For example, positive externalities may arise in an insurance market if some of the costs covered by insurance would have fallen on external parties (outside the relevant consumers and producers) in the absence of insurance. Under the assumption that workers' compensation insurance decisions reflect the preferences of employers and their employees, an externality would arise if workers' compensation insurance purchase decisions affected costs borne by parties other than the insurer, the employer, and the associated employees. ${ }^{56}$ In the setting of workers' compensation insurance, it is plausible that there are positive externalities that accrue to formal or informal health insurers because of the presence of workers' compensation coverage. ${ }^{57}$ Approximately $60 \%$ of workers' compensation claim costs are due to medical bills associated with workplace injury. If an individual has workers' compensation coverage, the workers' compensation insurer is the first payer for these medical costs. In the absence of workers' compensation insurance, external parties such as health insurers, hospitals, or other sources of charity care incur some of the costs that would have otherwise been covered under workers' compensation insurance. Thus, if external parties such as health insurers bear some of the costs that would otherwise be covered by workers' compensation insurance and there are no adjustments to make consumers internalize these costs, there is an externality in this market: workers' compensation insurers and consumers do not account for the fact that workers' compensation coverage can drive down the costs of formal or informal health insurers.

While prior studies have shown that expanding health insurance coverage or generosity leads to reductions in workers' compensation insurance medical expenditures (Dillender, 2015; Bronchetti and McInerney, 2021; Fomenko and Gruber, 2017, 2019), there is no evidence from the prior literature to guide us in assessing how the existence of workers' compensation insurance coverage affects health care expenditures borne by

\footnotetext{
${ }^{56}$ We also note that if the parties of the workers' compensation purchase decision include insurers, workers, and employers, externalities would not include uncompensated losses that are borne by workers or their families. Rather, externalities would derive from costs borne by other third parties not involved in the workers' compensation purchase decision, for example, private health insurers, government health insurance programs, and hospitals that provide charity care to the uninsured.

${ }^{57}$ Externalities across different types of insurance products can arise in several types of settings. For instance, an externality can arise when two types of insurance products may be eligible to pay for the same costs (such as medical costs associated with workplace injury that could be eligible for payment through either health insurance or workers' compensation insurance). Alternatively, externalities across insurers can arise if insurance products cover complementary costs, as is the case with Medicare and private Medigap coverage (Cabral and Mahoney, 2018).
} 
external parties (e.g., health insurers, charity care providers, etc.). Further, data are not available to quantify this externality using our variation. Thus, we are left to speculate about the importance of this potential externality. While this potential externality may exist, there are several reasons why the externality is likely quantitatively small in practice. First, the externality is mitigated to the extent that health insurers can successfully recover medical costs associated with workplace injury through suing liable employers. Second, this potential externality is also limited by the extent to which employer health insurance costs reflect workers' compensation insurance coverage (e.g., through actuarial adjustments to health insurance premiums, through experience rating for employer-provided health insurance, through self-insurance of employee health coverage, etc.). ${ }^{58}$ Third, the externality is mitigated to the extent that injured employees themselves pay their own medical bills out-of-pocket due to incomplete health insurance coverage. Fourth, this externality may be quantitatively small if many of the medical expenditures within the workers' compensation system would not have occurred in the absence of workers' compensation. ${ }^{59}$

While data limitations prevent us from estimating this externality in this setting, we assess the potential quantitative importance of externalities on formal and informal health insurers through conservative backof-the-envelope calculations. In these calculations, we are interested in whether positive externalities may justify government intervention to increase coverage. Our analysis of externalities is not exhaustive, as there could be other externalities beyond externalities on external payers for health care. We note there is almost no research on this topic, and the limited research that exists suggests that some other natural external parties may be unaffected by workers' compensation coverage. ${ }^{60,61}$ In the absence of evidence of other positive externalities, we focus on the external impacts of workers' compensation coverage on formal and informal health insurers as the most likely source of positive externalities in this setting.

We repeat the welfare analysis above under various conservative assumptions on the magnitude of the externality on formal or informal health insurers. Specifically, we model this externality as a constant shift

\footnotetext{
${ }^{58}$ Given these extensive mechanisms to internalize this externality in the setting of employer-provided health insurance, this externality may be most prevalent among those with health insurance through other sources (e.g., a spouse's employer, Medicaid, charity care, etc.).

${ }^{59}$ Some medical costs within workers' compensation are specific to that setting and are irrelevant outside of workers' compensation insurance. For instance, workers' compensation claims require a medical exam to assess the scope of the injury and the employee's work limitations. More generally, moral hazard responses may lead individuals to claim medical expenditures under workers' compensation that would not have occurred in the absence of this coverage.

${ }^{60}$ For instance, workers' compensation insurance may generate externalities for providers of public or private disability insurance. Because workers' compensation coverage is primarily aimed at providing temporary benefits while disability insurance covers longer spells after a waiting period, the direction of any such externality is ex ante theoretically ambiguous. Further, prior work has shown that the tightening of workers' compensation insurance programs does not appear to be associated with increased disability insurance claims (McInerney and Simon (2012)). Aside from work on potential externalities on disability insurance, we know of no other prior work on other externalities associated with workers' compensation coverage, and we note this is an important area for future research.

${ }^{61}$ One potential source of positive or negative externalities is legal or administrative costs borne by external parties on the margin, within the workers' compensation insurance system relative to the outside option of tort liability. Regulatory functions within the workers' compensation insurance system, such as adjudicating disputes and compliance auditing, may be associated with external legal and administrative costs. Because workplace injury cases are typically settled out of court, most of the legal costs in the tort system are borne by employers and employees. Thus, it is unclear whether there are significant external legal costs-borne by parties outside the employer and employee-associated with cases settled through the tort system. We note there is no systematic data to quantify any external legal and administrative costs, and the sign (and magnitude) of any associated externality is ex ante ambiguous.
} 
downward in the social marginal cost curve relative to the private marginal cost curve faced by workers' compensation insurers. In these calculations, we assume that health insurers do not make actuarial adjustments to premiums based on workers' compensation coverage, and we assume that health insurance (broadly defined as being inclusive of formal health insurance and charity care) provides $70 \%$ actuarial value coverage of medical costs, while workers' compensation provides $100 \%$ actuarial value coverage of medical costs. ${ }^{62}$ Table 6 reports the results of these additional calculations for both linear and constant elasticity demand specifications. For reference, the baseline results with no externality are displayed in column 1 for the linear specification and column 4 for the constant elasticity specification. The remaining columns display the results when repeating the welfare calculations assuming that $25 \%$ or $50 \%$ of workers' compensation medical claim costs would have otherwise occurred and been eligible for coverage through a formal or informal health insurer. Figure 6 Panel B graphically depicts these back-of-the-envelope welfare calculations using both the fitted linear and constant elasticity demand curves.

Inspecting Table 6, we see that the optimal quantity insured increases modestly with the magnitude of the externality on health insurers, but in no scenario does the optimal quantity insured approach full insurance. Between $67 \%$ and $68 \%$ of risk-adjusted payroll would be optimally insured if there were no externality, while the optimally insured share increases to $68.6 \%$ based on a linear extrapolation (or $69.7 \%$ based on a constant elasticity extrapolation) if a quarter of the medical claim costs would have been eligible for payment by external health insurers. In a more extreme (and, in our view, unrealistic) case where $50 \%$ of medical claim costs would have been eligible for payment by external health insurers, we see that the optimal insured share only increases to $70.0 \%$ under the linear specification (or $71.7 \%$ in the constant elasticity specification). We note that this calculation — under the more extreme $50 \%$ assumption—results in a projected optimal quantity insured at the edge of the identifying variation, so more caution should be exercised when interpreting these estimates. While the precise welfare estimates for the counterfactuals depend on the size of the externality, the main lessons of this analysis are robust across the specifications: (i) mandating workers' compensation coverage would not increase welfare relative to the status quo, (ii) the optimal allocation provides only a small increase in welfare relative to the status quo, and (iii) a subsidy to support the optimal allocation funded by a tax with marginal deadweight loss of $25 \%$ would decrease welfare relative to the status quo. Overall, these calculations suggest that externalities on external health care payers may not provide a compelling justification for further government intervention to increase coverage. ${ }^{63}$

\footnotetext{
${ }^{62}$ We make the approximation that formal and informal health insurance provides $70 \%$ actuarial value coverage; this is consistent with recent evidence that the uninsured pay in the range of $20 \%$ to $35 \%$ of their cost of care (e.g., Coughlin et al. (2014), Finkelstein, Mahoney and Notowidigdo (2018)).

${ }^{63}$ Our analysis suggests that externalities on external health care payers have a limited impact on coverage rates for workers' compensation insurance. This work contributes to a broader literature investigating the importance of insurance-related externalities on health care payers. For example, recent work in health insurance settings has found that externalities on other health care payers (e.g., uncompensated care provided to the uninsured) are substantial and may explain a large amount of the observed low take-up of formal health insurance among low-income populations (e.g., Finkelstein, Hendren and Luttmer (2019), Finkelstein, Hendren and Shepard (2019),
} 


\subsection{Discussion}

The key take-away from the welfare analysis above is that the market failures examined here-adverse selection, market power, and externalities on external health care payers-may not justify further government intervention to expand coverage through a subsidy or mandate in the Texas workers' compensation insurance market. Below, we discuss two possible interpretations for these findings.

One interpretation of the evidence above is that there is no rationale for mandating coverage in this setting. If we interpret the estimated demand curve as representing the value of this insurance to consumers, the welfare analysis indicates that some segment of the population is optimally uninsured as their willingnessto-pay for coverage lies below the cost of providing this coverage and government intervention to expand coverage in this setting would harm welfare. It is certainly plausible that some segment of risk averse consumers (jointly, employers and employees) may be optimally outside the workers' compensation insurance system. For instance, consumers may not value workers' compensation coverage above the cost of providing this coverage because of factors such as moral hazard and/or administrative costs. Moral hazard is a plausible explanation for the low valuations in this setting, as several studies (e.g., Cabral and Dillender (2020), Krueger (1990b), Krueger (1990a), Meyer, Viscusi and Durbin (1995)) have suggested that there may be substantial scope for moral hazard in workers' compensation insurance. ${ }^{64}$ Administrative costs may also contribute to the estimated low valuations relative to costs in the analysis above. It is also important to emphasize that this is not a classic vertically differentiated insurance setting where a consumer either has insurance or no insurance for some underlying risk. Instead, this is a setting with horizontally differentiated options for recourse for work-related injuries: workers' compensation insurance or tort liability. In any setting with horizontally differentiated options, there is not necessarily an ex ante reason to believe that consumers should all prefer one option over the other, even beyond considerations such as moral hazard and administrative costs.

Another interpretation of the findings above is that there may still exist alternative justifications for mandating coverage if the estimated demand curve does not fully capture the value of this insurance to consumers (jointly employers and employees in this setting) and thus the welfare analysis above does not accurately capture the welfare gained through a mandate. There are a few potential reasons why the demand curve may not fully reflect consumer values in this setting. First, consumers in this setting may have limited information

\footnotetext{
Finkelstein, Mahoney and Notowidigdo (2018), Mahoney (2015), Garthwaite, Gross and Notowidigdo (2018)).

${ }^{64}$ Consistent with the notion that some workers may value workers' compensation insurance below the cost of this coverage because of moral hazard, Cabral and Dillender (2020) provide recent evidence on behavioral responses to workers' compensation wage replacement benefit generosity and conduct welfare calibrations which illustrate that coverage is more generous than would be optimal under a range of plausible risk aversion values. Because the prior literature examines the elasticity of claims with respect to the benefit level within workers' compensation systems, none of these studies provide the elasticity of interest in this setting: how do the costs from work-related injuries respond to the existence of workers' compensation insurance? Theoretically, we might expect moral hazard in this setting, as workers' compensation insurance provides more generous coverage than the outside option for many workplace injuries through a combination of increased benefits relative to the outside option for many injuries and reduced barriers to getting these benefits (e.g., reduced hassle costs, no-fault coverage, etc.). Unfortunately, comparable data on workplace injuries is not available for covered and uncovered firms, so we are unable to estimate moral hazard using our variation.
} 
or be subject to behavioral biases that lead them to inappropriately weigh risks and costs associated with settling workplace injuries within the workers' compensation insurance system or within the tort system. If consumers inappropriately value this coverage, traditional revealed preference welfare analysis using demand curves may not be appropriate. ${ }^{65}$ Note that this concern is not particular to this setting. Any study that uses demand in welfare analysis must confront the fact that behavioral biases may influence demand in such a way that the distribution of true consumer values departs from the estimated demand curve. Second, there may be labor market frictions (e.g., wage rigidities, bargaining frictions between employers and employees, informational asymmetries between workers and firms, etc.) that lead employer workers' compensation insurance purchase decisions to not reflect the joint value of this insurance to employers and employees.

While the precise welfare estimates discussed above rely on interpreting the demand curve as representing consumer values of insurance, it is important to note that some of the broader conclusions from the analysis above do not depend on the interpretation of the demand curve. In particular, even if we cannot interpret the demand curve as representing consumer values in this setting (e.g., due to behavioral biases, information frictions, wage rigidities), there is no evidence of adverse selection-the typical first-order market failure concern used to justify mandates in insurance markets. The test for selection-whether we can reject a zero slope of the marginal cost curve-is independent of the interpretation of the demand curve. Additionally, regardless of the interpretation of the demand curve, our calculations suggest that market power and externalities have a modest impact on market quantities. While we cannot measure the welfare cost of the impact on market quantities without taking a stand on the interpretation of the demand curve, the relatively small predicted changes in equilibrium quantities based on these factors suggest that market power and externalities are unlikely justifications for a coverage mandate in this setting even if the demand curve does not accurately reflect consumer values. Of course, if consumer values for insurance systematically exceed those implied by the estimated demand curve, the underlying reasons for the departure between the demand curve and consumer values— for example, underlying behavioral biases or labor market frictionsmay themselves provide an alternative "internality" justification for government intervention in the form of a

\footnotetext{
${ }^{65}$ One potentially important aspect of consumer information is the extent to which workers understand the outside option of legal recourse. Workers might have inaccurate beliefs about options for pursuing compensation for injuries through the tort system in the absence of workers' compensation insurance. One example of a subtle issue that might not be salient to workers before an injury occurs is that a worker might have difficulty recovering costs through the tort system for injuries at a small employer with too few assets. That is, small employers might have de facto limited legal liability in the tort system. Misinformation about the limits of tort liability could lead workers to undervalue workers' compensation insurance. On the other hand, some workers may not be aware-before an injury occurs- that they have the option to recover damages through the tort system when working for a non-participating employer or that they forgo this option when working at a participating employer. This could lead some workers to inaccurately overvalue workers' compensation insurance. As with other behavioral biases or sources of limited consumer information, we are not aware of evidence on the extent to which workers understand or account for the implications of employer participation in workers' compensation insurance.
} 
subsidy or mandate. ${ }^{66,67}$ We are aware of no research on the importance of limited consumer information and behavioral biases in the setting of workers' compensation insurance. ${ }^{68}$ Prior studies have found that mean wages among workers in select occupations respond sharply to changes in the cost (and actuarial value) of mandated workers' compensation benefits (Gruber and Krueger, 1991) and the establishment of workers' compensation systems (Fishback and Kantor, 1995), suggesting that wage rigidities may be limited on average. ${ }^{69}$ Our data and variation do not allow us to assess the quantitative importance of behavioral biases or labor market frictions in this setting. We note this is an important area for future research.

While the market failures we investigate may not justify a mandate in this setting, it is important to note that consumers may highly value the option to buy workers' compensation from the regulated voluntary market. Recall that a large segment of consumers (jointly employees and employers) appear to value workers' compensation coverage more than the mean cost of providing this coverage: roughly $66 \%$ of employers (employing $78 \%$ of workers) are covered by workers' compensation insurance in the absence of a mandate. Moreover, based on our modest estimated demand elasticity, many of these consumers are not close to indifferent between purchasing or not purchasing this coverage at the market price. Thus, while the revealed preference welfare analysis indicates that some consumers may be optimally uninsured, the estimates suggest that some consumers derive significant surplus from this coverage and that on average consumers appear to value workers' compensation insurance more than the cost of providing this coverage. For instance, if we extrapolate based on a parametric linear demand curve, the estimates suggest that on average consumers value workers' compensation coverage at $146 \%$ of the mean premiums for this coverage. ${ }^{70}$ In summary, the

\footnotetext{
${ }^{66}$ While demand may not be a reliable measure of consumer value if there are important behavioral biases or labor market frictions, it is ex ante ambiguous whether such factors would lead demand to under-estimate or over-estimate the value of workers' compensation insurance relative to the outside option of tort liability. Because workers' compensation insurance and the outside option are horizontally differentiated forms of coverage from an employee's perspective, the impact of labor market frictions on demand will depend on whether employees place positive or negative value on workers' compensation coverage relative to the outside option. If employees generally value workers' compensation insurance more highly than the outside option, labor market frictions may lead demand to under-estimate the value of workers' compensation insurance and these frictions could represent an independent rationale for a mandate.

${ }^{67}$ The National Commission on State Workmen's Compensation Laws (1972) endorsed universal coverage of workers as one of the four basic objectives of workers' compensation policy. Among other arguments, the National Commission cited labor market imperfections and the bounded rationality of workers as justifications for a coverage mandate. "For several reasons we do not find the freedom-tocontract plea convincing. A classic point against that plea is that employees do not have equal bargaining power with their employers, particularly when employees are not unionized. An even more compelling reason for mandatory insurance is that the task of selecting a job is complex. Most workers are unlikely to assess properly the probabilities of being exposed to work-related impairments." (National Commission on State Workmen's Compensation Laws, 1972, pg. 36).

${ }^{68}$ There is a growing literature illustrating that choice frictions and limited information impact individual decisions in some settings, including health insurance (e.g., Handel (2013), Handel and Kolstad (2015), Handel, Kolstad and Spinnewijn (2019)) and prescription drug insurance (e.g., Abaluck and Gruber (2011), Ho, Hogan and Scott Morton (2017)). In contrast to most settings examined in this literature, employers-not individuals-make purchase decisions for workers' compensation insurance. An important area for future work is examining the extent to which choice frictions may impact employer workers' compensation insurance decisions and employer insurance decisions more broadly.

${ }^{69}$ These two prior studies investigate the impact of workers' compensation insurance changes on the wages of workers in selected highrisk occupations: Gruber and Krueger (1991) investigate five types of workers (carpenters, gasoline station workers, nonprofessional hospital employees, plumbers, and truck drivers), while Fishback and Kantor (1995) investigate three types of workers (coal workers, lumber workers, and unionized building trades). While these prior studies suggest that mean wages in select occupations respond to changes in the cost (and actuarial value) of mandated workers' compensation benefits (Gruber and Krueger, 1991) and the establishment of workers' compensation systems (Fishback and Kantor, 1995), there could be heterogeneity in responses across firms and workers. Our work provides the first estimates of the value of workers' compensation insurance to employers and employees, and our estimates suggest substantial heterogeneity in the value of workers' compensation coverage across firms and workers.

${ }^{70}$ This average represents an average across all consumers, not just those that are covered. Estimating the mean value of this coverage
} 
revealed preference welfare analysis suggests that mandated workers' compensation insurance may improve welfare over the absence of any workers' compensation insurance system, but a coverage mandate may reduce welfare relative to the existing regulated, voluntary market for workers' compensation insurance. ${ }^{71}$ Lastly, it is important to emphasize that our investigation of the welfare impact of government intervention in this market holds fixed the attributes of workers' compensation insurance and the outside option of resolution through the tort system. There may be opportunities to improve welfare through broader reform aimed at re-designing the workers' compensation insurance system or the tort system.

\section{Conclusion}

This paper provides the first estimates of the demand for workers' compensation insurance. To estimate the demand for workers' compensation insurance, we leverage the unique voluntary feature of the Texas workers' compensation insurance system and policy-induced variation in premiums paired with administrative data on the Texas workers' compensation insurance market. Though there is no coverage mandate in this setting, voluntary participation is high: approximately $66 \%$ of private sector employers participate in the workers' compensation insurance system, representing roughly $78 \%$ of private sector employees. Leveraging regulatory updates to relative premiums across industry-occupation classifications, the difference-in-differences analysis reveals that the demand for coverage is price-sensitive: a $1 \%$ increase in premiums leads to approximately a $0.3 \%$ decline in coverage. Using these demand estimates and data on costs among the insured, we analyze some common market failure justifications for government intervention to increase coverage through subsidies or a mandate. Our analysis suggests that some common insurance market failures—such as adverse selection, market power, and externalities on external health care payers-may not justify further government intervention to expand coverage through a subsidy or mandate in this setting. Importantly, we note that our empirical strategy does not allow us to rule out (or rule in) alternative justifications for a coverage mandate that go beyond the market failure justifications we investigate. More broadly, this evidence may inform the ongoing policy debate in states considering repealing their coverage mandates in favor of a regulated voluntary workers' compensation market. For instance, one implication of our findings is that such debates may

\footnotetext{
requires extrapolating far from the identifying variation, and thus appropriate caution should be used in interpreting this estimate.

${ }^{71}$ In this way, our results connect with those of prior studies on workers' compensation that show that employers reduced wages to partially offset the costs of changes in the cost (and actuarial value) of mandated workers' compensation benefits (Gruber and Krueger (1991)) and the establishment of workers' compensation systems (Fishback and Kantor (1995)). The wage offsets documented in these prior studies could be consistent with workers placing some value on these coverage expansions, though wage offsets may simply reflect standard tax incidence predictions if labor supply is much more inelastic than labor demand (even if workers place little or no value on this coverage). In contrast to prior work, our study is the first to directly investigate the demand for workers' compensation insurance- and the implied value consumers place on this coverage. While there are many differences between the present setting and the setting of these older studies, our results in this setting suggest that either a voluntary or mandated workers' compensation insurance system generates positive net surplus compared to the absence of a workers' compensation insurance system. While our analysis does not allow us to investigate the division of surplus between employers and employees, our findings suggest that there could be scope to reduce mean employee wages to offset the costs of coverage associated with a voluntary or mandated workers' compensation insurance system. Importantly, our revealed preference welfare analysis suggests there is substantial heterogeneity in the value of this coverage across firms and workers, and there may be gains to allowing choice in this setting.
} 
more productively focus on whether other factors—such as behavioral biases or labor market frictions—lead to systemic under-insurance and could justify mandating coverage.

\section{References}

Abaluck, Jason, and Jonathan Gruber. 2011. "Choice Inconsistencies among the Elderly: Evidence from Plan Choice in the Medicare Part D Program." American Economic Review, 101(4): 1180-1210.

Baldwin, Marjorie, and Christopher McLaren. 2016. "Workers' Compensation: Benefits, Coverage, and Costs, (2014 data)." National Academy of Social Insurance.

Bronchetti, Erin Todd, and Melissa P. McInerney. 2021. "Health Care Reform and Workers' Compensation: Evidence from Massachusetts." ILR Review, 74(2): 388-418.

Bundorf, M. Kate. 2002. "Employee demand for health insurance and employer health plan choices." Journal of Health Economics, 21(1): 65 - 88. Health Plan Choice.

Bundorf, M. Kate, Jonathan D. Levin, and Neale Mahoney. 2012. "Pricing and Welfare in Health Plan Choice." American Economic Review, 102(7): 3214-3248.

Butler, Richard J. 1996. "Lost Injury Days: Moral Hazard Differences between Tort and Workers' Compensation." The Journal of Risk and Insurance, 63(3): 405-433.

Cabral, Marika, and Marcus Dillender. 2020. "The Impact of Benefit Generosity on Workers' Compensation Claims: Evidence and Implications." National Bureau of Economic Research Working Paper 26976.

Cabral, Marika, and Mark R. Cullen. 2019. "Estimating the Value of Public Insurance Using Complementary Private Insurance." American Economic Journal: Economic Policy, 11(3): 88-129.

Cabral, Marika, and Neale Mahoney. 2018. "Externalities and Taxation of Supplemental Insurance: A Study of Medicare and Medigap." American Economic Journal: Applied Economics, 11(2): 33-73.

Chetty, Raj, and Amy Finkelstein. 2013. "Social Insurance: Connecting Theory to Data." Handbook of Public Economics, 5: 111.

Choi, Soon-Yong. 2011. "Costs to Employers and Efficiencies In the Texas Workers' Compensation System." Texas Department of Insurance Workers' Compensation Research and Evaluation Group. https : / / www . tdi.texas.gov/reports/wcreg/documents/Employers_cost.pdf. (Date accessed: 12/2021).

Coughlin, Teresa A., John Holahan, Kyle Caswell, and Megan McGrath. 2014. "Uncompensated Care for the Uninsured in 2013: A Detailed Examination." Kaiser Family Foundation.

Courtemanche, Charles, and Daifeng He. 2009. "Tax incentives and the decision to purchase long-term care insurance." Journal of Public Economics, 93(1): 296-310.

Dillender, Marcus. 2015. “The Effect of Health Insurance on Workers' Compensation Filing: Evidence from the Affordable Care Act's Age-Based Threshold for Dependent Coverage." Journal of Health Economics, 43: 204-228.

DOL. 2019. “Unemployment Insurance Data." Accessed on 05/26/2020.

Dranove, David, Kathryn E. Spier, and Laurence Baker. 2000. "'Competition' among employers offering health insurance." Journal of Health Economics, 19(1): 121 - 140.

Einav, Liran, Amy Finkelstein, and Jonathan Levin. 2010. “Beyond Testing: Empirical Models of Insurance Markets." Annual Review of Economics, 2: 311-336.

Einav, Liran, Amy Finkelstein, and Mark R. Cullen. 2010. "Estimating Welfare in Insurance Markets Using Variation in Prices." Quarterly Journal of Economics, 125(3): 877-921.

Einav, Liran, Amy Finkelstein, and Paul Schrimpf. 2010. "Optimal Mandates and the Welfare Cost of Asymmetric Information: Evidence From the U.K. Annuity Market." Econometrica, 78(3): 1031-1092.

Einav, Liran, and Amy Finkelstein. 2011. "Selection in Insurance Markets: Theory and Empirics in Pictures." Journal of Economic Perspectives, 25(1): 115.

Elaine Weiss, Griffin Murphy, and Leslie I. Boden. 2019. “Workers' Compensation: Benefits, Costs, and Coverage (2017 data)." National Academy of Social Insurance.

Finkelstein, Amy. 2002. "The Effect of Tax Subsidies to Employer-Provided Supplementary Health Insurance: Evidence from Canada." Journal of Public Economics, 84(3): 305 - 339.

Finkelstein, Amy, and James Poterba. 2004. "Adverse Selection in Insurance Markets: Policyholder Evidence from the U.K. Annuity Market." Journal of Political Economy, 112(1): 183-208.

Finkelstein, Amy, Nathaniel Hendren, and Erzo F. P. Luttmer. 2019. "The Value of Medicaid: Interpreting Results from the Oregon Health Insurance Experiment." Journal of Political Economy, 127(6): 2836-2874. 
Finkelstein, Amy, Nathaniel Hendren, and Mark Shepard. 2019. "Subsidizing Health Insurance for LowIncome Adults: Evidence from Massachusetts." American Economic Review, 109(4): 1530-67.

Finkelstein, Amy, Neale Mahoney, and Matthew J. Notowidigdo. 2018. "What Does (Formal) Health Insurance Do, and for Whom?" Annual Review of Economics, 10(1): 261-286.

Fishback, Price V, and Shawn Everett Kantor. 1995. "Did Workers Pay for the Passage of Workers' Compensation Laws?" Quarterly Journal of Economics, 713-742.

Fishback, Price V, and Shawn Everett Kantor. 1998. "The Adoption of Workers' Compensation in the United States, 1900-1930." Journal of Law and Economics, 41(2): 305-342.

Flood, Sarah, Miriam King, Renae Rodgers, Steven Ruggles, J. Robert Warren, and Michael Westberry. 2021. "Integrated Public Use Microdata Series, Current Population Survey: Version 9.0 [dataset]." Minneapolis, MN: IPUMS. https://doi.org/10.18128/D030.V9.0.

Fomenko, Olesya, and Jonathan Gruber. 2017. "Claims-shifting: The problem of parallel reimbursement regimes." Journal of Health Economics, 51: 13-25.

Fomenko, Olesya, and Jonathan Gruber. 2019. "Reclassification to Avoid Consumer Cost-Sharing in Group Health Plans." National Bureau of Economic Research Working Paper 25870.

Garthwaite, Craig, Tal Gross, and Matthew J. Notowidigdo. 2018. "Hospitals as Insurers of Last Resort." American Economic Journal: Applied Economics, 10(1): 1-39.

Gruber, Jonathan. 1994. "The Incidence of Mandated Maternity Benefits." The American Economic Review, 84(3): 622-641.

Gruber, Jonathan. 1997. “The Incidence of Payroll Taxation: Evidence from Chile." Journal of Labor Economics, 15(S3): S72-S101.

Gruber, Jonathan, and Alan B Krueger. 1991. “The Incidence of Mandated Employer-Provided Insurance: Lessons from Workers' Compensation Insurance." In Tax Policy and the Economy, Volume 5. 111-144. The MIT Press.

Gruber, Jonathan, and Michael Lettau. 2004. "How Elastic is the Firm's Demand for Health Insurance?" Journal of Public Economics, 88(7): 1273-1293.

Hackmann, Martin B, Jonathan T Kolstad, and Amanda E Kowalski. 2015. "Adverse Selection and an Individual Mandate: When Theory Meets Practice." American Economic Review, 105(3): 1030-66.

Handel, Benjamin R. 2013. "Adverse Selection and Inertia in Health Insurance Markets: When Nudging Hurts." American Economic Review, 103(7): 2643-82.

Handel, Benjamin R., and Jonathan T. Kolstad. 2015. "Health Insurance for "Humans": Information Frictions, Plan Choice, and Consumer Welfare." American Economic Review, 105(8): 2449-2500.

Handel, Benjamin R., Jonathan T. Kolstad, and Johannes Spinnewijn. 2019. "Information Frictions and Adverse Selection: Policy Interventions in Health Insurance Markets." The Review of Economics and Statistics, 101(2): 326-340.

Hendren, Nathaniel. 2017. "Knowledge of Future Job Loss and Implications for Unemployment Insurance." American Economic Review, 107(7): 1778-1823.

Ho, Kate, Joseph Hogan, and Fiona Scott Morton. 2017. "The impact of consumer inattention on insurer pricing in the Medicare Part D program." The RAND Journal of Economics, 48(4): 877-905.

Howard, Christopher. 2002. "Workers' Compensation, Federalism, and the Heavy Hand of History." Studies in American Political Development, 16: 28-47.

IRS. 2020. "Earned Income Tax Statistics." United States Internal Revenue Service.

Kolstad, Jonathan T., and Amanda E. Kowalski. 2016. "Mandate-Based Health Reform and the Labor Market: Evidence from the Massachusetts Reform." Journal of Health Economics, 47: 81 - 106.

Krueger, Alan B. 1990a. "Incentive Effects of Workers' Compensation Insurance." Journal of Public Economics, 41(1): 73-99.

Krueger, Alan B. 1990b. "Workers' Compensation Insurance and the Duration of Workplace Injuries." National Bureau of Economic Research 3253.

Landais, Camille, Arash Nekoei, Peter Nilsson, David Seim, and Johannes Spinnewijn. 2021. "RiskBased Selection in Unemployment Insurance: Evidence and Implications." American Economic Review, 111(4): 1315-55.

Larson, Arthur. 1951-1952. "Nature and Origins of Workmen's Compensation." Cornell Law Quarterly, 37(2): 206-234.

Mahoney, Neale. 2015. “Bankruptcy as Implicit Health Insurance.” American Economic Review, 105(2): 710-46. 
McInerney, Melissa, and Kosali Simon. 2012. “The Effect of State Workers' Compensation Program Changes on the Use of Federal Social Security Disability Insurance." Industrial Relations, 51(1): 57-88.

Meyer, Bruce D, W Kip Viscusi, and David L Durbin. 1995. "Workers' Compensation and Injury Duration: Evidence from a Natural Experiment." American Economic Review, 322-340.

Morantz, Alison. 2010. "Opting Out of Workers' Compensation in Texas: A Survey of Large, Multistate Nonsubscribers." In Regulation vs. Litigation: Perspectives from Economics and Law. , ed. Daniel P. Kessler. Chicago, IL:University of Chicago Press.

Morantz, Alison. 2016. “Rejecting the Grand Bargain: What Happens When Large Companies Opt Out of Workers' Compensation?" SIEPR Discussion Paper No. 16-007.

National Commission on State Workmen's Compensation Laws. 1972. "The Report of the National Commission on State Workmen's Compensation Laws." National Commission on State Workmen's Compensation Laws.

NCCI. 2019. "ABCs of Experience Rating." National Council on Compensation Insurance.

Neuhauser, Frank, and Steven Raphael. 2004. "The Effect of an Increase in Workers' Compensation Benefits on the Duration and Frequency of Benefit Receipt." Review of Economics and Statistics, 86(1): 288-302.

Powell, David, and Seth Seabury. 2018. "Medical Care Spending and Labor Market Outcomes: Evidence from Workers' Compensation Reforms." American Economic Review, 108(10): 2995-3027.

Rosen, Sherwin. 1974. "Hedonic Prices and Implicit Markets: Product Differentiation in Pure Competition." Journal of Political Economy, 82(1): 34-55.

Rosen, Sherwin. 1986. "Chapter 12 The theory of equalizing differences." In . Vol. 1 of Handbook of Labor Economics, 641 - 692. Elsevier.

Sengupta, Ishita, Marjorie Baldwin, and Virginia Reno. 2014. “Workers' Compensation: Benefits, Coverage, and Costs, (2012 data)." National Academy of Social Insurance.

Solon, Gary, Steven J. Haider, and Jeffrey Wooldridge. 2015. "What are we weighting for?" Journal of Human Resources, 50(2): 301-316.

Summers, Lawrence H. 1989. “Some Simple Economics of Mandated Benefits.” The American Economic Review, 79(2): 177-183.

Texas Department of Insurance (TDI). 2011. “Workers' Compensation Relativities Studies 2011." Exhibit 12-1. Texas Department of Insurance. https: / / www.tdi.texas.gov/reports/report9.html. (Date accessed: 9/2014).

Texas Department of Insurance (TDI). 2014. “Texas Workers' Compensation Proof-of-Coverage Electronic Data Interchange Data (2005-2014Q1)." Texas Department of Insurance.

Texas Department of Insurance (TDI). 2016a. "Certified Self-Insured Extracts (2006-2011)." Texas Department of Insurance.

Texas Department of Insurance (TDI). 2016b. "Workers' Compensation Relativities Studies." Studies available within period 2003 to 2015. Texas Department of Insurance. https://www.tdi.texas.gov/ reports/report 9.html. (Date accessed: 9/2016).

Texas Department of Insurance (TDI). 2019. “Unit Statistical Data (2004-2014).” Texas Department of Insurance.

Texas Department of Insurance Workers' Compensation Research and Evaluation Group (TDI WCREG). 2010a. "Setting the Standard: An Analysis of the Impact of the 2005 Legislative Reforms on the Texas Workers' Compensation System, 2010 Results." Figure 2.1 pg. 8 (2006 estimates). Texas Department of Insurance. https://www.tdi.texas.gov/reports/wc/documents/wcsetstd2010.pdf. (Date accessed: 12/2021).

Texas Department of Insurance Workers' Compensation Research and Evaluation Group (TDI WCREG). 2010b. "Setting the Standard: An Analysis of the Impact of the 2005 Legislative Reforms on the Texas Workers' Compensation System, 2010 Results." Texas Department of Insurance. https://www.tdi.texas . gov/reports/wc/documents/wcsetstd2010.pdf. (Date accessed: 12/2021).

Texas Department of Insurance Workers' Compensation Research and Evaluation Group (TDI WCREG). 2014. "Employer Participation in the Texas Workers' Compensation System: 2014 Estimates." Texas Department of Insurance. https://www.tdi.texas.gov/reports/wcreg/documents/nonsub.pdf. (Date Accessed: 12/2021).

Texas Department of Insurance Workers' Compensation Research and Evaluation Group (TDI WCREG). 2016a. "Employer Participation in the Texas Workers' Compensation System: 2016 Estimates." pg. 5-8 (2006, 
2008, and 2010 estimates). Texas Department of Insurance. https://www.tdi.texas.gov/reports/ wcreg/documents/nonsub2016.pdf. (Date accessed: 12/2021).

Texas Department of Insurance Workers' Compensation Research and Evaluation Group (TDI WCREG). 2016b. "Setting the Standard: An Analysis of the Impact of the 2005 Legislative Reforms on the Texas Workers' Compensation System, 2016 Results." Texas Department of Insurance. https://www.tdi.texas . gov/reports/wcreg/documents/biennial2016.pdf. (Date accessed: 12/2021).

Texas Department of Insurance Workers' Compensation Research and Evaluation Group (TDI WCREG). 2016c. "Setting the Standard: An Analysis of the Impact of the 2005 Legislative Reforms on the Texas Workers' Compensation System, 2016 Results." Figure 2.1 pg. 7 (2007-2011 estimates). Texas Department of Insurance. https://www.tdi.texas.gov/reports/wcreg/documents/biennial2016.pdf. (Date accessed: 12/2021).

U.S. Bureau of Labor Statistics. 2014. Quarterly Census of Employment and Wages (QCEW), Retrieved from https://www.bls.gov/cew/downloadable-data-files.htm, June 15, 2014.

USDA. 2020. "Supplemental Nutrition Assistance Program: National Level Annual Summary, 1969-2019." United States Department of Agriculture, Food and Nutrition Service. 


\section{Figure 1: Histogram of Base Rate Updates}

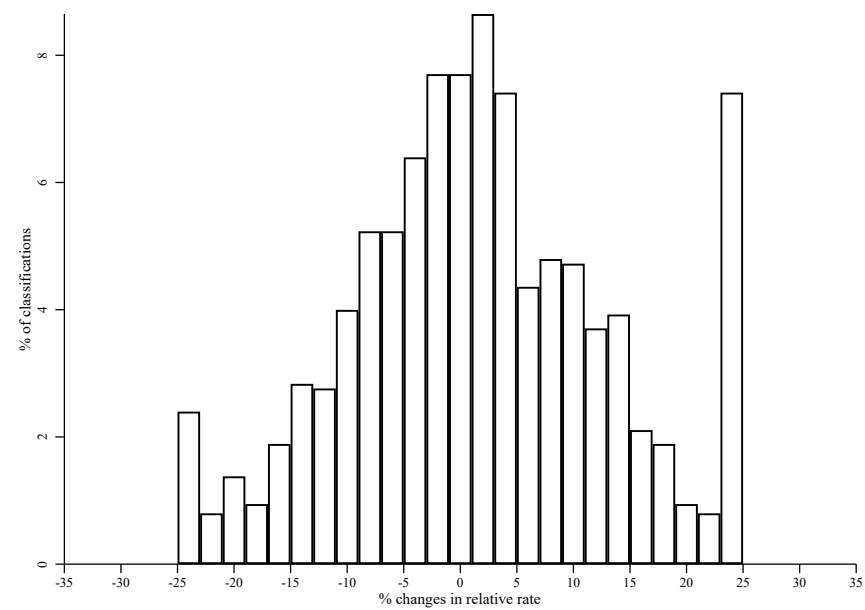

Notes: The above histogram describes the proposed updates to the base rates (before any across-the-board adjustments) pooling across all the updates in the analysis period: 2006-2011. Following the definitions in Appendix Section B, the percent change here is defined as: $\frac{\text { rroRel }_{j}-\mathrm{crtRel}_{j}}{\mathrm{crtRel}}$ for classification $j$. Histograms by update year for the proposed updates are depicted in Appendix Figure A1, and the updates in the final implemented base rates (after across-the-board adjustments) are depicted in Appendix Figure A2.

Figure 2: Event Study: Base Rates and Premiums

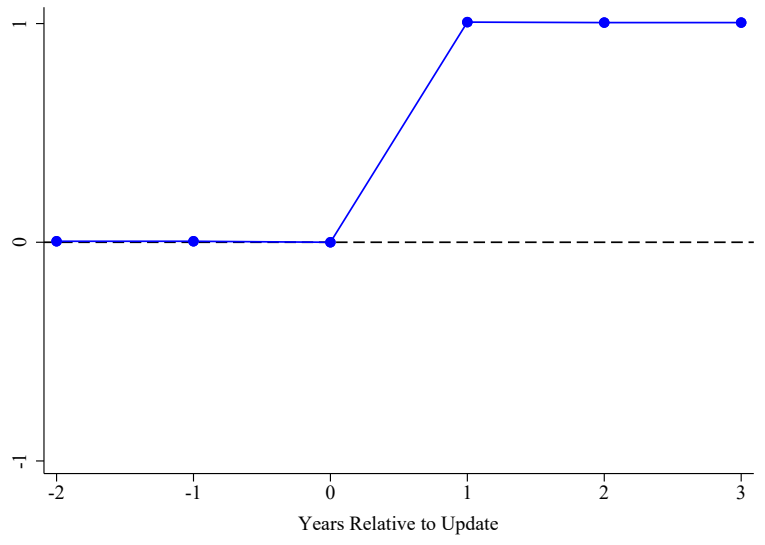

(a) $\ln ($ Base Rate)

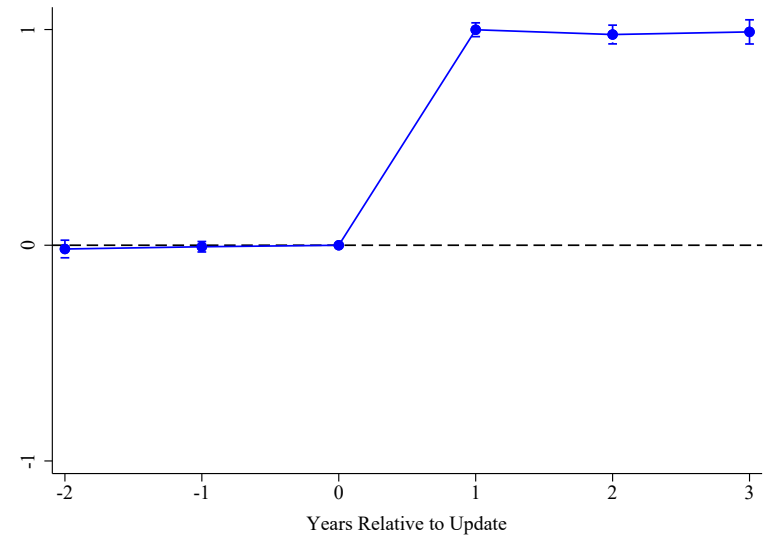

(b) $\ln$ (Mean Premiums)

Notes: The above figure displays estimates from the event study estimation described in equation 6 . The dependent variables are as indicated in the figure, the natural logarithm of: statutory base rates (panel A) and mean premiums per $\$ 100$ of risk-adjusted payroll (panel B). Panel A illustrates the legislated change in statutory base rates isolated by the event study specification, while the estimates in panel B illustrate how this change in statutory base rates impacts mean premiums. The horizontal axis displays time since the reference base rate update, where each point on the horizontal axis represents policies initiated in the indicated 12 month increment of event time. The event study representation focuses on the rate updates occurring between 2006 and 2011. The data used for this estimation is a series of balanced panels, where each panel includes data from three years pre- and post-update. Capped vertical bars indicate $95 \%$ confidence intervals, and robust standard errors are clustered at the classification level. 
Figure 3: Graphical Depiction of Difference-in-Differences Demand Estimates

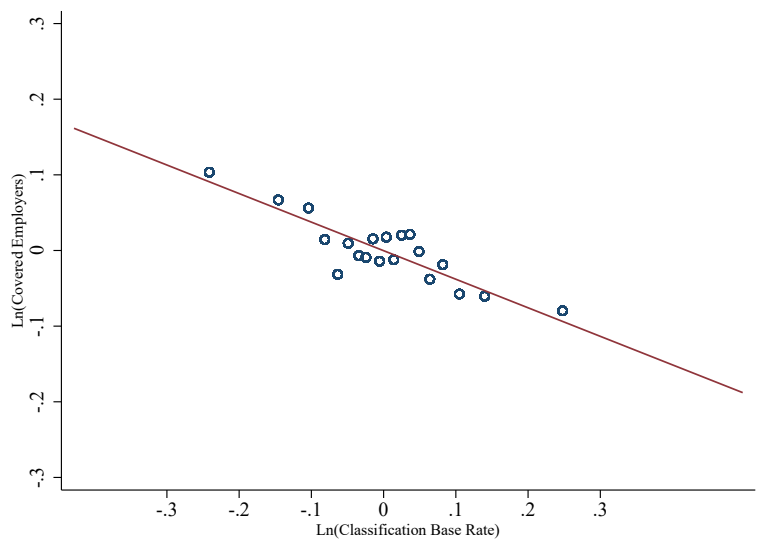

(a) Covered Employers

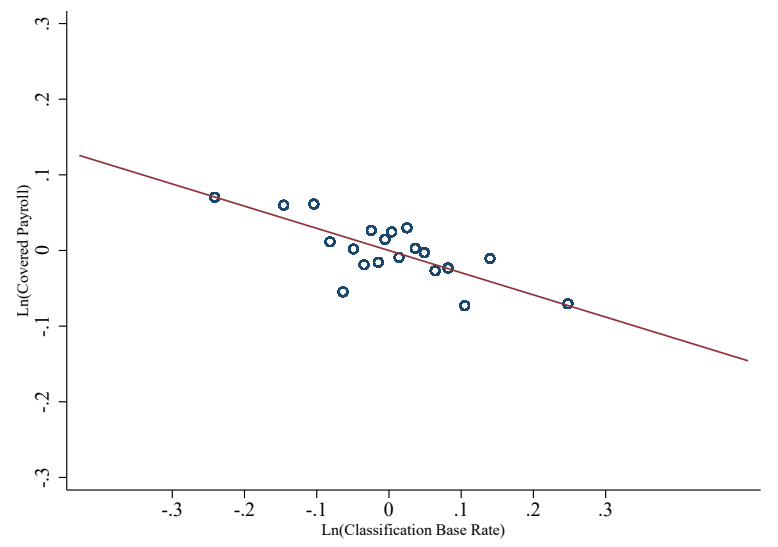

(b) Covered Payroll

Notes: This figure displays binned mean residual scatter plots for the baseline demand specifications. Each dot represents $5 \%$ of the classification-year observations in the baseline analytical dataset, where bins are defined based on the values on the horizontal axis. Panel A displays the results for covered employers (analogous to the estimates in Table 3 column 1), and Panel B displays the results for covered payroll (analogous to the estimates in Table 3 column 5).

Figure 4: Event Study: Demand Estimates

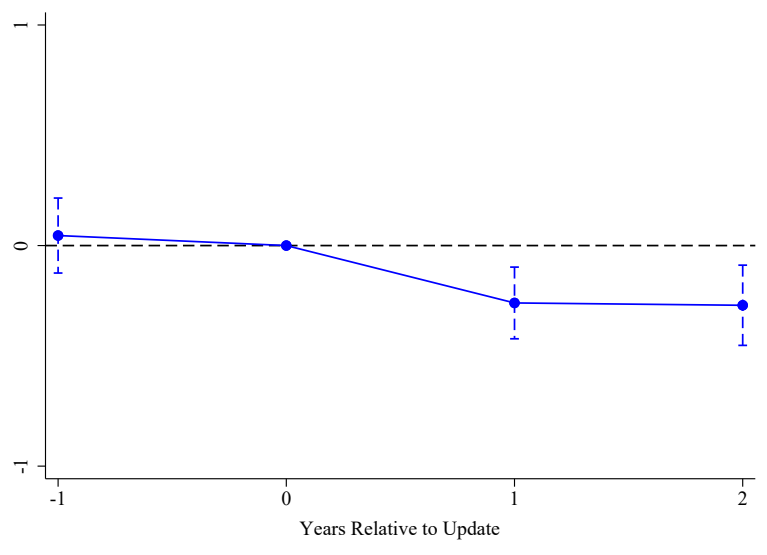

(a) $\ln ($ Covered Employers)

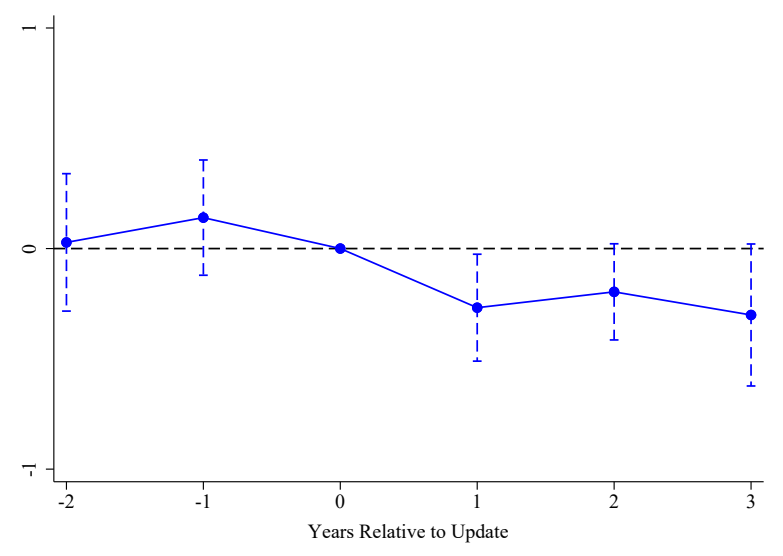

(b) $\ln ($ Covered Payroll)

Notes: The above figure displays estimates from the event study estimation described in equation 6 . The dependent variables are as indicated in the figure, the natural logarithm of: covered employers (panel A) and covered payroll (panel B). The horizontal axis displays time since the reference base rate update, where each point on the horizontal axis represents policies initiated in the indicated 12 month increment of event time. The event study representation focuses on the rate updates occurring between 2006 and 2011 . The data used for this estimation is a series of balanced panels, where each panel includes data from three years (in Panel B) or two years (in Panel A) pre- and post-update. Capped vertical bars indicate $95 \%$ confidence intervals, and robust standard errors are clustered at the classification level. 


\section{Figure 5: Potential Market Failure Justifications for Government Intervention}

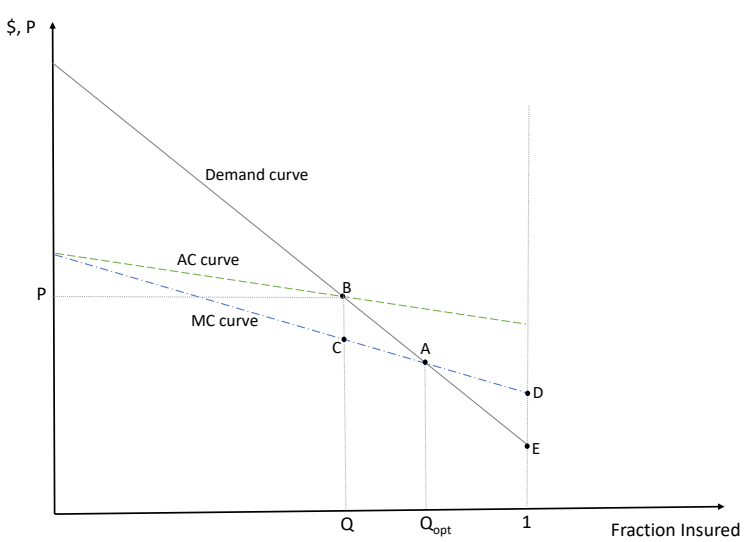

(a) Adverse Selection

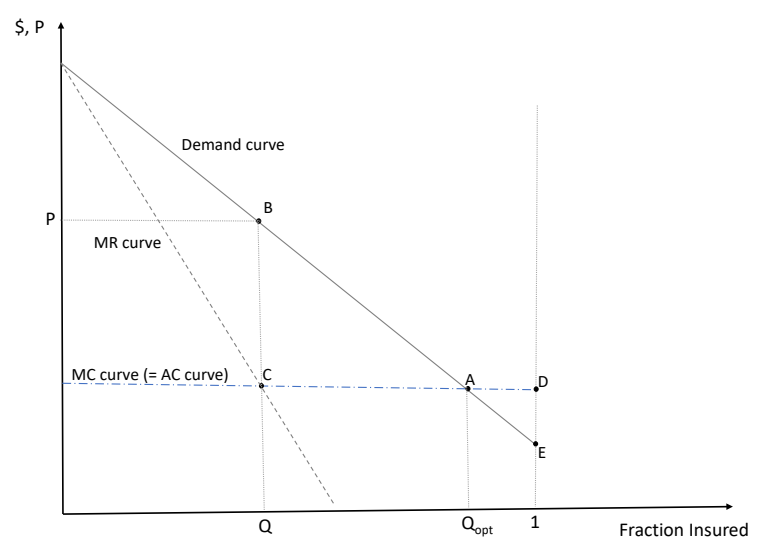

(b) Market Power

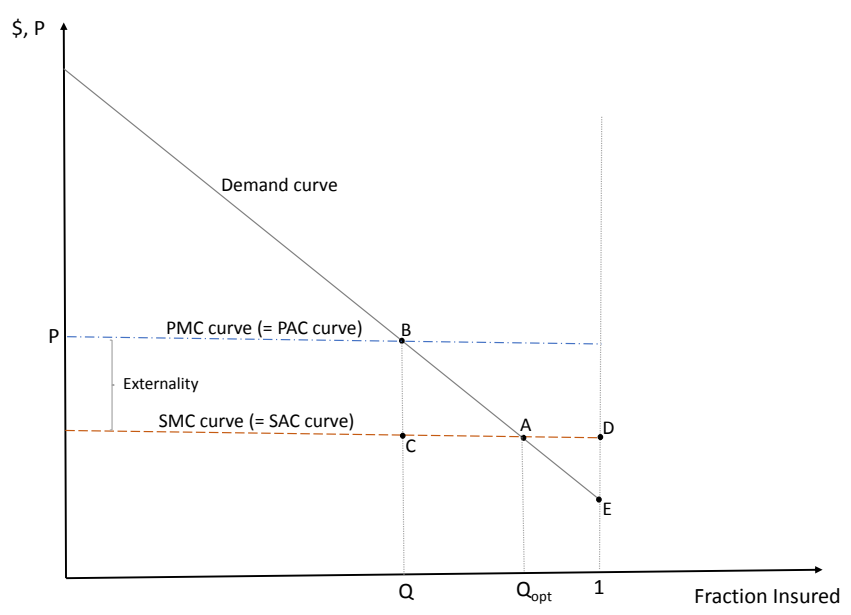

(c) Positive Externality

Notes: The above figure depicts potential justifications for government intervention to increase coverage. Panel A depicts a competitive market in which there is adverse selection (characterized by a downward sloping marginal cost curve). Panel B depicts a setting with no selection but with market power, where a monopolist insurer sets the price such that marginal cost equals marginal revenue. Panel $\mathrm{C}$ depicts a setting with no selection but with a positive externality associated with insurance; the figure depicts the case of a constant positive externality, where the social marginal cost curve is represented by shifting the private marginal cost curve downward by the size of the externality. 
Figure 6: Welfare: Graphical Representation

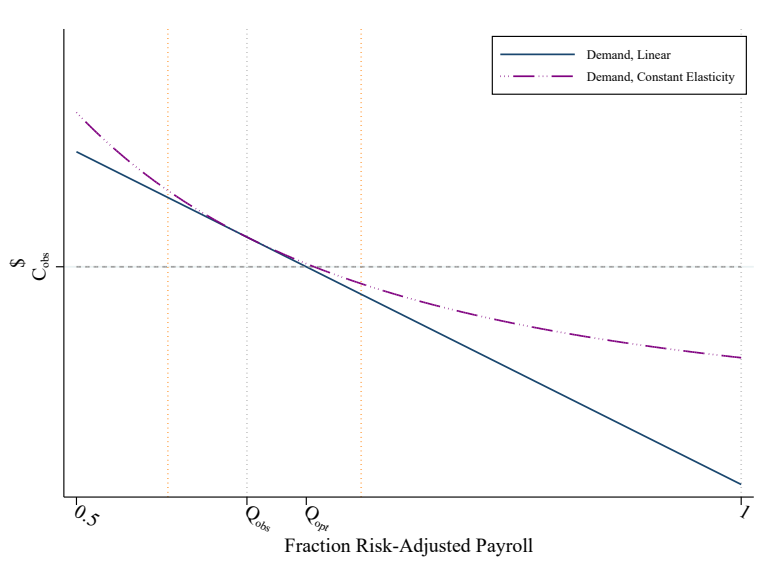

(a) Baseline Welfare Calculation: No Selection

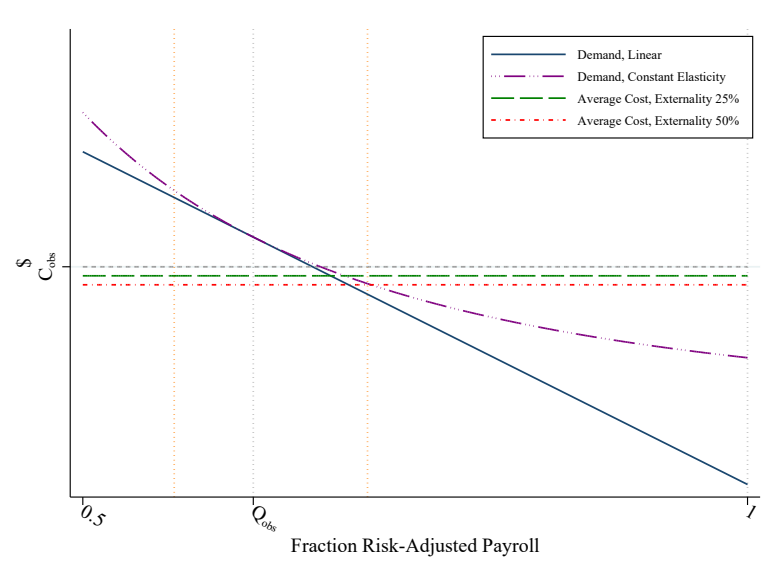

(b) Incorporating an Externality

Notes: The above figure depicts a graphical representation of demand based on the empirical estimates. As discussed in the text, we obtain these curves by combining the estimated elasticities and aggregate summary statistics from the overall market on mean premiums, mean quantities, and mean insurer combined loss ratios. See Appendix Section C for further details on this calculation. Both panels depict the marginal cost and average cost curves as flat, given the selection estimates are consistent with no selection in this market. Both panels illustrate the observed quantity of risk-adjusted covered payroll (63\%). To give a sense of the range of variation used to identify demand, the figure also displays vertical reference lines indicating the quantities associated with a $+/-25 \%$ premium change based on the constant elasticity demand specification $(57 \%, 71 \%)$. Panel A depicts a setting with no selection and no externality, where the optimal quantity insured is between $67 \%$ and $68 \%$ in either specification. Panel B depicts the conservative backof-the-envelope calculations regarding potential externalities on external parties that may bear some of the health care costs otherwise covered under workers' compensation. 
Table 1: Summary Statistics: Workers' Compensation Take-Up

\begin{tabular}{|c|c|c|}
\hline \multicolumn{3}{|c|}{ Panel A: Statewide Aggregates from Administrative Data } \\
\hline & Mean & Standard Deviation \\
\hline Statewide Covered Payroll (\$ billions) & 256.78 & 10.30 \\
\hline Statewide Covered Payroll (\%) & 0.74 & 0.02 \\
\hline Statewide Number of Participating Employers & 199,045 & 12,357 \\
\hline \multicolumn{3}{|c|}{ Panel B: Statewide Fraction Insured from TDI Survey on Employer Participation } \\
\hline & Mean & Standard Deviation \\
\hline \multicolumn{3}{|l|}{ Statewide } \\
\hline Employees & 0.78 & 0.04 \\
\hline Employers & 0.66 & 0.03 \\
\hline \multicolumn{3}{|l|}{ Employers by Firm Size } \\
\hline 1-4 employees & 0.59 & 0.02 \\
\hline 5-9 employees & 0.68 & 0.03 \\
\hline 10-49 employees & 0.77 & 0.03 \\
\hline 50-99 employees & 0.82 & 0.02 \\
\hline 100-499 employees & 0.85 & 0.02 \\
\hline $500+$ employees & 0.79 & 0.06 \\
\hline \multicolumn{3}{|l|}{ Employers by Industry } \\
\hline Agriculture/Forestry/Fishing/Hunting & 0.74 & 0.01 \\
\hline Mining/Utilities/Construction & 0.77 & 0.05 \\
\hline Manufacturing & 0.67 & 0.03 \\
\hline WholesaleTrade/Retail Trade/Transportation & 0.67 & 0.04 \\
\hline Finance/Real Estate/Professional Services & 0.67 & 0.00 \\
\hline Health Care/Educational Services & 0.62 & 0.06 \\
\hline Arts/Entertainment/Accommodation/Food Services & 0.54 & 0.06 \\
\hline Other Services Except Public Administration & 0.60 & 0.03 \\
\hline
\end{tabular}

Notes: This table displays the mean and standard deviation of statewide annual aggregates describing workers' compensation takeup among private industry employers in Texas. Panel A describes statewide annual aggregates from the administrative data used in this paper from the years 2006-2011. In Panel A, the fraction of payroll insured is calculated by comparing administrative covered payroll data to aggregate private industry payroll data from the Quarterly Census of Employment and Wages (QCEW). Further details on these data and the construction of these aggregates are in Appendix Section C. In the above table, dollar quantities are adjusted using the CPI-U to be 2006 dollars. Panel B displays summary statistics on the fraction insured from an employer phone survey commissioned by the Texas Department of Insurance (TDI) to elicit information about the employer participation rate and associated employer characteristics. This phone survey takes place every other year, and these descriptive statistics summarize aggregate data from the 2006, 2008, and 2010 surveys obtained from TDI WCREG (2016a). 
Table 2: Implementation of Base Rates

\begin{tabular}{|c|c|c|c|c|}
\hline \multicolumn{5}{|c|}{ Dependent Variable: $\ln \left(\right.$ mean premiums $\left.s_{j t}\right)$} \\
\hline & (1) & (2) & (3) & (4) \\
\hline \multirow[t]{3}{*}{$\ln \left(\right.$ baseRate $\left._{j t}\right)$} & 0.996 & 0.972 & 0.984 & 0.975 \\
\hline & $(0.023)$ & $(0.022)$ & $(0.025)$ & (0.030) \\
\hline & {$[<0.001]$} & {$[<0.001]$} & {$[<0.001]$} & {$[<0.001]$} \\
\hline \multirow[t]{3}{*}{$\ln \left(\right.$ baseRate $\left._{j t+2}\right)$} & & & 0.029 & \\
\hline & & & $(0.032)$ & \\
\hline & & & {$[0.365]$} & \\
\hline \multirow[t]{3}{*}{$\ln \left(\right.$ uncappedBaseRate $\left.{ }_{j t}\right) *\left(\right.$ capBinding $\left._{j}\right)$} & & & & 0.036 \\
\hline & & & & $(0.034)$ \\
\hline & & & & {$[0.287]$} \\
\hline \multicolumn{5}{|l|}{ Controls } \\
\hline Classification Fixed Effects & $\mathrm{x}$ & $\mathrm{x}$ & $\mathrm{x}$ & $\mathrm{x}$ \\
\hline Year Fixed Effects & $\mathrm{x}$ & $\mathrm{x}$ & $\mathrm{x}$ & $\mathrm{x}$ \\
\hline Classification-specific Time Trend, 2-digit & & $\mathrm{x}$ & & \\
\hline
\end{tabular}

Notes: The table above presents estimates from the difference-in-differences specifications as outlined in equations 2 through 5 , replacing the dependent variable with mean premiums insurers charged per $\$ 100$ of risk-adjusted payroll. The data used in these regressions cover the time period 2006-2011, where each observation represents a classification-year $(\mathrm{N}=2,064)$. Each column represents a separate regression, where the estimated coefficients are displayed along with the associated standard errors in parentheses and p-values in brackets. These classification-year-level regressions include year fixed effects and classification fixed effects. While column 1 reports the baseline specification, the remaining columns report alternative specifications with additional variables: 2-digit classification-specific time trends (column 2), leads of the legislated base rates (column 3) and uncapped base rates that were not ultimately adopted (column 4). These uncapped base rates correspond to the balanced indicated relative base rates discussed in Appendix Section B. Robust standard errors are clustered at the classification level.

Table 3: Demand Estimates

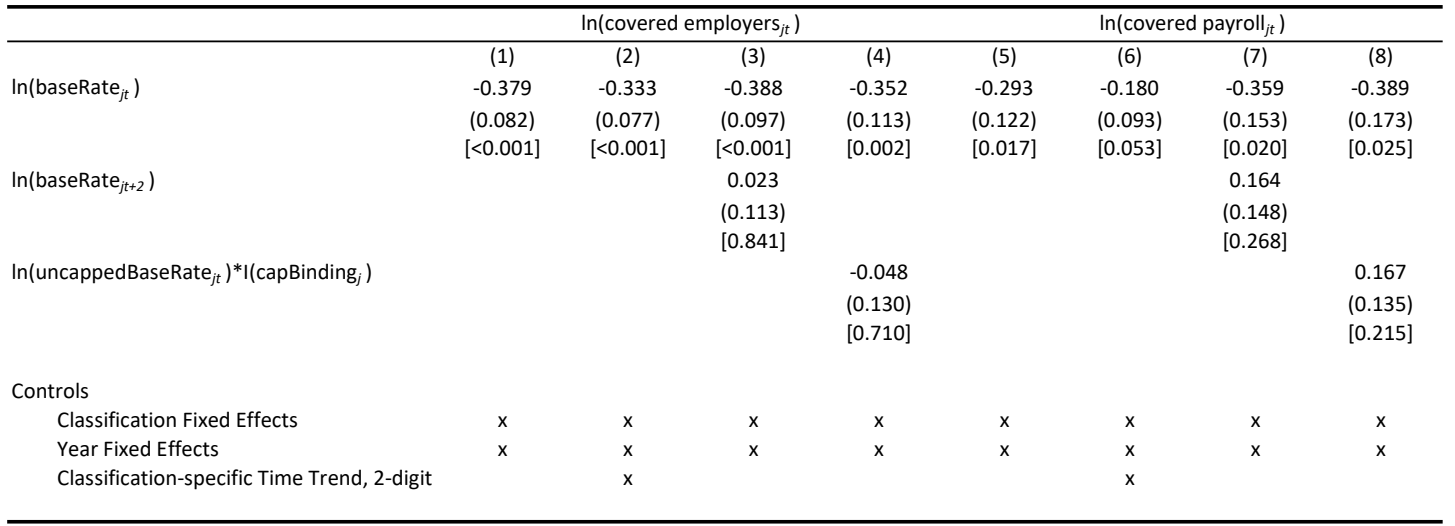

Notes: The table above presents demand estimates from the difference-in-differences specifications as outlined in equations 2 through 5. The data used in these regressions cover the time period 2006-2011, where each observation represents a classification-year. Two different dependent variables are used to estimate the demand elasticities: $\ln$ (covered employers) (columns 1 through $4 ; \mathrm{N}=2,058)$ and $\ln ($ covered payroll) (columns 5 through 8; N=2,064). Each column represents a separate regression, where the estimated coefficients are displayed along with the associated standard errors in parentheses and p-values in brackets. These classification-year-level regressions include year fixed effects and classification fixed effects. While columns 1 and 5 report the baseline specifications, the remaining columns report alternative specifications with additional variables: 2-digit classification-specific time trends (columns 2 and 6), leads of the legislated base rates (columns 3 and 7) and uncapped base rates that were not ultimately adopted (columns 4 and 8 ). These uncapped base rates correspond to the balanced indicated relative base rates discussed in Appendix Section B. Robust standard errors are clustered at the classification level. 
Table 4: Selection Estimates

\begin{tabular}{|c|c|c|c|c|}
\hline \multicolumn{5}{|c|}{ Panel A: Selection Estimates } \\
\hline & \multicolumn{2}{|c|}{$\begin{array}{c}\text { Mean Costs } \\
\text { IHS(Mean risk-adjusted costs } s_{j t} \text { ) }\end{array}$} & \multicolumn{2}{|c|}{$\begin{array}{c}\text { Quantity } \\
\left.\text { In(risk-adjusted covered payroll }{ }_{j t}\right)\end{array}$} \\
\hline & \multicolumn{2}{|c|}{ (1) } & \multicolumn{2}{|c|}{ (2) } \\
\hline \multirow[t]{3}{*}{$\ln \left(\right.$ baseRate $\left._{j t}\right)$} & \multicolumn{2}{|c|}{0.025} & \multicolumn{2}{|c|}{-0.446} \\
\hline & \multicolumn{2}{|c|}{$(0.265)$} & \multicolumn{2}{|c|}{$(0.117)$} \\
\hline & \multicolumn{2}{|c|}{$[0.926]$} & \multicolumn{2}{|c|}{$[<0.001]$} \\
\hline \multicolumn{5}{|c|}{ Panel B: Welfare Cost of Selection } \\
\hline & \multicolumn{2}{|c|}{ Linear } & \multicolumn{2}{|c|}{ Constant Elasticity } \\
\hline & Estimate & Standard Error & Estimate & Standard Error \\
\hline & (1) & (2) & (3) & (4) \\
\hline \multicolumn{5}{|c|}{ Quantity (fraction risk-adjusted payroll covered) } \\
\hline Optimal & 0.688 & $(0.176)$ & 0.698 & $(0.172)$ \\
\hline Perfect Competition & 0.674 & $(0.015)$ & 0.680 & $(0.025)$ \\
\hline Difference & 0.015 & $(0.172)$ & 0.018 & $(0.160)$ \\
\hline \multicolumn{5}{|c|}{ Welfare per $\$ 100$ risk-adjusted payroll (relative to status quo) } \\
\hline Optimal & 0.0136 & $(0.3717)$ & 0.0149 & $(0.1901)$ \\
\hline Perfect Competition & 0.0128 & $(0.0734)$ & 0.0140 & $(0.0899)$ \\
\hline Difference & 0.00080 & $(0.3778)$ & 0.00090 & (0.1209) \\
\hline
\end{tabular}

Notes: The table above presents estimates relating to the degree of selection in this market. In Panel A, the coefficients reported above are from a difference-in-differences specification as outlined in equation 2. These classification-year-level regressions include year fixed effects and classification fixed effects. Each column represents a separate regression, where the estimated coefficients are displayed along with the associated standard errors in parentheses and p-values in brackets. Robust standard errors are clustered at the classification level. The data used in these regressions cover the time period 2006-2011, where each observation represents a classification-year $(\mathrm{N}=2,064)$. The dependent variables are as indicated in the table: inverse hyperbolic sine of costs per $\$ 10 \mathrm{~K}$ riskadjusted covered payroll (column 1) and natural logarithm of risk-adjusted covered payroll (column 2). Panel B displays estimates pertaining to the welfare cost of selection using the elasticities reported in Panel A and aggregate summary statistics from the overall market on mean premiums, mean insurer combined loss ratios, and mean quantities. For the purpose of these welfare calculations, we measure the quantity insured as the fraction of risk-adjusted payroll that is insured. See Appendix Section C for more details on the welfare analysis and associated data inputs. The counterfactuals are conducted using two alternative parametric specifications: linear (displayed in columns 1 and 2) and constant elasticity (displayed in columns 3 and 4). The table reports welfare measured in dollars per $\$ 100$ of risk-adjusted payroll. The table reports bootstrapped standard errors clustered at the classification level, where 1,000 randomly drawn bootstrap samples are used. 
Table 5: Baseline Welfare Calculations

\begin{tabular}{|c|c|c|c|c|}
\hline \multicolumn{5}{|c|}{ Panel A: Welfare Calculations } \\
\hline & \multicolumn{2}{|c|}{ Linear } & \multicolumn{2}{|c|}{ Constant Elasticity } \\
\hline & $\begin{array}{c}\text { Estimate } \\
\text { (1) }\end{array}$ & $\begin{array}{c}\text { Standard Error } \\
\text { (2) }\end{array}$ & $\begin{array}{c}\text { Estimate } \\
\text { (3) }\end{array}$ & $\begin{array}{c}\text { Standard Error } \\
\text { (4) }\end{array}$ \\
\hline \multicolumn{5}{|l|}{ Counterfactuals } \\
\hline \multicolumn{5}{|l|}{ Quantity (fraction risk-adjusted payroll covered) } \\
\hline Mandate & 1.000 & - & 1.000 & - \\
\hline Perfect Competition (Optimal) & 0.673 & $(0.012)$ & 0.679 & $(0.014)$ \\
\hline \multicolumn{5}{|l|}{ Welfare (relative to status quo) } \\
\hline \multicolumn{5}{|l|}{ Mandate } \\
\hline per $\$ 100$ of risk-adjusted payroll & -0.4118 & $(0.1720)$ & -0.1992 & $(0.0624)$ \\
\hline scaled by $\$ 50,000$ & -205.91 & $(85.98)$ & -99.59 & $(31.19)$ \\
\hline$\%$ of mean premium & $-18.8 \%$ & $(7.83 \%)$ & $-9.1 \%$ & $(2.84 \%)$ \\
\hline \multicolumn{5}{|l|}{ Perfect Competition (Optimal) } \\
\hline per $\$ 100$ of risk-adjusted payroll & 0.0078 & $(0.0020)$ & 0.0085 & $(0.0023)$ \\
\hline scaled by $\$ 50,000$ & 3.91 & $(1.01)$ & 4.24 & $(1.13)$ \\
\hline$\%$ of mean premium & $0.4 \%$ & $(0.09 \%)$ & $0.4 \%$ & $(0.10 \%)$ \\
\hline \multicolumn{5}{|c|}{ Subsidy to support optimal allocation--25\% marginal deadweight loss of taxation } \\
\hline per $\$ 100$ of risk-adjusted payroll & -0.0511 & $(0.0010)$ & -0.0509 & $(0.0011)$ \\
\hline scaled by $\$ 50,000$ & -25.55 & $(0.51)$ & -25.47 & $(0.53)$ \\
\hline$\%$ of mean premium & $-2.3 \%$ & (0.05\%) & $-2.3 \%$ & $(0.05 \%)$ \\
\hline \multicolumn{5}{|c|}{ Panel B: Underlying Data and Corresponding Demand Curve } \\
\hline & \multicolumn{2}{|c|}{ Linear } & \multicolumn{2}{|c|}{ Constant Elasticity } \\
\hline & $\begin{array}{c}\text { Estimate } \\
(1)\end{array}$ & $\begin{array}{c}\text { Standard Error } \\
\text { (2) }\end{array}$ & $\begin{array}{c}\text { Estimate } \\
(3)\end{array}$ & $\begin{array}{c}\text { Standard Error } \\
\text { (4) }\end{array}$ \\
\hline \multicolumn{5}{|l|}{ Demand Curve } \\
\hline Constant & 7.1229 & $(1.56)$ & 0.7736 & $(0.21)$ \\
\hline Slope & -7.8431 & $(2.49)$ & -2.2441 & $(0.71)$ \\
\hline \multicolumn{5}{|l|}{ Status Quo } \\
\hline Quantity & \multicolumn{2}{|c|}{0.628} & \multicolumn{2}{|c|}{0.628} \\
\hline Price & \multicolumn{2}{|c|}{2.20} & \multicolumn{2}{|c|}{2.20} \\
\hline Expenses as a $\%$ of Premiums & \multicolumn{2}{|c|}{$84 \%$} & \multicolumn{2}{|c|}{$84 \%$} \\
\hline
\end{tabular}

Notes: The table above presents welfare calculations as discussed in Section 4. Panel A displays the welfare calculations, while Panel B reports the underlying summary statistics and corresponding fitted demand curve. As discussed in the text, we obtain these curves by combining the estimated elasticities from the baseline specification and aggregate summary statistics from the overall market on mean premiums, mean insurer combined loss ratios, and mean quantities. For the purpose of these welfare calculations, we measure the quantity insured as the fraction of risk-adjusted payroll that is insured. See Appendix Section $C$ for more details on the welfare analysis and associated data inputs. In Panel B, the reported "constant" and "slope" in the constant elasticity specification $\left(P=A Q^{\beta}\right)$ refer to $A$ and $\beta$, respectively; in the linear specification $(P=A+\beta Q)$, the "constant" and "slope" refer to $A$ and $\beta$, respectively. Because our empirical analysis indicates there is no evidence of selection in this market, we do these calculations under the assumption of no selection, meaning that there is a flat market-level average/marginal (risk-adjusted) cost curve. The counterfactuals are conducted using two alternative parametric demand specifications: linear demand (displayed in columns 1 and 2) and constant elasticity demand (displayed in columns 3 and 4). The table reports welfare measured in dollars per $\$ 100$ of risk-adjusted payroll. In addition, the table reports two scaled measures of welfare to ease interpretation: (i) welfare measures scaled by $\$ 50 \mathrm{~K}$, approximately the mean annual earnings for this population, and (ii) welfare as a percent of mean premiums observed in the status quo (one measure of the size of the market). The table reports bootstrapped standard errors clustered at the classification level, where 1,000 randomly drawn bootstrap samples are used. 
Table 6: Welfare Calculations: Incorporating Potential Externality

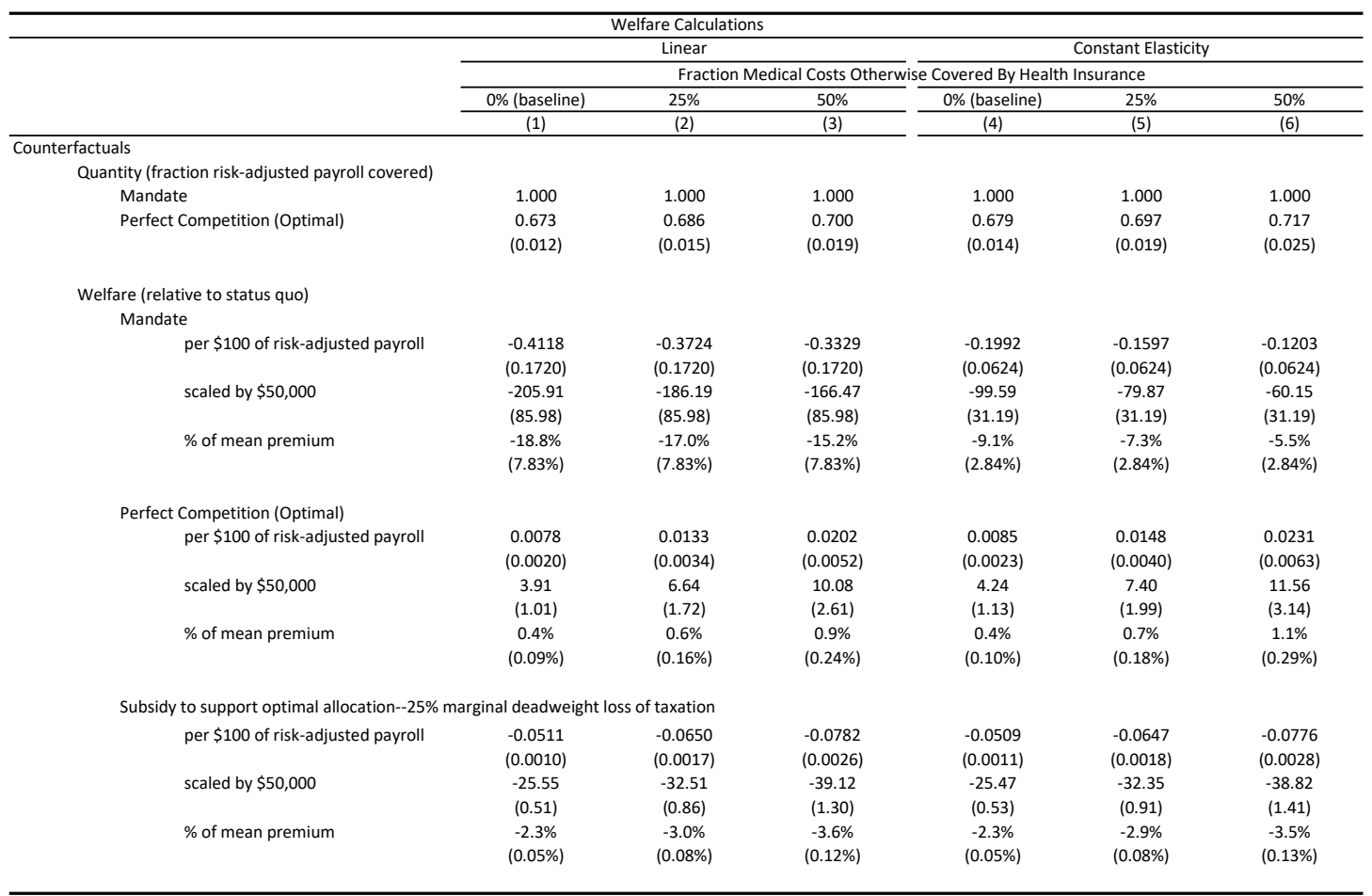

Notes: The table above presents welfare calculations as discussed in Section 4 . This table repeats the welfare analysis in Table 5 under various alternative assumptions regarding the fraction of the medical costs covered by workers' compensation insurance that fall to an external party (e.g., health insurance, charity care) in the absence of coverage. For the purpose of this robustness analysis, we use "health insurance" to refer to any external party that may bear these medical costs in the absence of workers" compensation, which may include formal health insurance but also could include informal insurance (e.g., charity care). In these calculations, we assume that health insurers do not make actuarial adjustments to premiums based on workers' compensation coverage, and we assume that health insurance provides $70 \%$ actuarial value coverage of medical costs, while workers' compensation provides $100 \%$ actuarial value coverage of medical costs. For the linear specification, the baseline results with no externality are displayed in column 1 , while the results in columns 2 and 3 assume that $25 \%$ or $50 \%$ of workers' compensation medical claim costs would otherwise be eligible for coverage under health insurance. The analogous results for the constant elasticity specifications are reported in columns 4 through 6 . The table reports bootstrapped standard errors clustered at the classification level, where 1,000 randomly drawn bootstrap samples are used. See Table 5 and Appendix Section $C$ for further details on the welfare calculations. 


\title{
The Demand for Insurance and Rationale for a Mandate: Evidence from Workers' Compensation Insurance
}

\section{ONLINE APPENDIX}

\author{
Marika Cabral, Can Cui, and Michael Dworsky
}

\section{A Description of Data Sources}

Below, we provide more detail on the data sources used in this paper and variable construction based on these underlying data sources. There are three main sources of administrative data we obtained from the Texas Department of Insurance (TDI).

1. Covered Employers. Data on covered employers is obtained from the "Proof-of-Coverage Data," released by TDI in response to an open records request (TDI (2014)). This database includes information on covered employers including: employer identifiers (e.g., FEIN), policy effective dates, and employer governing classification. To construct our analytical dataset, we use employer identifiers (based on employer FEIN) to define unique employers. ${ }^{1}$ We aggregate data across employers using information on employer governing classifications as described in the text. We also obtain supplemental data from regulatory documents on certified self-insured firms, which were also released through an open records request (TDI (2016a)). These data are reported monthly, and we use information about the certified self-insured status and number of covered employees reported in January of each calendar year.

2. Covered Payroll and Claims. Data on covered payroll and claims is obtained from the "Unit Statistical Data" (TDI (2019)). These data were released by TDI in response to an open records request. These actuarial data cover every workers' compensation insurance policy sold in Texas, including information on: industry-occupation classification code, coverage dates, covered payroll, premiums, experience rating modifiers, and data on each associated claim. For each workers' compensation claim, the data include information on: the date of claim, type of claim (e.g., major indemnity, minor indemnity, medical only), classification of injured employee, incurred medical benefits, and incurred indemnity benefits. Losses are valued at pre-specified intervals since the policy effective date, and our baseline cost measure draws on costs valued at 42 months after the policy effective date. The mean claim cost measure used in the selection analysis draws on underlying claim cost data that are winsorized at the $99^{\text {th }}$ percentile and that exclude losses flagged as due to aggregate catastrophic events (e.g., natural disasters). See Section 1 for more description on the construction of our cost measure. To construct our analytical dataset, we aggregate payroll and claims data to the classification-time level as described in the text.

3. Base Rates and Supplemental Data. Data on classification base rates-commonly known as relativitieswas obtained from the "Workers' Compensation Relativities Studies" files posted on the TDI website (TDI (2016b)). The data we extract from these files include: classification code, classification base rates (the final adopted rates and intermediate rates used in earlier steps within the update algorithm), and precise effective dates. We also obtain loss development factor data from the Workers' Compensation Relativities Studies files (TDI (2011)). Finally, we obtain data on insurer combined loss ratios from TDI publications (TDI WCREG (2016), TDI WCREG (2010)).

\footnotetext{
${ }^{1}$ In instances with multiple observations for the same employer (as defined by employer FEIN), we assign the employer the governing classification and NAICS industry code of the observation representing the largest share of premiums.
} 


\section{B Description of Base Rate Update Algorithm}

Below, we describe the algorithm used by the Texas Department of Insurance (TDI) to update base rates. The data associated with the base rate update algorithm (e.g., inputs, outputs, intermediate outputs) come from the Workers' Compensation Relativities Studies files. We are thankful to employees of the TDI Actuarial Office for several helpful discussions as we worked to understand the details of the rate update process. We first outline the steps for updating base rates in a typical year with a revenue neutral update, and we then explain how this update algorithm is adjusted in years in which the overall level of base rates is adjusted (i.e., "re-basing years").

Step 1: The initial inputs into the algorithm are: (i) the raw loss experience for relevant policy years, which is a five-year window lagged by four years and (ii) the current base rates. For example, for base rates in 2007, the raw loss experience considered is the loss experience from policy years 1999 to 2003 . Below, we will represent the year the update will take effect as $t$, and consider the window used as input as $[t-8, t-4]$. Indemnity losses were grouped into categories depending on the injury type. These categories are serious (i.e., death, permanent total, and major permanent partial) and non-serious (i.e., minor permanent partial and temporary total). Medical losses are similarly grouped into serious, nonserious, and medical only categories.

Step 2: Raw losses were adjusted to exclude all amounts in excess of per-claim or per-accident caps (e.g., $\$ 350,000$ per claim, $\$ 700,000$ per accident). These adjusted amounts are referred to as limited losses. The purpose of limiting the losses is to reduce the possibility of large random fluctuations that might otherwise occur from the occurrence or non-occurrence of a single large accident.

Step 3: The limited losses are adjusted for loss development and scaled so that the mean equals the mean of the current base rates.

Step 4: The adjusted limited losses summed across all the input policy years for each classification-category $\left(\right.$ AggLimitedLoss $_{j c}$ ) are used to determine a set of experience relative base rates. These experience relative base rates are then credibility weighted against the current relative base rates. The experience relative base rate, $\exp R e l_{j c}$, for classification $j$ and category $c$ is defined as follows,

$$
\exp _{\operatorname{Re}}{ }_{j c}=\frac{(\text { AggLimitedLoss })_{j c} \times 100}{\text { AggPayroll }_{j}} .
$$

These experience relative base rates are then weighted depending on whether a specified number of claims threshold is met using the following weights:

$$
\operatorname{Cred}_{j c}= \begin{cases}1, & \text { if full credibility number of claims threshold met } \\ \left(\frac{\left(\text { AggPayroll }_{j} \times \text { crtRel }_{j c}\right) / 100}{\text { full credibility losses }_{c}}\right)^{0.4}, & \text { otherwise }\end{cases}
$$

where the current relative base rate for classification $j$ category $c\left(\operatorname{crtRel}_{j c}\right)$, the full credibility number of claims threshold, and full credibility losses are in TDI Documentation (Workers' Compensation Relativities Studies, Exhibits 21 and 22). Lastly, the weighted relative base rate, wgtRel, is defined as follows:

$$
\operatorname{wgtRel}_{j c}=\operatorname{Cred}_{j c} \exp \operatorname{Re}_{j c}+\left(1-\operatorname{Cred}_{j c}\right) \operatorname{crt} \operatorname{Re}_{j c} .
$$

The final step works with the overall base rates, which is simply the sum across categories $c$. We denote overall base rates by dropping the $c$ subscript.

Step 5: Next, the balanced indicated relative base rate, balRel, is calculated as follows:

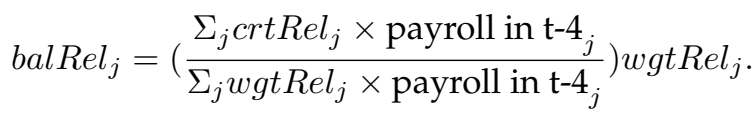


Lastly, the relative rates are capped so that the change is at most a $25 \%$ change in either direction to create the limited relative base rate, limRel:

$$
\operatorname{limRe}_{j}= \begin{cases}1.25 \times \mathrm{crtRel}_{j}, & \text { if } \text { balRel }_{j}>1.25 \times \mathrm{crtRel}_{j} \\ 0.75 \times \mathrm{crtRel}_{j}, & \text { if } \text { balRel }_{j}<0.75 \times \mathrm{crtRel}_{j} \\ \text { balRel }_{j}, & \text { otherwise }\end{cases}
$$

In these terms, the proposed relative base rate, proRel $_{j}$, is:

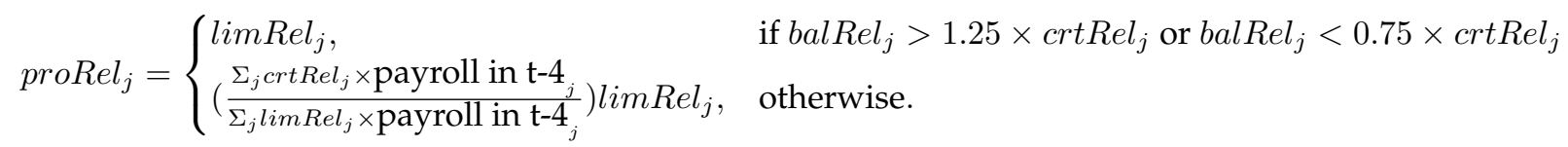

Note the above calculation yields a new set of relative base rates that are approximately revenue neutral. $^{2}$

Step 6: Three updates during our analysis period $(2008,2009$, and 2011) included across-the-board decreases in the level of base rates. These level decreases are made after all of the other steps described above. An $\mathrm{X} \%$ drop in base rates is achieved by an adjustment of the following form:

$$
\text { Final Base } \text { Rate }_{j}=(1-X) \text { proRel }_{j} .
$$

In a year with no across-the-board reduction, the final base rate is simply the proposed base rate $(X=0)$.

\section{Welfare Analysis: More Details on Empirical Implementation}

\section{C.1 Approach}

The approach to empirically implementing the welfare analysis follows Einav and Finkelstein (2011), adapting the framework to accommodate the risk-adjusted premiums observed in this setting. Throughout the discussion below, the risk adjustment we refer to is employer-level experience rating. To ease notation, let us represent risk-adjusted payroll units as: $\mathbb{Q}$. Specifically, we use the variation in classification base rates to estimate reduced form elasticities in terms of risk-adjusted payroll for demand $\left(\epsilon_{\mathbb{Q}, b} \equiv \frac{\partial \mathbb{Q}}{\partial b} \cdot \frac{b}{\mathbb{Q}}\right)$ and average $\operatorname{cost}\left(\epsilon_{A C, b} \equiv \frac{\partial A C(\mathbb{Q})}{\partial b} \cdot \frac{b}{A C(\mathbb{Q})}\right)$. We can combine these elasticities to get the elasticity of the average cost curve with respect to risk-adjusted payroll:

$$
\frac{\partial A C(\mathbb{Q})}{\partial \mathbb{Q}} \cdot \frac{\mathbb{Q}}{A C(\mathbb{Q})}=\frac{\frac{\partial A C(\mathbb{Q})}{\partial b} \cdot \frac{b}{A C(\mathbb{Q})}}{\frac{\partial \mathbb{Q}}{\partial b} \cdot \frac{b}{\mathbb{Q}}} .
$$

Suppose that marginal costs are monotonic in $\mathbb{Q}$. Then, the sign of the above elasticity in equation 5 offers a test for selection: $\frac{\partial A C(\mathbb{Q})}{\partial \mathbb{Q}}>0$ indicates advantageous selection, and $\frac{\partial A C(\mathbb{Q})}{\partial \mathbb{Q}}<0$ indicates adverse selection.

To go beyond a test for selection in the quantitative welfare analysis, we need to make parametric assumptions on the form of the demand and cost curves. We proceed by making such assumptions and combining the reduced form elasticities with market-level data reported by the Texas Department of Insurance (TDI) on mean premiums, mean quantities, and mean insurer combined loss ratios to trace out the empirically relevant curves in this setting (analogous to those presented in the graphical illustration in Figure 5). Consider two different parametric forms for the demand and cost curves as a function of $\mathbb{Q}$ : linear and constant elasticity.

We take as inputs our two elasticity estimates $\left(\epsilon_{\mathbb{Q}, b} \equiv \frac{\partial \mathbb{Q}}{\partial b} \cdot \frac{b}{\mathbb{Q}} ; \epsilon_{A C, b} \equiv \frac{\partial A C(\mathbb{Q})}{\partial b} \cdot \frac{b}{A C(\mathbb{Q})}\right)$ and market-level aggregates from TDI on mean premium per risk-adjusted unit $\left(p^{*}\right)$, mean cost per risk-adjusted unit $\left(c^{*}\right),{ }^{3}$ and mean risk-adjusted quantity $\left(\mathbb{Q}^{*}\right)$.

\footnotetext{
${ }^{2}$ In practice, there are two reasons why these rates may depart from revenue neutral updates slightly. First, in some years there seem to be some slight deviations from the above Step 5 description due to a rounding error. Second, Step 5 described above produces relative base rates that are close to (but not perfectly) revenue neutral. This is because the "capped" classifications are not re-normalized in the final stage. In practice, this does not make a difference because it is so close to revenue neutral.

${ }^{3}$ The mean costs are inferred from the reported mean insurer combined loss ratios and mean premiums.
} 
- Linear: We use the reduced form estimates along with the aggregate TDI data and a linear parametric extrapolation to back out the parameters in the demand and average cost curves: $D(p)=A+B p$; $A C(p)=C+E p$. We can derive the MC curve from these curves using:

$$
M C(p)=\left(\frac{\partial D}{\partial p}\right)^{-1} \frac{\partial(A C(p) \times D(p))}{\partial p} .
$$

Using this relationship, we get that:

$$
M C(p)=\frac{A E}{B}+C+2 E p
$$

We can re-write these in terms of $\mathbb{Q}$,

$$
\begin{aligned}
& -P(\mathbb{Q})=\frac{\mathbb{Q}}{B}-\frac{A}{B} \\
& \text { - } A C(\mathbb{Q})=C-\frac{A E}{B}+\frac{\mathbb{Q} E}{B} \\
& \text { - } M C(\mathbb{Q})=C-\frac{A E}{B}+\frac{2 E \mathbb{Q}}{B} .
\end{aligned}
$$

We can back out these parameters with our reduced form elasticity estimates and the available aggregates: $A \equiv \mathbb{Q}^{*}\left(1-\epsilon_{\mathbb{Q}, b}\right) ; B \equiv \epsilon_{\mathbb{Q}, b}\left(\frac{\mathbb{Q}^{*}}{p^{*}}\right) ; C \equiv c^{*}\left(1-\epsilon_{A C, b}\right) ; E \equiv \epsilon_{A C, b}\left(\frac{c^{*}}{p^{*}}\right)$.

- Constant Elasticity: We use the reduced form estimates along with the aggregate TDI data and a constant elasticity parametric extrapolation to back out the parameters in the demand and average cost curves: (i) $A C(p)=A p^{e_{c}}$ and (ii) $D(p)=B p^{e_{d}}$. We can derive the MC curve from these curves using:

$$
M C(p)=\left(\frac{\partial D}{\partial p}\right)^{-1} \frac{\partial(A C(p) \times D(p))}{\partial p} .
$$

Using this relationship, we get that:

$$
M C(p)=\frac{e_{c}+e_{d}}{e_{d}} A C(p) .
$$

So, we can write $M C(p)=C p^{e_{c}}$, where $C \equiv A \frac{e_{c}+e_{d}}{e_{d}}$. In terms of $\mathbb{Q}$ we can express the inverse demand and cost curves as:

$$
\begin{aligned}
& \text { - } P(\mathbb{Q})=\left(\frac{\mathbb{Q}}{B}\right)^{\frac{1}{e_{d}}} \\
& \text { - } A C(\mathbb{Q})=A\left(\frac{\mathbb{Q}}{B}\right)^{\frac{e_{c}}{e_{d}}} \\
& \text { - } M C(\mathbb{Q})=A \frac{e_{c}+e_{d}}{e_{d}}\left(\frac{\mathbb{Q}}{B}\right)^{\frac{e_{c}}{e_{d}}} .
\end{aligned}
$$

We can back out these parameters with our reduced form elasticity estimates and the available aggregates: $e_{c} \equiv \epsilon_{A C, b} ; e_{d} \equiv \epsilon_{\mathbb{Q}, b} ; A \equiv \frac{c^{*}}{\left(p^{*}\right)^{\epsilon} A C, b} ; B \equiv \frac{\mathbb{Q}^{*}}{\left(p^{*}\right)^{\epsilon_{Q}, b}}$.

\section{C.2 Definition of Data Elements}

While Section 1.2 describes our data sources, this section elaborates on the available data and the definition of several variables of interest in our analysis. The administrative data focus on information about employers and payroll covered by workers' compensation insurance. To conduct the welfare analysis described in the text, we additionally need to measure the size of the market: the total eligible payroll that could be covered by the workers' compensation system. Following the methodology used by TDI for internal research on participation rates (Choi, 2011), we measure the size of the market through comparing the administrative covered payroll data to private sector covered payroll data from the Quarterly Census of Employment and Wages (QCEW) (U.S. Bureau of Labor Statistics (2014)). Because the administrative data on covered payroll exclude certified self-insured employers, we adjust the denominator of private sector payroll to exclude payroll represented by certified self-insured employers during our analysis period. Because there is no covered payroll information for the certified self-insured employers, we approximate covered payroll at these firms 
by combining administrative data on the number of covered employees at these firms with data on mean earnings in private sector employment from the QCEW.

Recall that premiums in this market are represented as in equation 1 described in Section 1.1 of the main text. We have data on several components of these premiums. We use data on regulatory base rates $\left(b_{t}\left(c_{j}\right)\right)$ in our primary estimation. In addition, we use data on premiums before experience rating is applied and experience rating modifiers. The welfare analysis measures quantity in units of risk-adjusted (experience-rated) payroll. To measure the fraction insured, we need an estimate of the total eligible risk-adjusted payroll that could be insured in the market. In practice, we estimate the total eligible risk-adjusted payroll by calculating how the mean experience rating modifier varies with covered payroll, and we use this function-in combination with market-wide data on the total eligible payroll in Texas-to estimate the total eligible risk-adjusted payroll that could potentially be insured. To estimate how the experience rating modifier varies with the covered payroll, we estimate reduced form regressions relating: (i) the mean risk adjustment modifier to base rates and (ii) the mean covered payroll to base rates. We then use a linear extrapolation from these estimated elasticities to predict the average experience rating modifier if all eligible payroll were insured in the market, and scale the total eligible payroll in Texas by this prediction to obtain the total eligible risk-adjusted payroll.

\section{Additional Robustness Analysis}

\section{D.1 Workers' Compensation Classification Coding}

The identification strategy outlined in the main text takes workers' compensation classification coding of employers as exogenous. In this appendix section, we investigate the possibility of problematic endogenous coding related to our identifying variation. Let $j$ represent an employer and $t$ represent year. Specifically, we estimate specifications such as the following:

$$
I\left(c_{j, t} \neq c_{j, t-1}\right)=\beta \Delta \ln (b)_{c_{j, t-1}}+\tau_{t}+\gamma_{j}+\alpha_{c_{j, t-1}}+\epsilon_{j t},
$$

where $c_{j, t}$ represents the classification of employer $j$ in year $t$, and $\Delta \ln (b)_{k}$ is defined as the difference in log base rate for classification $k$ between year $t$ and $t-1\left(\Delta \ln (b)_{k} \equiv \ln \left(b_{k_{t}}\right)-\ln \left(b_{k_{t-1}}\right)\right)$. As noted above, additional controls include year fixed effects $\left(\tau_{t}\right)$, employer fixed effects $\left(\gamma_{j}\right)$, and fixed effects for the classification in year $t-1\left(\alpha_{c_{j, t-1}}\right)$. Robust standard errors are clustered by classification in year $t-1$.

As noted in the text, in practice employers may have multiple classifications if they have a diverse workforce. In the employer-level data we use, we observe the employer's primary classification, often referred to as the governing classification, which covers most of the employer's payroll. Actual premiums paid are adjusted to account for the fraction of the employer's workforce dedicated to other categories (most commonly clerical and sales services), and the percent of payroll allocated to each classification is subject to verification with ex post payroll auditing. In the analysis here, we focus on whether there is endogenous coding of an employer's governing classification (i.e., an employer's primary classification). We note that any observed changes in the governing classification of an employer could represent true underlying changes in the workforce composition of an employer.

With the inclusion of employer fixed effects, the coefficient $\beta$ in equation 10 measures the degree to which employer classification switching is correlated with regulatory base rate increases associated with an employer's classification. Specifically, a positive and significant coefficient estimate for $\beta$ would indicate that employers are more likely to switch away from a particular classification when the relative price increases for this classification. Appendix Table A2 presents the results. There are a few important things to note. First, changes in employer governing classifications are uncommon. Among the classification-year observations in this data, $91 \%$ represent employers who have the same classification in this year as in the prior year. Second, there is no detectable association between the base rate variation and classification switching. Appendix Table A2 displays the estimates from equation 10 with the controls listed above (in column 1) and with additional controls (in column 2); both specifications yield estimates for $\beta$ that are small and statistically indistinguishable from zero.

\section{D.2 Impact of Governing Classification Base Rates on Overall Mean Base Rates}

While our data does not allow us to investigate the prevalence of firms with multiple classifications, we conduct some conservative back-of-the-envelope calculations to assess the potential importance of this data limitation on the demand estimation. This analysis suggests that this data limitation has limited potential 
impact on the demand estimation.

According to the Texas Department of Insurance (TDI) actuarial office, it is common for large firms with multiple classifications to have $80-90 \%$ of payroll attributable to their governing classification, with adjustments for the remaining $10-20 \%$ of payroll attributable to other classifications, most commonly clerical and sales classifications. Because premium adjustments for secondary classifications are concentrated in clerical and sales classifications-classifications that are low risk with low base rates-these adjustments typically account for a small share of premiums for employers with multiple classifications. For instance, the most common clerical classification (classification 8810) has a classification base rate that is 0.17 times the mean classification base rate in the baseline year 2006.

We conduct conservative back-of-the-envelope analysis to understand how adjustments for secondary classifications may affect our estimates. Specifically, we analyze the impact of a firm's governing classification base rate on the total premiums paid by the firm for this coverage. Though most firms have a single classification, suppose we conservatively assume that all firms have $20 \%$ of payroll attributable to another classification-clerical services (classification 8810). We can estimate the impact of the employer's governing classification base rate on the associated employer's overall mean base rate (and premiums) by estimating the following specification:

$$
\ln \left(y_{j, t}\right)=\theta_{0}+\theta_{1} \ln \left(b_{j, t}\right)+\rho_{j}+\gamma_{t}+u_{j t},
$$

where the overall mean base rate for firms with governing classification $j$ in year $t$ is represented by $y_{j, t} \equiv$ $0.8 b_{j, t}+0.2 b_{\text {clerical }, t}$. We note that this regression accounts for any correlation in rate updates across the governing classifications and the secondary clerical classification and accounts for heterogeneity across classifications in the relative magnitude of these adjustments compared to the governing classification base rate. We also estimate a specification that replaces the overall mean base rate with the overall mean premiums per unit of risk-adjusted payroll: $y_{j, t} \equiv 0.8 p_{j, t}+0.2 p_{\text {clerical }, t}$. The results are displayed in Appendix Table A3. Based on these estimates, we see that a $1 \%$ increase in the governing classification base rate leads to a $0.975 \%$ increase in the overall mean base rate and a $0.970 \%$ increase in premiums paid per unit of risk-adjusted payroll. This analysis illustrates that percent changes in governing classification base rates would translate nearly one-for-one in percent changes to employer overall mean base rates and premiums, even if adjustments for secondary classifications were more prevalent than indicated by TDI.

\section{D.3 Exclusion of Certified Self-Insured Employers}

Our baseline analysis excludes certified self-insured employers and associated employee payroll. We make this exclusion for two key reasons: (i) our identification strategy leverages variation in the premiums for coverage purchased from workers' compensation insurance providers, and (ii) the administrative data on covered payroll and claims are only available for the payroll covered through policies purchased from a workers' compensation insurance provider. As discussed in the text, there are strict requirements to become a certified self-insured firm. Perhaps because of these requirements, very few employers take up this option: only 95 firms are ever self-insured during our analysis period (2006-2011). Among these 95 firms that are ever self-insured from 2006-2011, 89 firms are continuously self-insured for the entire time period. In other words, there are only a handful of firms who ever switch between being self-insured and another status (purchased policy or no insurance). While the persistence in self-insurance implies it is unlikely that the exclusion of these firms affects our demand estimates, we directly analyze the robustness of the results with respect to our baseline sample definition, as described below.

We have administrative data on the identity of each certified self-insured firm in addition to each employer with a purchased policy. Thus, we can repeat the analysis analyzing the number of participating employers, either excluding or not excluding the certified self-insured firms. The baseline analysis reported in Table 3 columns 1 through 4 in the main text excludes certified self-insured firms, and Appendix Table A4 displays the analysis including all covered employers within the proof-of-coverage data (with no restriction to exclude the certified self-insured). Comparing these results, we see the results are very similar.

\section{D.4 Eligible Population of Firms and Workers}

Our baseline analysis uses dependent variables (the natural logarithm of covered employers, the natural logarithm of covered payroll) that are constructed solely from the administrative data. As discussed in Section 
2 , there is no administrative data on the universe of eligible firms and workers in each classification, so it is not possible to estimate demand in terms of the fraction of payroll insured (or the fraction of firms insured). A more detailed explanation is below. The ideal demand estimation would be in terms of the share of eligible firms or eligible payroll that is covered:

$$
\ln \left(\frac{\text { TotInsured }_{j t}}{\text { TotEligible }_{j t}}\right)=\gamma+\pi \ln \left(b_{j t}\right)+\lambda_{j}+\tau_{t}+\mu_{j t} .
$$

Rearranging terms we get:

$$
\ln \left(\text { TotInsured }_{j t}\right)=\gamma+\pi \ln \left(b_{j t}\right)+\lambda_{j}+\tau_{t}-\ln \left(\text { TotEligible }_{j t}\right)+\mu_{j t},
$$

where $\ln \left(\right.$ TotEligible $\left._{j t}\right)$ is unobserved. Suppose we can represent this term as:

$$
\ln \left(\text { TotEligible }_{j t}\right)=\phi+\rho \ln \left(b_{j t}\right)+\eta_{j}+\sigma_{t}+e_{j t} .
$$

Substituting this into the ideal demand specification we get:

$$
\ln \left(\text { TotInsured }_{j t}\right)=(\gamma+\phi)+(\pi+\rho) \ln \left(b_{j t}\right)+\left(\eta_{j}+\lambda_{j}\right)+\left(\sigma_{t}+\tau_{t}\right)+\left(e_{j t}+\mu_{j t}\right) .
$$

Thus, the feasible regression will provide an estimate of $\pi+\rho$. This is a consistent estimate of the true demand elasticity $\pi$ if and only if $\rho=0$. Thus, to interpret the baseline estimates as reflecting the demand for insurance, a key assumption is that the eligible population of workers and firms in each classification is not changing in response to the identifying premium variation (i.e., $\rho=0$ ). While the lack of classification-level data on the eligible population prevents us from testing this directly, we present some supporting evidence for this assumption by using North American Industry Classification System (NAICS) industry-year level data on the Texas workforce from the Quarterly Census of Employment and Wages (QCEW) and relating this to the classification-year-level variation in workers' compensation premiums using a crosswalk derived from the administrative data.

Specifically, we take aggregate data on the universe of firms and workers at the NAICS industry-yearlevel from the QCEW. We then match these to the classification-year-level workers' compensation premium variation using a crosswalk that is derived from the administrative data. We construct this crosswalk using the administrative proof-of-coverage data on employers participating in the Texas workers' compensation system. Importantly, these data include the workers' compensation governing classification code for each employer and these data also include information on the NAICS six-digit industry code.

In practice, there are a few challenges to creating a crosswalk from industry codes to classification codes. First, the NAICS industry code field is missing for approximately one-fifth of observations. Second, each NAICS code does not always map nicely to one workers' compensation classification code. In the face of these challenges, we proceed as follows. Starting with the pooled data across our analysis period, we use the observed NAICS industry-classification pairs to construct a frequency-weighted crosswalk under the assumption that the missing industry values are not selected. To remove outliers that may represent measurement error, we exclude industry-classification pairs that represent fewer than 10 observations or fewer than $5 \%$ of the observations associated with a particular NAICS industry code. In this analysis, we restrict attention to industries with mean annual employment exceeding 1,000 workers over the analysis period.

We examine whether the eligible population is related to the identifying variation by estimating variants of the following equation:

$$
\ln \left(y_{i t}\right)=\alpha+\beta \ln \left(b_{i t}\right)+\delta_{i}+\theta_{t}+\lambda_{i} t+\epsilon_{i t},
$$

where $i$ is a NAICS industry, and $t$ is a year. In this specification, $\ln \left(b_{i t}\right)$ represents the natural logarithm of the mean base rate applicable in the industry based on the constructed NAICS-classification weighted crosswalk described above. All specifications include year and industry fixed effects, and we also estimate specifications with an additional control: a three-digit NAICS industry-specific time trend.

Appendix Table A6 presents the results. Overall, the results suggest that neither the aggregate number of firms nor the aggregate number of workers in an industry is responsive to the premium variation in classifications associated with the industry. This evidence builds confidence in our interpretation of the primary baseline regressions as reflecting the demand for insurance. 


\section{D.5 Demand Analysis: Additional Robustness}

In addition to the alternative specifications discussed in the main text, we further probe the robustness of the demand estimates with respect to a few additional potential concerns.

Incidence of Premium Changes It is unclear how the burden of increased premiums (or the benefit from reduced premiums) is shared among employers and employees. To the extent that employers shift the cost of workers' compensation premiums onto workers, wages may be partially shifted upward or downward to reflect changes in workers' compensation premiums. Ideally, the demand estimation would use a pure quantity measure that is not sensitive to possibly endogenous wage adjustments. While we analyze covered employers which is a pure quantity measure, we also analyze covered payroll (wages multiplied by hours) which only represents a pure quantity measure if wages are not responsive to the identifying variation in workers' compensation premiums. ${ }^{4}$ To evaluate the sensitivity of our estimates to potential endogenous wage adjustment, we repeat the covered payroll regression analysis under various assumptions on the fraction of premiums passed through to employees in the form of reduced wages. Specifically, these additional specifications repeat the baseline payroll regression replacing the dependent variable with the natural logarithm of normalized covered payroll: $\ln \left(\frac{\text { payroll }_{j t}}{1-\theta \times \text { premium }_{j t}}\right)$, where premium $_{j t}$ represents the mean premium per dollar of payroll for classification $j$ in year $t$, and $\theta$ represents the fraction of premiums shifted to employees in the form of reduced wages.

Appendix Table A8 Panel A displays the results of these additional specifications. These estimates illustrate that regardless of the division of premiums between employers and employees on the margin, increases in classification base rates lead to a decline in covered payroll. Across the range of possible assumptions on the division of premiums between employees and employers, a $1 \%$ increase in classification base rates leads to an estimated decline in normalized covered payroll of $0.22 \%$ to $0.29 \% .{ }^{5}$ For the purpose of our discussion of mandates in Section 4, we use demand estimates where quantity is measured using unadjusted covered payroll.

Alternative Samples We investigate the stability of our estimates when estimating alternative specifications in which we restrict attention to a subset of classifications. Appendix Table A8 Panel B displays estimates from a specification focusing on larger classifications (excluding classifications with annual insured payroll of less than $\$ 10$ million) and estimates from a specification that excludes clerical and sales classifications (classifications that are the most common secondary classifications). The estimates in these alternative specifications are very similar to the baseline estimates.

Alternative Weighting While the descriptive statistics throughout represent market-level aggregates weighted by the payroll insured within each classification, the baseline regressions estimating the causal effect of rates on coverage are unweighted. There are two key reasons for this. First, it is not clear whether unweighted or weighted regressions are preferred when estimating causal effects. ${ }^{6}$ Second, data is not available to construct

\footnotetext{
${ }^{4}$ Analyzing data from compulsory workers' compensation insurance systems, Gruber and Krueger (1991) find that workers' compensation premium changes in the 1980s in some high-risk industries were largely shifted into wages. As these authors discuss, their findings are consistent with multiple explanations, including that labor supply is more inelastic than labor demand (a typical finding in tax incidence analyses of labor markets) or that employees value workers' compensation coverage changes that were coincident with the premium changes they analyze. Because the present empirical setting is quite different from the setting these authors investigate (for example, in the present empirical setting coverage is optional, all occupational groups are included, etc.), it is not clear whether employers or employees bear the incidence of workers' compensation insurance premium updates. While our baseline approach is to analyze unadjusted covered payroll, the key results are not sensitive to which segment of consumers bears the incidence of workers' compensation insurance premiums.

${ }^{5}$ It is not surprising that the results are robust across the different possible divisions of premium updates across employers and employees. To see this, note that the average premium is $\$ 1.81$ per $\$ 100$ in payroll; thus, a $1 \%$ across-the-board increase in premiums would lead to approximately a $0.0181 \%$ decrease in covered payroll if coverage rates were held fixed and premium changes were fully shifted onto employees in the form of reduced wages. In other words, any mechanical effect of premiums on wages is expected to be an order of magnitude smaller than the estimated demand elasticity, regardless of the incidence of workers' compensation insurance premiums.

${ }^{6}$ As discussed in Solon, Haider and Wooldridge (2015), weighted regressions do not recover the average partial treatment effect in the presence of unmodeled treatment effect heterogeneity; if there is no heterogeneity in partial effects, both weighted and unweighted regressions provide consistent estimates of the homogeneous partial effect. Heteroskedasticity may be another motivation to weight regressions, though weighting may either ameliorate or exacerbate heteroskedasticity concerns depending on the degree to which outcomes are correlated within clusters. Solon, Haider and Wooldridge (2015) recommend comparing weighted and unweighted estimates to assess model mis-specification and recommend that researchers report heteroskedasticity robust standard errors. In line with these recommendations, we report heteroskedasticity robust standard errors throughout and assess robustness to weighting as described
} 
the most natural weights for the demand estimation in this setting: total eligible payroll or total eligible employers within each classification. Though weighting by eligible payroll (or eligible employers) is infeasible, we present supplemental analysis which suggests that the results of this infeasible analysis would likely be similar to the estimates in the unweighted analysis. Appendix Table A8 Panel C illustrates that we obtain similar estimates in alternative specifications, where we weight the regressions using feasible proxies for eligible payroll within each classification: covered payroll, risk-adjusted covered payroll, and premiums paid in the first year of the analysis period.

\section{D.6 Selection Analysis: Additional Robustness}

In addition to the analysis in the main text, we further explore the robustness of the selection analysis. Appendix Table A9 presents estimates from additional specifications with alternative transformations of the cost measure and alternative cost measures. The results reported in Appendix Table A9 illustrate that these additional specifications yield similar findings. Appendix Figure A8 depicts a binned mean residual plot to graphically illustrate the baseline selection estimates. While the cost regression estimates are nosier than the demand estimates, these plots show no evidence of selection. Finally, Appendix Figure A9 displays estimates from the complementary event study approach outlined in equation 6, with mean claim costs (Panel A) and risk-adjusted payroll (Panel B) as outcomes. This figure shows no evidence of selection and no evidence of pre-existing trends.

\section{D.7 Welfare Analysis and Empirical Cost Curves}

Based on the empirical analysis which finds no evidence of selection in this market, the primary welfare calculations in the text are conducted under the assumption of no selection, meaning that there is a flat market-level average/marginal (risk-adjusted) cost curve. Appendix Table A11 presents alternative welfare calculations employing the small (and statistically indistinguishable from zero) risk-adjusted cost elasticity estimates reported in Table 4. The key patterns in these welfare estimates are similar to those in the baseline welfare analysis in Table 5.

\section{E Interpretation of Demand}

While the decision to purchase workers' compensation insurance is made by employers, the welfare analysis relies on the assumption that employer decisions reflect both employer and employee values for workers' compensation insurance. In Section 4 of the text, we describe one simple model that provides sufficient conditions for demand to reflect both employer and worker values of workers' compensation insurance. Below, we present a more detailed description of this model, and we discuss a simple alternative model that yields the same result.

\section{E.1 Detailed Description of Model}

Below, we apply the model of equalizing differentials outlined in Rosen (1986) to the setting of a labor market where firms choose wages and whether to purchase workers' compensation insurance over the outside option of settling workplace injuries through the tort system. The intuition behind this model is simple. Labor markets tie together two transactions: workers sell their labor services to firms and buy a set of job attributes from firms, while firms buy labor services from workers and sell a set of job attributes to workers. In this way, the labor market induces sorting of workers across firms, and job attributes reflect worker preferences and firm costs.

Consider a competitive labor market where workers have homogeneous productivity, and there are two types of jobs. Let $I$ index the job type, where $I=1$ in jobs with workers' compensation insurance and $I=0$ in jobs without workers' compensation insurance. Let $w_{1}$ and $w_{0}$ represent the wages earned in the associated job type, and let the wage differential be represented by $\Delta w \equiv w_{0}-w_{1}$. Both workers and firms make rational, privately optimal decisions.

Worker Preferences Worker $i^{\prime}$ 's preferences are represented by utility function $U^{i}$, which is a function of consumption $(C)$, and workers' compensation insurance at his/her job $(I)$, where $I=1$ if insured and 0 otherwise. Worker utility is increasing in consumption $\left(U_{C}^{i}>0\right)$ and workers may place positive or negative value on workers' compensation insurance relative to the outside option of legal recourse through the tort system $\left(U_{I}^{i} \lessgtr 0\right)$. 
Let $C_{i}^{1}$ denote market consumption for individual $i$ when $I=1$. Let $C_{i}^{*}$ denote the consumption level that would give the same utility to the worker in a job without workers' compensation insurance as would have been attained in a job with workers' compensation at consumption level $C_{i}^{1}: U^{i}\left(C_{i}^{*}, 0\right)=U^{i}\left(C_{i}^{1}, 1\right)$. If the worker places a positive (negative) value on workers' compensation insurance then $C_{i}^{*} \geq C_{i}^{1}\left(C_{i}^{*} \leq C_{i}^{1}\right)$.

Define $\beta_{i}=C_{i}^{*}-C_{i}^{1}$, which represents worker $i$ 's value of a job with workers' compensation insurance relative to a job with the outside option of tort liability (i.e., the compensating differential for $I=0$ compared to $I=1)$. Worker $i$ chooses to apply to a job with workers' compensation insurance if and only if $\beta_{i} \geq \Delta w$.

Market Supply Holding total employment fixed, the labor supply for each type of job is simply the fraction of workers applying to jobs in each market segment: jobs with and without workers' compensation insurance. $^{7}$ Let $G$ represent the distribution of $\beta$ in the worker population. Let $L_{I}^{s}$ be the fraction of workers applying to jobs of type $I$. In this notation, we can represent labor supply in each market segment as:

$$
\begin{aligned}
& L_{1}^{s}(\Delta w)=P(\beta \geq \Delta w)=1-G(\Delta w) \\
& L_{0}^{s}(\Delta w)=P(\beta<\Delta w)=G(\Delta w) .
\end{aligned}
$$

Firm Production and Costs Firms choose which job type $(I=0$ or $I=1)$ offered to the market. Suppose firms' production scales linearly with the number of workers $L$. Further, suppose the following describes profits for firm $j$ :

$$
\pi=\underbrace{\delta L}_{=\text {Total Production }}-\underbrace{\left(\left(p+w_{1}\right) I+\left(\alpha_{j}+w_{0}\right)(1-I)\right) L}_{=\text {Total Costs }},
$$

where $\delta$ represents per-worker productivity of labor, $\alpha_{j}$ represents the per-worker expected costs associated with tort liability, and $p$ represents the per-worker price of workers' compensation insurance. The expected costs of tort liability are weakly positive $\left(\alpha_{j} \geq 0\right)$, and this represents the per-worker cost savings (or value) to the firm from purchasing workers' compensation insurance. While firms face the same price for workers' compensation insurance, firms may differ in the cost savings they get from avoiding tort liability $\left(\alpha_{j}\right)$. For instance, there may be variation across firms in the transaction costs and legal fees associated with injury settlements in the outside option. Firm $j$ will purchase workers' compensation insurance if and only if $p \leq$ $\Delta w+\alpha_{j}$, or equivalently when $\alpha_{j} \geq p-\Delta w$.

Market Demand Suppose the number of firms and firm size are fixed. Let $F$ represent the distribution of $\alpha$ across jobs offered by firms. This distribution incorporates the size of each firm as well as production technology, meaning $F(\alpha)$ indicates the fraction of potential jobs in the economy for which the expected perworker costs from tort liability are less than or equal to $\alpha$. Let $L_{I}^{d}$ represent labor demand for job type $I$. This can be represented as:

$$
\begin{aligned}
& L_{1}^{d}(p-\Delta w)=P(\alpha \geq p-\Delta w)=1-F(p-\Delta w) \\
& L_{0}^{d}(p-\Delta w)=P(\alpha<p-\Delta w)=F(p-\Delta w) .
\end{aligned}
$$

Market Equilibrium The market clears when labor supply equals labor demand in each segment of the market: $L_{1}^{d}(p-\Delta w)=L_{1}^{s}(\Delta w)$ (or equivalently, $L_{0}^{d}(p-\Delta w)=L_{0}^{s}(\Delta w)$ ). In the notation above, this equilibrium condition can be represented as:

$$
1-F(p-\Delta w)=1-G(\Delta w) .
$$

A direct consequence of this model is that there will be positive assortative matching of firms and workers, meaning workers with higher values for workers' compensation insurance sort toward firms with higher perworker values from purchasing workers' compensation insurance (i.e., greater cost savings from avoiding tort liability). In equilibrium, the sum of the per-worker value of this coverage to the marginal firm and the value of this coverage to the marginal worker equals the price of workers' compensation insurance. Thus, the demand for workers' compensation insurance reflects the value of this coverage to marginal employers and employees. Given the equilibrium wage differential $\Delta w^{*}$, the marginal worker $i^{\prime}$ is indifferent between working at a job with and without workers' compensation insurance, $\beta_{i^{\prime}}=\Delta w^{*}$. The marginal firm $j^{\prime}$ is

\footnotetext{
${ }^{7}$ Because this exercise holds fixed total employment, the labor supply in each market segment only depends on the wage differential $\Delta w$ rather than the wage level in each segment $\left(w_{0}\right.$ and $\left.w_{1}\right)$. A general equilibrium model would be required to determine the wage level in each market segment.
} 
indifferent between purchasing workers' compensation insurance or not, $p=\alpha_{j^{\prime}}+\Delta w^{*}$. Combining these expressions, we see that in equilibrium, the sum of the per-worker value of this coverage to the marginal firm and the value of this coverage to the marginal worker equals the price of workers' compensation insurance, $p=\alpha_{j^{\prime}}+\beta_{i^{\prime}}$. Hence, at any given price, the share of the workforce covered by workers' compensation insurance is the share of the workforce for which the sum of the per-worker employer value and the employee value exceeds the price.

\section{E.2 Simple Alternative Model}

We present one simple alternative model employing different assumptions that produces the same basic result: the demand for workers' compensation insurance reflects the value of this coverage to marginal employers and employees. Consider an employer's decision to allocate employee compensation across wage and non-wage job attributes, where we focus on one non-wage attribute: the provision of workers' compensation insurance. Suppose employer-employee matches and total employee compensation, $c_{i}$ (the aggregate value of wage and non-wage compensation for employee $i$ ), are determined within the broader labor market and are taken as given by an employer. Let $\alpha_{j}$ represent employer $j$ 's per-worker expected costs of tort liability. The expected costs of tort liability are weakly positive $\left(\alpha_{j} \geq 0\right)$, may vary across employers, and represent the cost savings (or value) to the firm from purchasing workers' compensation insurance. Let $\beta_{i}$ represent employee $i$ 's value of workers' compensation insurance relative to the outside option of tort liability. There may be heterogeneity in employee values, and employee values may be either positive or negative, as workers' compensation insurance and recourse through the tort system are horizontally differentiated from a worker's perspective.

Let $p$ represent the per-employee premium for workers' compensation insurance. Suppose employers know employees' values for workers' compensation insurance, and employers can flexibly adjust employee wages. If an employer elects to purchase workers' compensation insurance, this insurance must be provided to all employees. Let $N_{j}$ represent the number of workers employed by employer $j$. Employer $j$ will choose to purchase workers' compensation coverage if and only if it minimizes the total compensation costs to do so:

$$
\sum_{i=1}^{N_{j}}\left(w_{i}^{W C}+p-\alpha_{j}\right) \leq \sum_{i=1}^{N_{j}} w_{i}^{0}
$$

where $w_{i}^{W C}$ is employee $i^{\prime}$ s wage compensation if offered workers' compensation insurance and $w_{i}^{0} \equiv c_{i}$ is employee $i$ 's wage compensation if not offered workers' compensation insurance. Total compensation from employee $i^{\prime}$ 's perspective is held constant by setting $w_{i}^{W C}=w_{i}^{0}-\beta_{i}$. Thus, employer $j$ will offer workers' compensation insurance if and only if the per-capita benefits accruing to the employer and associated employees exceed the per-capita premiums paid, $p \leq \frac{1}{N_{j}} \sum_{i=1}^{N_{j}}\left(\alpha_{j}+\beta_{i}\right)$. At a given price, the share of the workforce covered by workers' compensation insurance reflects the share of the workforce for which the sum of the per-worker value of this coverage to firms and the mean value of this coverage to employees exceeds the price of coverage.

\section{References}

Choi, Soon-Yong. 2011. "Costs to Employers and Efficiencies In the Texas Workers' Compensation System." Texas Department of Insurance Workers' Compensation Research and Evaluation Group. https : / / www . tdi.texas.gov/reports/wcreg/documents/Employers_cost.pdf. (Date accessed: 12/2021).

Einav, Liran, and Amy Finkelstein. 2011. "Selection in Insurance Markets: Theory and Empirics in Pictures." Journal of Economic Perspectives, 25(1): 115.

Flood, Sarah, Miriam King, Renae Rodgers, Steven Ruggles, J. Robert Warren, and Michael Westberry. 2021. "Integrated Public Use Microdata Series, Current Population Survey: Version 9.0 [dataset]." Minneapolis, MN: IPUMS. https://doi.org/10.18128/D030.V9.0.

Gruber, Jonathan, and Alan B Krueger. 1991. "The Incidence of Mandated Employer-Provided Insurance: Lessons from Workers' Compensation Insurance." In Tax Policy and the Economy, Volume 5. 111-144. The MIT Press.

Rosen, Sherwin. 1986. "Chapter 12 The theory of equalizing differences." In . Vol. 1 of Handbook of Labor Economics, 641 - 692. Elsevier. 
Solon, Gary, Steven J. Haider, and Jeffrey Wooldridge. 2015. "What are we weighting for?" Journal of Human Resources, 50(2): 301-316.

Texas Department of Insurance (TDI). 2011. "Workers' Compensation Relativities Studies 2011." Exhibit 12-1. Texas Department of Insurance. https: / / www.tdi.texas.gov/reports/report9.html. (Date accessed: 9/2014).

Texas Department of Insurance (TDI). 2014. “Texas Workers' Compensation Proof-of-Coverage Electronic Data Interchange Data (2005-2014Q1)." Texas Department of Insurance.

Texas Department of Insurance (TDI). 2016a. "Certified Self-Insured Extracts (2006-2011)." Texas Department of Insurance.

Texas Department of Insurance (TDI). 2016b. "Workers' Compensation Relativities Studies." Studies available within period 2003 to 2015. Texas Department of Insurance. https://www.tdi.texas.gov/ reports/report 9.html. (Date accessed: 9/2016).

Texas Department of Insurance (TDI). 2019. “Unit Statistical Data (2004-2014).” Texas Department of Insurance.

Texas Department of Insurance Workers' Compensation Research and Evaluation Group (TDI WCREG). 2010. "Setting the Standard: An Analysis of the Impact of the 2005 Legislative Reforms on the Texas Workers' Compensation System, 2010 Results." Figure 2.1 pg. 8 (2006 estimates). Texas Department of Insurance. https://www.tdi.texas.gov/reports/wc/documents/wcsetstd2010.pdf. (Date accessed: 12/2021).

Texas Department of Insurance Workers' Compensation Research and Evaluation Group (TDI WCREG). 2016. "Setting the Standard: An Analysis of the Impact of the 2005 Legislative Reforms on the Texas Workers' Compensation System, 2016 Results." Figure 2.1 pg. 7 (2007-2011 estimates). Texas Department of Insurance. https://www.tdi.texas.gov/reports/wcreg/documents/biennial2016.pdf. (Date accessed: 12/2021).

U.S. Bureau of Labor Statistics. 2014. Quarterly Census of Employment and Wages (QCEW), Retrieved from https://www.bls.gov/cew/downloadable-data-files.htm, June 15, 2014. 
Figure A1: Histogram of Proposed Base Rate Updates

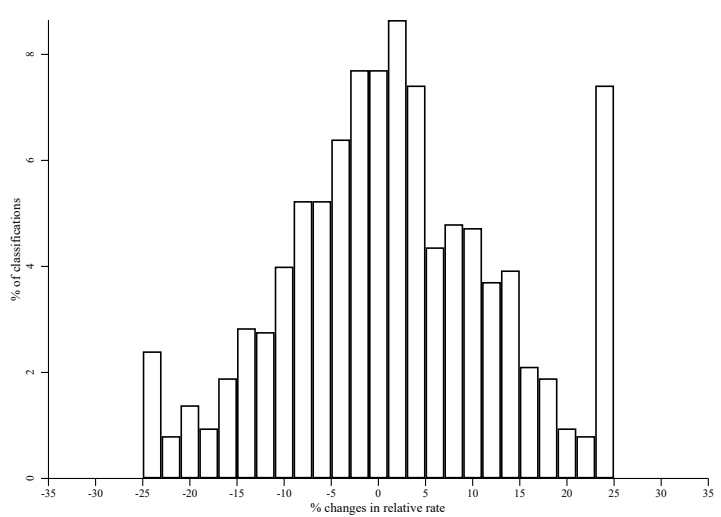

(a) Pooled

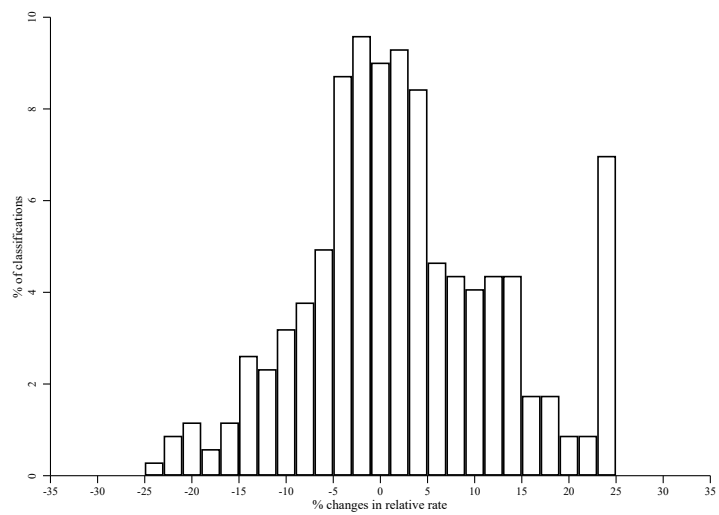

(c) Update 2008

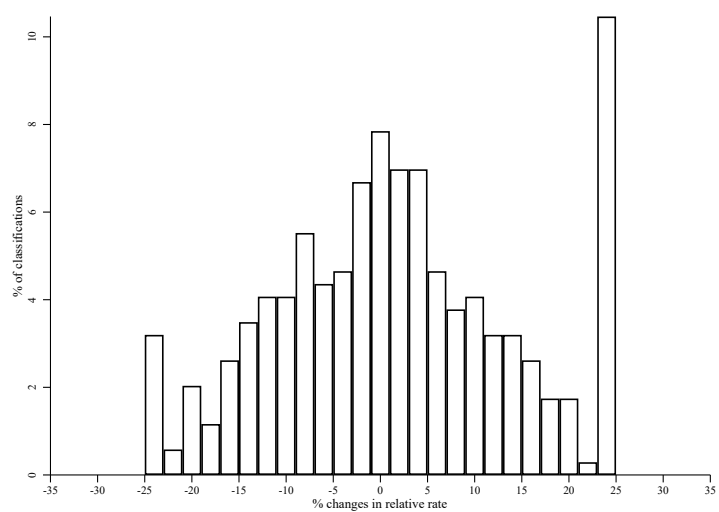

(e) Update 2011

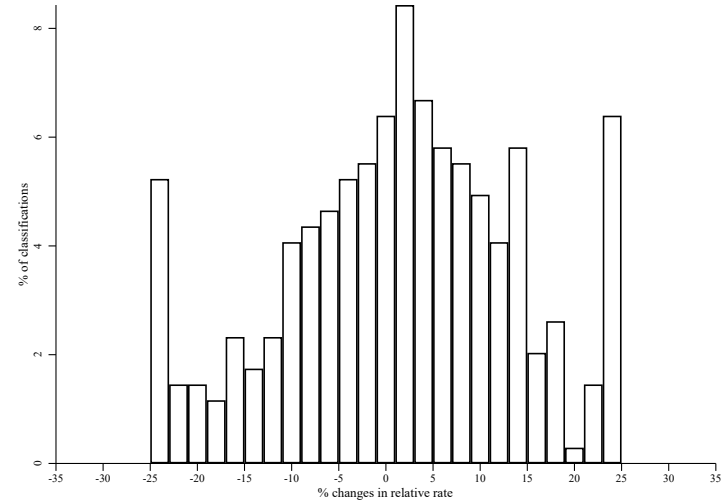

(b) Update 2007

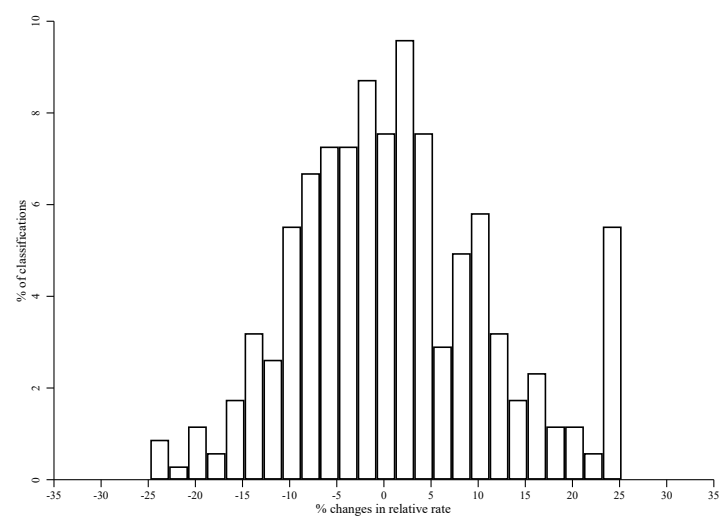

(d) Update 2009

Notes: The above histograms describe the proposed updates to the base rates (before any across-the-board adjustments). Following the definitions in Appendix Section B, the percent change here is defined as: $\frac{\text { proRel }_{j}-\mathrm{crtRel}_{j}}{c r t \operatorname{Rel}_{j}}$ for classification $j$. The updates in the final implemented base rates (after across-the-board adjustments) are depicted in Appendix Figure A2. 
Figure A2: Histogram of Percent Change in Final Base Rates

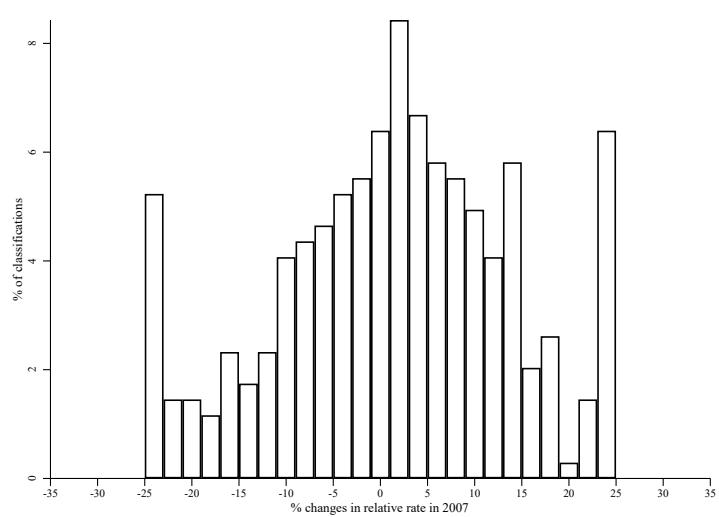

(a) Update 2007

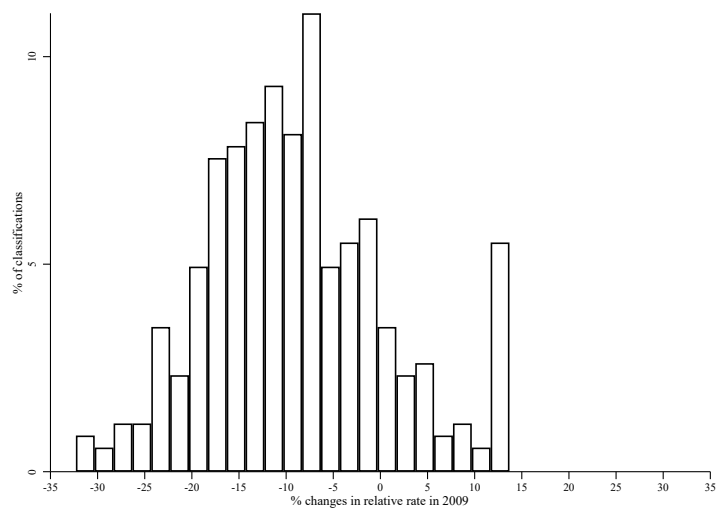

(c) Update 2009

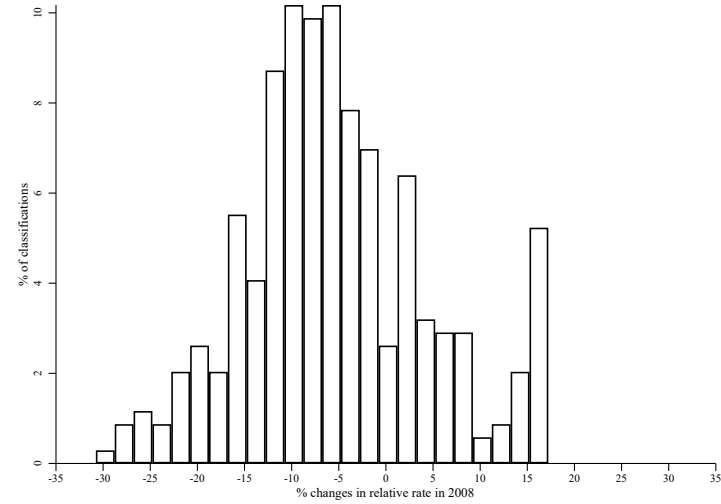

(b) Update 2008

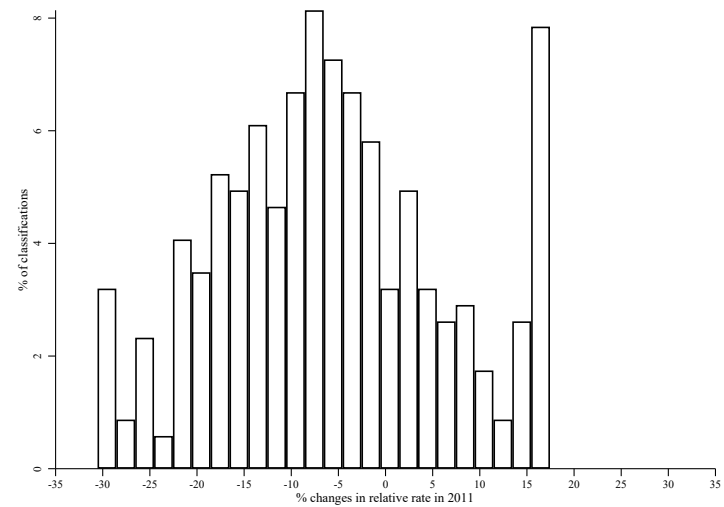

(d) Update 2011

Notes: The above histograms describe the change in the final relative base rates. These histograms focus on the change in the final implemented base rates (after any across-the-board adjustments). Following the definitions in Appendix B, the percent change here is defined as: $\frac{\text { Final Base } \text { Rate }_{j}-\text { crtRel }_{j}}{\text { crtRel }_{j}}$ for classification $j$. 
Figure A3: Base Rate Updates: Proposed Capped Rates and Hypothetical Uncapped Rates

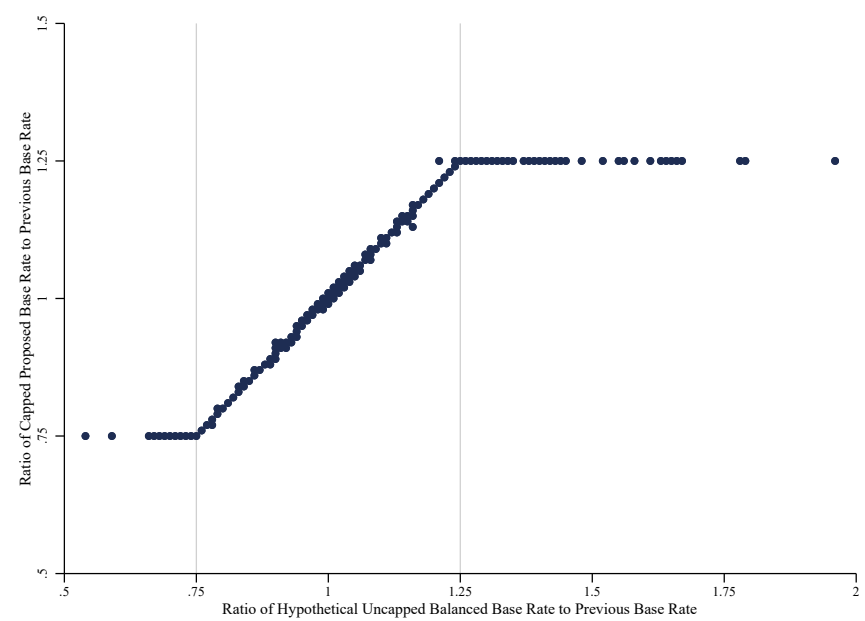

Notes: Each dot in the figure represents a classification update, where classification observations are pooled across updates in the analysis period (2006-2011). The figure displays a scatter plot of the following two ratios: the ratio of capped proposed relative base rate to previous base rate ( $\frac{\mathrm{proRel}_{j}}{\mathrm{crtRel}_{j}}$ for classification $j$ ) and the ratio of hypothetical uncapped balanced base rate to previous base rate $\left(\frac{\text { balRel }_{j}}{\text { crtRel }_{j}}\right.$ for classification $j$ ). See Appendix Section B for more details on these inputs into the base rate update algorithm. 
Figure A4: Event Study: Excluding Controls for Prior and Subsequent Rate Updates

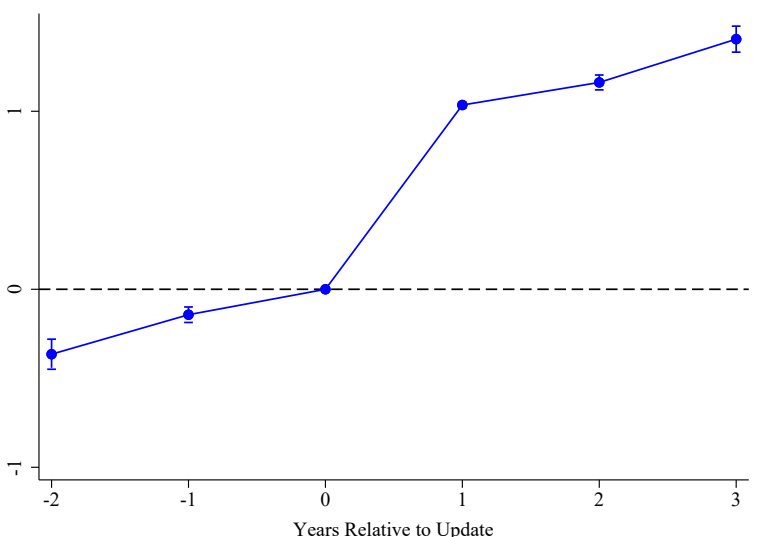

(a) $\ln ($ Base Rate)

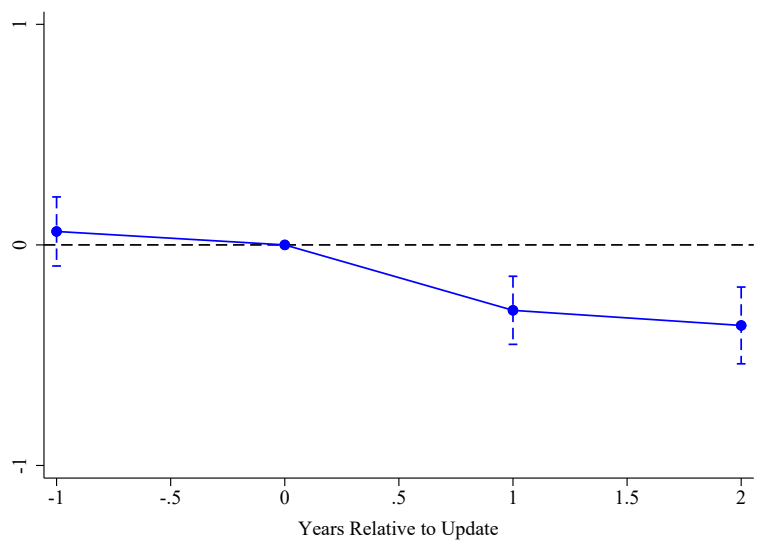

(c) $\ln$ (Covered Employers)

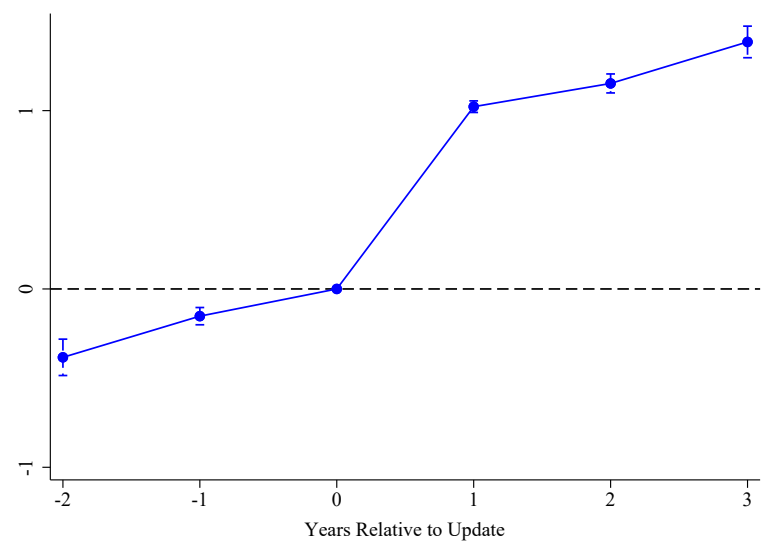

(b) $\ln ($ Mean Premiums)

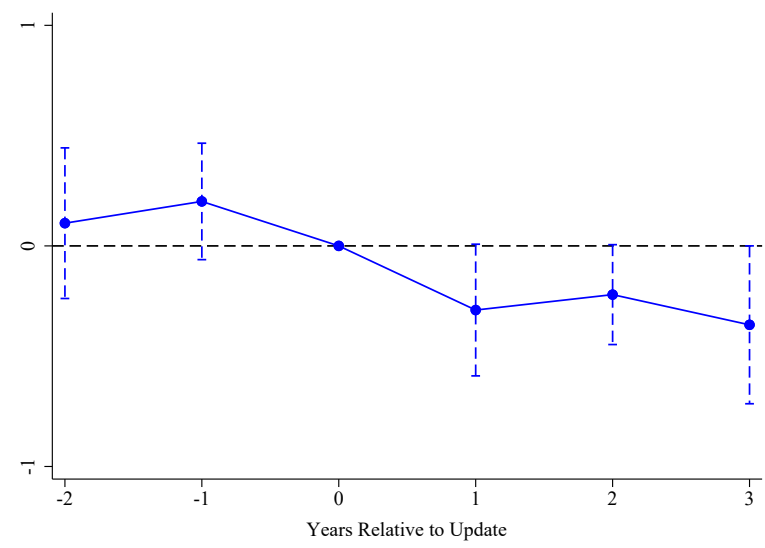

(d) $\ln ($ Covered Payroll)

Notes: The above figure displays estimates from the event study estimation described in equation 6 excluding controls for prior and subsequent rate updates. The dependent variables are as indicated in each panel. The horizontal axis displays time since the reference base rate update, where each point on the horizontal axis represents policies initiated in the indicated 12 month increment of event time. The event study representation focuses on the rate updates occurring between 2006 and 2011. The data used for this estimation is a series of balanced panels, where each panel includes data from three years (or two years in Panel C) pre- and post-update. Capped vertical bars indicate 95\% confidence intervals, and robust standard errors are clustered at the classification level. 
Figure A5: Graphical Depiction of Difference-in-Differences Demand Estimates

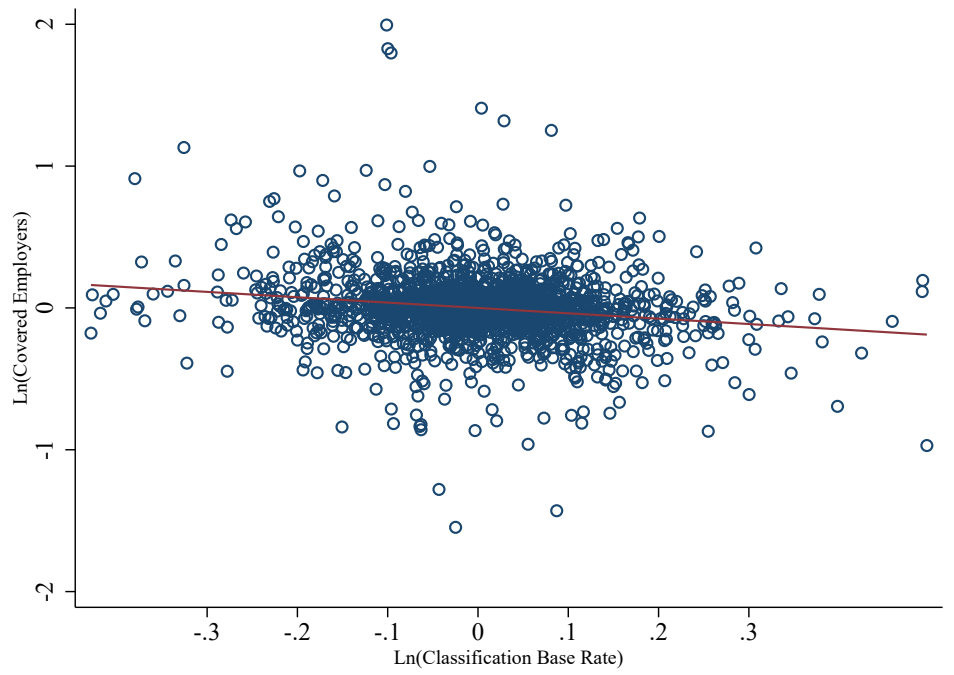

(a) Covered Employers

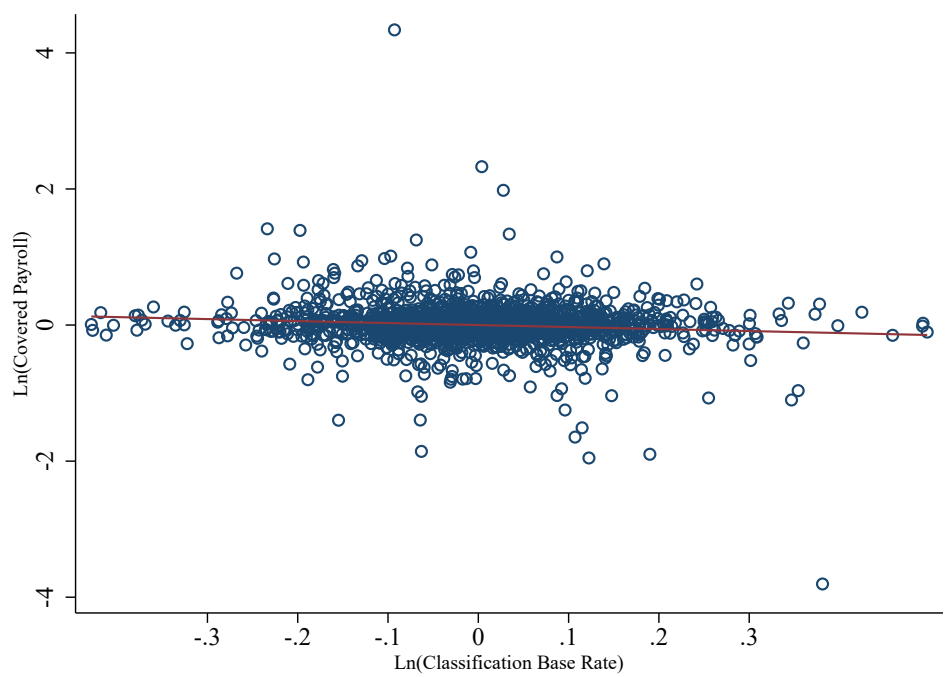

(b) Covered Payroll

Notes: This figure displays residual scatter plots for the baseline demand specifications. Each dot represents a classification-year observation in the baseline analysis data. Panel A displays the results for covered employers (analogous to the estimates in Table 3 column 1), and Panel B displays the results for covered payroll (analogous to the estimates in Table 3 column 5). 


\section{Figure A6: Event Study for Covered Employers: Alternative Specification}

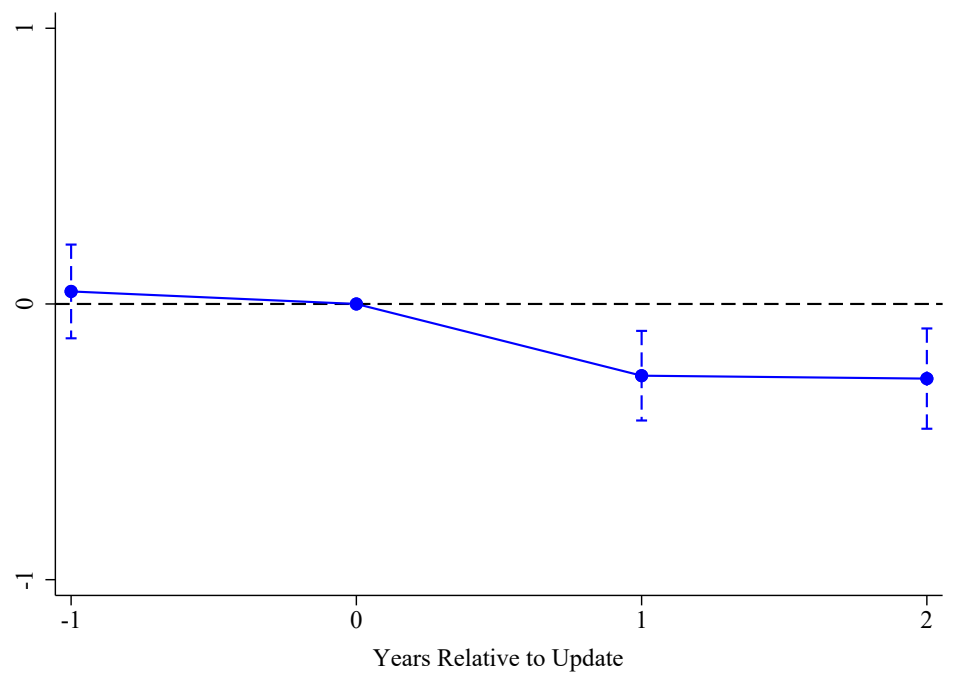

(a) Baseline: Balanced Panel

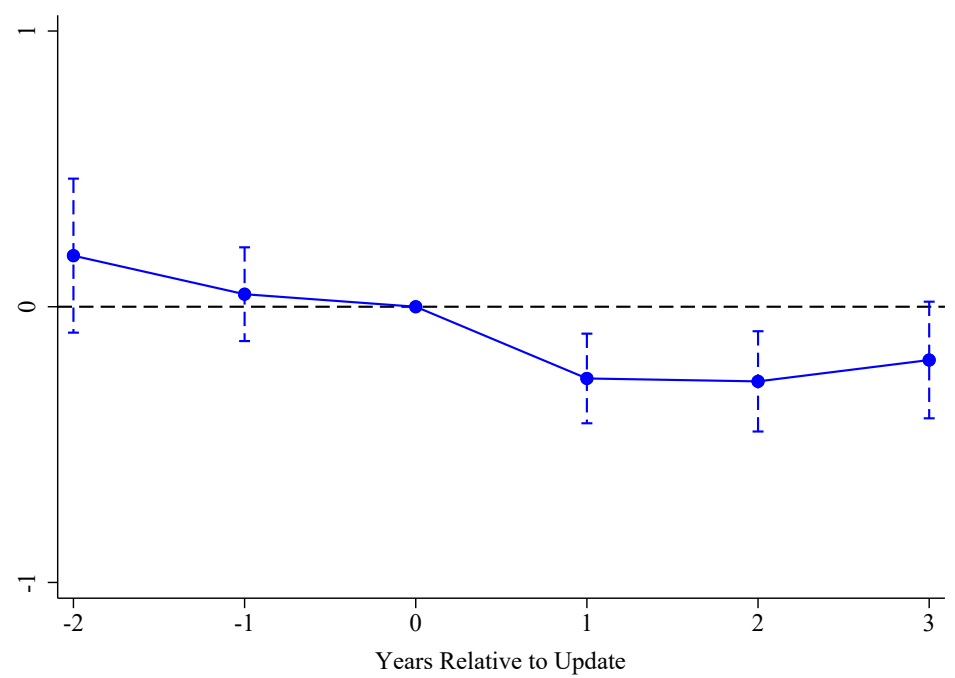

(b) Unbalanced Panel

Notes: The above figure displays estimates from the event study demand estimation described in equation 6 . The dependent variable is the natural logarithm of covered employers. The horizontal axis displays time since the reference base rate update, where each point on the horizontal axis represents policies initiated in the indicated 12 month increment of event time. The event study representation focuses on the rate updates occurring between 2006 and 2011. The data used for this estimation is a series of panels, where each panel includes data from years pre- and post-update. Panel A focuses on a balanced panel (two years pre- and post- each update), while Panel B focuses on an unbalanced panel (three years pre- and post- update) excluding years for which the data is incomplete. Capped vertical bars indicate $95 \%$ confidence intervals, and robust standard errors are clustered at the classification level. 
Figure A7: Selection: Graphical Illustration of Range of Magnitudes From Estimates

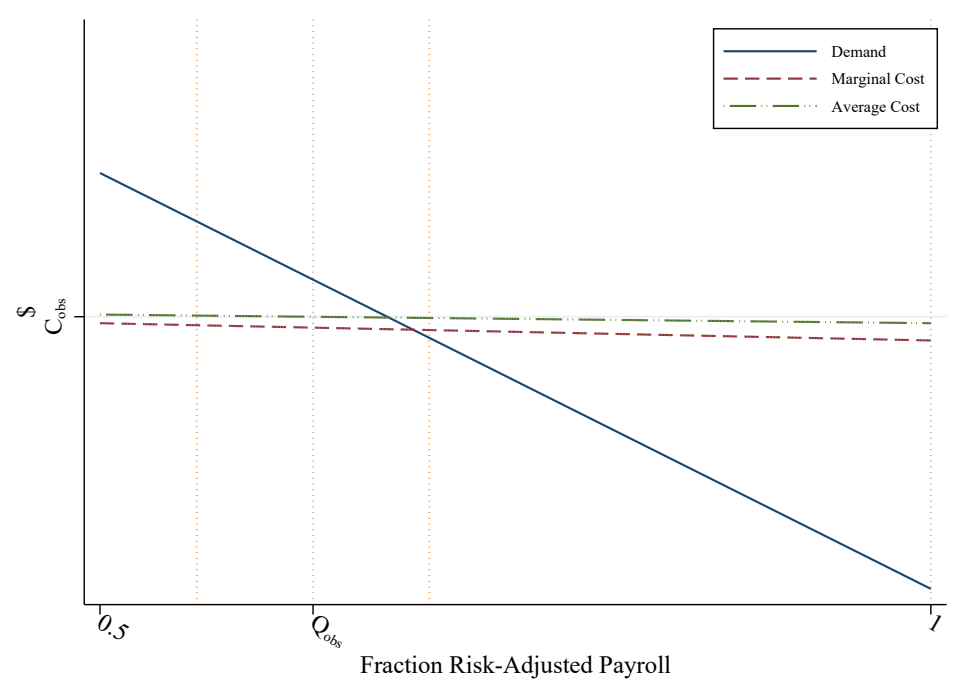

(a) Linear

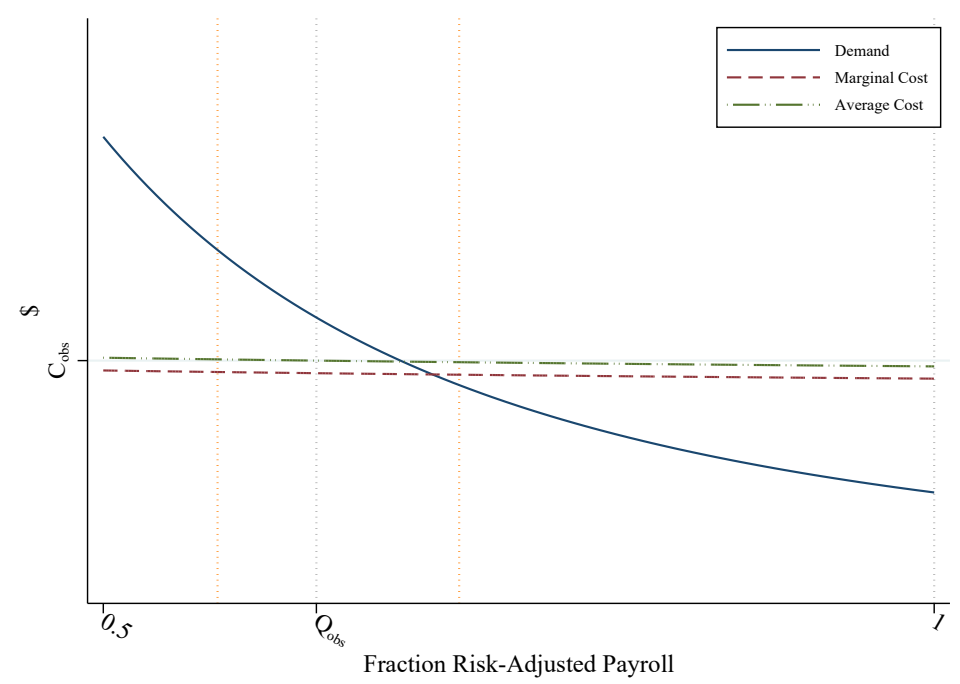

(b) Constant Elasticity

Notes: The above figure depicts a graphical representation of demand and costs based on the empirical estimates in Table 4 . While the selection estimates presented in the text are not statistically distinct from zero, this figure plots the implied marginal and average cost curves based on the point estimates from Table 4 Panel A to give a sense of the magnitude of the point estimates. As discussed in the text, we obtain these curves by combining the estimated elasticities and aggregate summary statistics from the overall market on mean premiums, mean quantities, and mean insurer combined loss ratios. Panel A plots the estimates based on a linear extrapolation, while Panel B presents estimates based on a constant elasticity extrapolation. See Appendix Section C for further details on this calculation. 


\section{Figure A8: Graphical Depiction of Difference-in-Differences Selection Estimates}

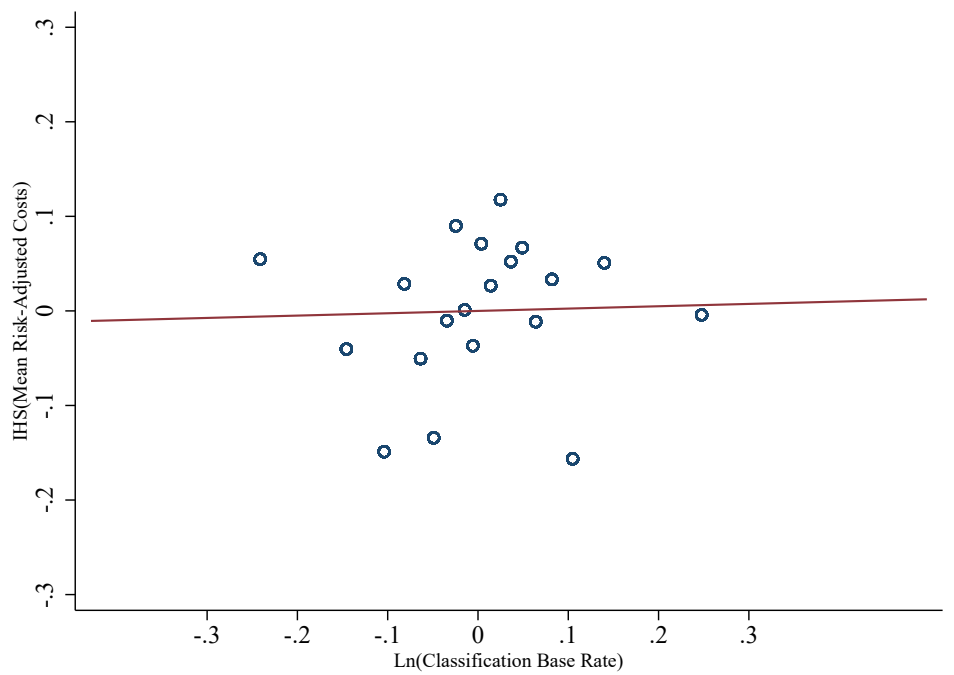

(a) Mean Risk-Adjusted Costs

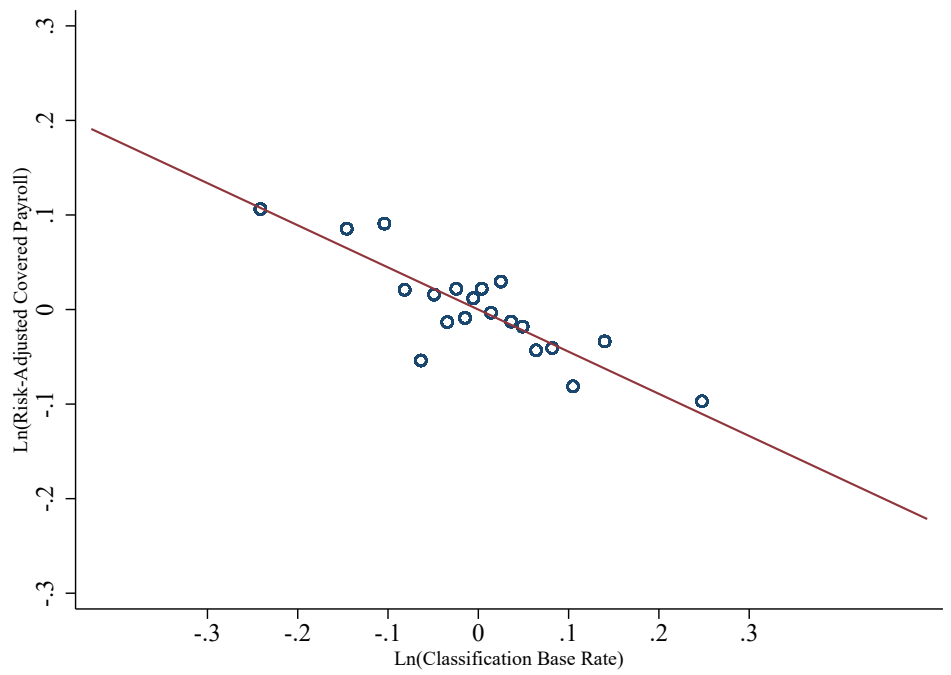

(b) Risk-Adjusted Covered Payroll

Notes: This figure displays binned mean residual scatter plots for the baseline selection analysis. Each dot represents $5 \%$ of the classification-year observations in the baseline analysis data, where bins are defined based on the values on the horizontal axis. Panel A displays the results for mean risk-adjusted costs (analogous to the estimates in Table 4 Panel A column 1), and Panel B displays the results for risk-adjusted covered payroll (analogous to the estimates in Table 4 Panel A column 2). 
Figure A9: Event Study: Selection Estimates

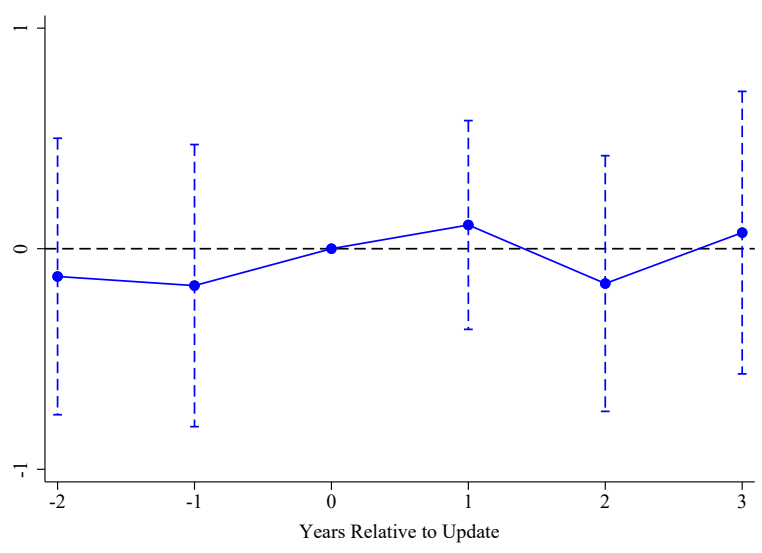

(a) IHS(Mean Risk-Adjusted Costs)

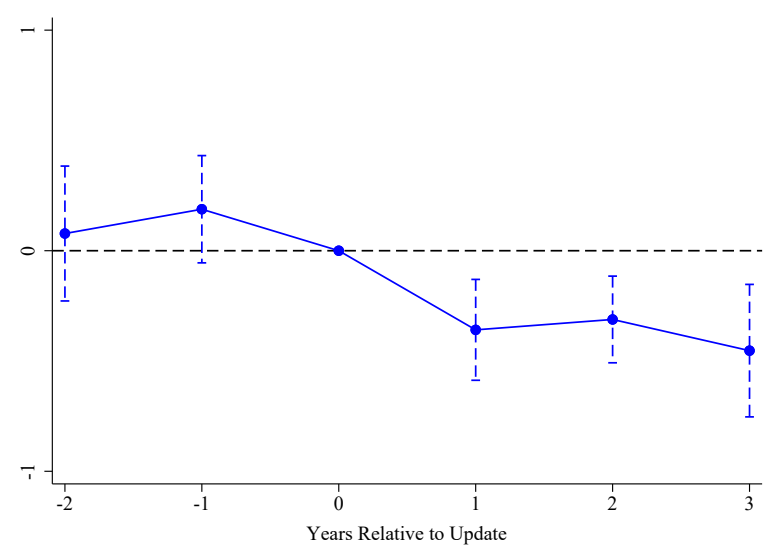

(b) $\ln ($ Risk-Adjusted Covered Payroll)

Notes: The above figure displays estimates from the event study estimation described in equation 6 . The dependent variables are: mean risk-adjusted costs (= costs per $\$ 10 \mathrm{~K}$ of risk-adjusted payroll) (panel A) and risk-adjusted covered payroll (panel B). The horizontal axis displays time since the reference base rate update, where each point on the horizontal axis represents policies initiated in the indicated 12 month increment of event time. The event study representation focuses on the rate updates occurring between 2006 and 2011. The data used for this estimation is a series of balanced panels, where each panel includes data from three years pre- and post-update. Robust standard errors are clustered at the classification level. 
Table A1: Comparison of Workers in Texas and Broader Populations

\begin{tabular}{|c|c|c|c|}
\hline & Texas & $\begin{array}{l}\text { States Recently Considering } \\
\text { Mandate Repeal } \\
\text { (Arkansas, Florida, Oklahoma, } \\
\text { South Carolina, Tennessee) }\end{array}$ & All States \\
\hline Age & 40.6 & 42.0 & 41.4 \\
\hline$\%$ Male & $54.6 \%$ & $52.3 \%$ & $52.9 \%$ \\
\hline$\%$ Worked full time & $82.7 \%$ & $81.5 \%$ & $79.3 \%$ \\
\hline Family income & $\$ 72,743$ & $\$ 69,652$ & $\$ 78,668$ \\
\hline Individual earnings & $\$ 35,757$ & $\$ 34,641$ & $\$ 37,293$ \\
\hline Weekly earnings & $\$ 747$ & $\$ 724$ & $\$ 783$ \\
\hline Health Care/Educational Services & $20.2 \%$ & $20.9 \%$ & $21.5 \%$ \\
\hline Manufacturing & $9.5 \%$ & $9.2 \%$ & $10.8 \%$ \\
\hline Mining/Utilities/Construction & $12.8 \%$ & $10.3 \%$ & $9.9 \%$ \\
\hline Public Adminstration/Other Services & $4.4 \%$ & $5.1 \%$ & $4.7 \%$ \\
\hline Wholesale Trade/Retail Trade/Transportation & $20.1 \%$ & $20.1 \%$ & $18.9 \%$ \\
\hline
\end{tabular}

Notes: This table compares the population of workers in Texas (column 1), in states recently considering mandate repeal (Arkansas, Florida, Oklahoma, South Carolina, Tennessee) (column 2) and in the entire United States (column 3) using data from the Current Population Survey Annual Social and Economic Supplement 2007-2012 (representing years 2006-2011) (Flood et al. (2021)). For this table, we define a worker as an individual with positive weeks of work reported in the prior year. All dollar values are CPI-U adjusted to 2006 dollars. 
Table A2: Robustness: Workers' Compensation Classification Coding

\begin{tabular}{|c|c|c|}
\hline & Dependent Variable: & $I\left(c_{j, t} \neq c_{j, t-1}\right)$ \\
\hline & (1) & (2) \\
\hline \multirow[t]{3}{*}{$\Delta \ln (\text { baseRate })_{c_{j, t-1}}$} & -0.036 & -0.019 \\
\hline & (0.039) & $(0.046)$ \\
\hline & [0.360] & [0.678] \\
\hline \multicolumn{3}{|l|}{ Controls } \\
\hline Employer Fixed Effects & $\mathrm{x}$ & $\mathrm{x}$ \\
\hline Classification Fixed Effects & $\mathrm{x}$ & $\mathrm{x}$ \\
\hline Year Fixed Effects & $\mathrm{x}$ & \\
\hline \multicolumn{2}{|c|}{ Two-digit Classification X Year Fixed Effects } & $x$ \\
\hline Mean Dep Var & 0.087 & 0.087 \\
\hline
\end{tabular}

Notes: The table above presents estimates from specifications as outlined in Appendix equation 10. These employer-year-level regressions include controls as listed above: employer fixed effects, classification fixed effects, year fixed effects (in column 1), and twodigit-classification-year fixed effects (in column 2). Each column represents a separate regression, where the estimated coefficients are displayed along with the associated standard errors in parentheses and p-values in brackets. The data used in these regressions cover the time period 2006-2011. This analysis focuses on employer-year observations where the employer is insured both in year $t$ and year $t-1(\mathrm{~N}=789,223)$. Standard errors are clustered at the classification level. Both the classification-level clustering and the classification fixed effects described above are based on the classification in the prior year, $c_{j, t-1}$. 
Table A3: Supplemental Evidence: Impact of Governing Base Rates on Overall Base Rates

\begin{tabular}{lcc}
\hline & $\ln \left(\right.$ Mean Overall Base Rate $\left.{ }_{\mathrm{jt}}\right)$ & $\ln \left(\right.$ Mean Overall Premiums $\left._{\mathrm{jt}}\right)$ \\
\hline & $(1)$ & $(2)$ \\
\hline $\ln \left(\right.$ baseRate $\left._{j t}\right)$ & 0.975 & 0.970 \\
& $(0.002)$ & $(0.023)$ \\
& {$[<0.001]$} & {$[<0.001]$} \\
\hline
\end{tabular}

Notes: The table above presents estimates from specifications as outlined in Appendix equation 11. These classification-year-level regressions include year fixed effects and classification fixed effects. The dependent variables are as indicated in the table. Each column represents a separate regression, where the estimated coefficients are displayed along with the associated standard errors in parentheses and p-values in brackets. The data used in these regressions cover the time period 2006-2011. Standard errors are clustered at the classification level. 
Table A4: Robustness: Demand Estimates Without Excluding Certified Self-Insured Employers

\begin{tabular}{|c|c|c|c|c|}
\hline \multicolumn{5}{|c|}{ Dependent Variable: $\ln \left(\right.$ covered employers $_{j t}$ ) } \\
\hline & (1) & (2) & (3) & (4) \\
\hline \multirow[t]{3}{*}{$\ln \left(\right.$ baseRate $\left._{j t}\right)$} & -0.380 & -0.333 & -0.389 & -0.352 \\
\hline & $(0.082)$ & $(0.078)$ & $(0.097)$ & $(0.113)$ \\
\hline & {$[<0.001]$} & {$[<0.001]$} & {$[<0.001]$} & [0.002] \\
\hline \multirow{3}{*}{$\ln \left(\right.$ baseRate $\left._{j, t+2}\right)$} & & & 0.023 & \\
\hline & & & $(0.113)$ & \\
\hline & & & [0.841] & \\
\hline \multirow[t]{3}{*}{ In(uncappedBaseRate $\left.{ }_{j t}\right)^{*} \mid\left(\right.$ capBinding $\left._{j}\right)$} & & & & -0.049 \\
\hline & & & & $(0.130)$ \\
\hline & & & & [0.707] \\
\hline \multicolumn{5}{|l|}{ Controls } \\
\hline Classification Fixed Effects & $\mathrm{x}$ & $\mathrm{x}$ & $\mathrm{x}$ & $x$ \\
\hline Year Fixed Effects & $\mathrm{x}$ & $\mathrm{x}$ & $\mathrm{x}$ & $\mathrm{x}$ \\
\hline Classification-specific Time Trend, 2-digit & & $x$ & & \\
\hline
\end{tabular}

Notes: This table repeats the demand analysis in Table 3 columns 1 through 4 using all employers within the proof-of-coverage data, without excluding certified self-insured employers. The data used in these regressions cover the time period 2006-2011, where each observation represents a classification-year $(\mathrm{N}=2,058)$. The dependent variable is: $\ln$ (covered employers). Each column represents a separate regression, where the estimated coefficients are displayed along with the associated standard errors in parentheses and p-values in brackets. These classification-year-level regressions include year fixed effects and classification fixed effects. While column 1 reports the baseline specification, the remaining columns report alternative specifications with additional variables: 2-digit classification-specific time trends (column 2), leads of the legislated base rates (column 3) and uncapped base rates that were not ultimately adopted (column 4). These uncapped base rates correspond to the balanced indicated relative base rates discussed in Appendix Section B. Robust standard errors are clustered at the classification level. 
Table A5: Descriptive Statistics

\begin{tabular}{|c|c|c|}
\hline \multicolumn{3}{|c|}{ All Classification-Year Observations, 2006-2011 } \\
\hline & Mean & Std. Dev. \\
\hline Classification Base Rate ( $\$$ per $\$ 100$ in payroll) & 2.41 & 3.32 \\
\hline Mean Premium ( $\$$ per $\$ 100$ in risk-adjusted payroll) & 2.19 & 3.07 \\
\hline Mean Premium ( $\$$ per $\$ 100$ in payroll) & 1.81 & 2.54 \\
\hline \multicolumn{3}{|l|}{ Mean Claim Cost ( $\$$ per $\$ 100$ in payroll) } \\
\hline All & 0.69 & 1.22 \\
\hline Medical & 0.43 & 0.83 \\
\hline Indemnity & 0.26 & 0.48 \\
\hline \multicolumn{3}{|l|}{ Mean Claim Cost ( $\$$ per $\$ 100$ in risk-adjusted payroll) } \\
\hline All & 0.84 & 1.53 \\
\hline Medical & 0.52 & 1.03 \\
\hline Indemnity & 0.32 & 0.61 \\
\hline \multicolumn{3}{|l|}{ Mean Claims (\# per $\$ 50 \mathrm{~K}$ in payroll) } \\
\hline All & 0.031 & 0.040 \\
\hline Serious Indemnity & 4.03E-04 & 7.36E-04 \\
\hline Non-Serious Indemnity & 0.008 & 0.011 \\
\hline Medical Only & 0.022 & 0.030 \\
\hline
\end{tabular}

Notes: This table describes the classification-year data from 2006 to 2011 used in the baseline demand analysis $(\mathrm{N}=2,064)$. The means in this table represent market-wide averages, weighting by the payroll covered within each classification. The mean claim cost measures described above capture mean claim costs (total unwinsorized incurred losses per $\$ 100$ payroll or risk-adjusted payroll), where these claim costs are inclusive of both insurer costs and employer out-of-pocket costs. These cost measures reflect losses reported by the $42^{\text {nd }}$ month after the policy effective date, and we adjust these losses by TDI reported loss development factors to account for expected future reported costs related to these claims. In the above table, dollar quantities are adjusted using the CPI-U to be 2006 dollars. 
Table A6: Eligible Population of Workers and Firms

\begin{tabular}{|c|c|c|c|c|}
\hline \multicolumn{5}{|c|}{ Panel A: All Industries } \\
\hline & \multicolumn{2}{|c|}{ In(Total Number of Establishments) } & \multicolumn{2}{|c|}{$\ln$ (Total Number of Workers) } \\
\hline & (1) & (2) & (3) & (4) \\
\hline \multirow[t]{3}{*}{$\ln \left(\right.$ baseRate $\left._{j t}\right)$} & -0.107 & -0.049 & -0.106 & -0.019 \\
\hline & $(0.066)$ & $(0.045)$ & $(0.074)$ & $(0.063)$ \\
\hline & [0.109] & {$[0.273]$} & {$[0.149]$} & [0.764] \\
\hline \multicolumn{5}{|l|}{ Controls } \\
\hline Industry Fixed Effects & $\mathrm{x}$ & $\mathrm{x}$ & $\mathrm{x}$ & $\mathrm{x}$ \\
\hline Year Fixed Effects & $\mathrm{x}$ & $\mathrm{x}$ & $\mathrm{x}$ & $\mathrm{x}$ \\
\hline Industry-specific Time Trend, 3-digit & & $\mathrm{x}$ & & $\mathrm{x}$ \\
\hline \multicolumn{5}{|c|}{ Panel B: Industries Mapping to Only One Classification } \\
\hline & \multicolumn{2}{|c|}{ In(Total Number of Establishments) } & \multicolumn{2}{|c|}{ In(Total Number of Workers) } \\
\hline & (1) & (2) & (3) & (4) \\
\hline $\ln \left(\right.$ baseRate $_{j t}$ ) & 0.003 & 0.062 & 0.110 & 0.113 \\
\hline & $(0.080)$ & $(0.064)$ & $(0.144)$ & (0.100) \\
\hline & [0.974] & [0.335] & [0.444] & [0.262] \\
\hline \multicolumn{5}{|l|}{ Controls } \\
\hline Industry Fixed Effects & $\mathrm{x}$ & $\mathrm{x}$ & $\mathrm{x}$ & $\mathrm{x}$ \\
\hline Year Fixed Effects & $\mathrm{x}$ & $\mathrm{x}$ & $\mathrm{x}$ & $\mathrm{x}$ \\
\hline Industry-specific Time Trend, 3-digit & & $\mathrm{x}$ & & $x$ \\
\hline
\end{tabular}

Notes: The table above presents estimates from specifications as outlined in Appendix equation 16. In this table, $i$ is a 6-digit NAICS industry, and $t$ is a year. In this specification, $\ln \left(b_{i t}\right)$ represents the natural logarithm of the mean base rate applicable in the industry based on a crosswalk between NAICS-classification codes. All specifications include year and industry fixed effects, and we estimate specifications with an additional control: a 3-digit NAICS industry-specific time trend. Each column represents a separate regression, where the estimated coefficients are displayed along with the associated standard errors in parentheses and p-values in brackets. Panel A focuses on a balanced sample of industry-year observations from industries with average annual employment exceeding 1,000 workers during 2006-2011 ( $\mathrm{N}=3,582$ industry-year observations), and Panel B further restricts attention to industries where there is a unique associated classification ( $\mathrm{N}=540$ industry-year observations). The dependent variables are as indicated in the table. Robust standard errors are clustered at the industry level. See Appendix Section D.4 for more details on this analysis. 
Table A7: Event Study Regression Estimates

\begin{tabular}{|c|c|c|c|}
\hline & $\ln \left(\right.$ mean premiums $\left.{ }_{j t}\right)$ & In(covered employers $\mathrm{j}_{\mathrm{j}}$ ) & $\operatorname{In}\left(\right.$ covered payroll $\left.\mathrm{j}_{\mathrm{j} t}\right)$ \\
\hline & (1) & (2) & (3) \\
\hline \multirow{3}{*}{$\mathbb{I}_{\{-2\}} \times\left[\ln \left(b_{1 j p}\right)-\ln \left(b_{0 j p}\right)\right]$} & -0.017 & & 0.028 \\
\hline & $(0.021)$ & & (0.159) \\
\hline & {$[0.405]$} & & {$[0.861]$} \\
\hline \multirow[t]{3}{*}{$\mathrm{I}_{\{-1\}} \times\left[\ln \left(\mathrm{b}_{1 \mathrm{jp}}\right)-\ln \left(\mathrm{b}_{0 \mathrm{jp}}\right)\right]$} & -0.007 & 0.045 & 0.140 \\
\hline & $(0.012)$ & $(0.087)$ & $(0.133)$ \\
\hline & {$[0.578]$} & {$[0.601]$} & [0.294] \\
\hline \multirow[t]{3}{*}{$\mathrm{I}_{\{1\}} X\left[\ln \left(\mathrm{b}_{1 \mathrm{jp}}\right)-\ln \left(\mathrm{b}_{0 \mathrm{jp}}\right)\right]$} & 0.999 & -0.260 & -0.268 \\
\hline & $(0.016)$ & $(0.083)$ & $(0.124)$ \\
\hline & {$[<0.001]$} & {$[0.002]$} & [0.031] \\
\hline \multirow[t]{3}{*}{$\mathrm{I}_{\{2\}} X\left[\ln \left(\mathrm{b}_{1 \mathrm{jp}}\right)-\ln \left(\mathrm{b}_{0 \mathrm{jp}}\right)\right]$} & 0.977 & -0.271 & -0.196 \\
\hline & $(0.022)$ & $(0.093)$ & (0.111) \\
\hline & {$[<0.001]$} & {$[0.004]$} & [0.078] \\
\hline \multirow[t]{3}{*}{$\mathrm{I}_{\{3\}} X\left[\ln \left(\mathrm{b}_{1 \mathrm{jp}}\right)-\ln \left(\mathrm{b}_{0 \mathrm{jp}}\right)\right]$} & 0.989 & & -0.301 \\
\hline & (0.029) & & (0.164) \\
\hline & {$[<0.001]$} & & [0.068] \\
\hline
\end{tabular}

Notes: The table above presents estimates from specifications as outlined in equation 6 . The dependent variables are as indicated in each column: the natural logarithm of mean premiums per $\$ 100$ of risk-adjusted payroll (column 1), the natural logarithm of covered employers (column 2), and the natural logarithm of covered payroll (column 3). Time in this specification indicates time since the reference base rate update, where observations represent policies initiated in the indicated 12 month increment of event time. The event study specification focuses on the rate updates occurring between 2006 and 2011. The data used for this estimation is a series of balanced panels, where each panel includes data from three years (or two years in column 2) pre- and post-update. Robust standard errors are clustered at the classification level. 
Table A8: Demand Estimates: Additional Robustness Analysis

\begin{tabular}{|c|c|c|c|c|c|}
\hline \multirow{7}{*}{ In(baseRate $\left.{ }_{j t}\right)$} & \multicolumn{5}{|c|}{ 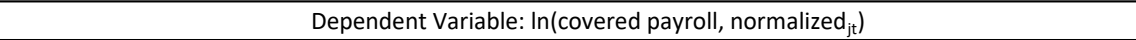 } \\
\hline & \multicolumn{5}{|c|}{$\%$ of premiums borne by employees } \\
\hline & $0 \%$ (baseline) & $10 \%$ & $25 \%$ & $50 \%$ & $100 \%$ \\
\hline & (1) & (2) & (3) & (4) & $(5)$ \\
\hline & -0.293 & -0.287 & -0.277 & -0.260 & -0.222 \\
\hline & $(0.122)$ & $(0.122)$ & $(0.122)$ & $(0.122)$ & $(0.122)$ \\
\hline & {$[0.017]$} & [0.019] & {$[0.024]$} & {$[0.034]$} & {$[0.070]$} \\
\hline \multicolumn{6}{|c|}{ Panel B: Robustness, alternative samples } \\
\hline & \multicolumn{5}{|c|}{ Dependent Variable: In (covered payroll $\mathrm{j}_{\mathrm{jt}}$ ) } \\
\hline \multirow{4}{*}{$\ln \left(\right.$ baseRate $\left._{j t}\right)$} & $(1)$ & $(2)$ & \multicolumn{3}{|l|}{$(3)$} \\
\hline & -0.293 & -0.292 & \multicolumn{2}{|l|}{-0.371} & \\
\hline & $(0.122)$ & $(0.123)$ & \multicolumn{2}{|l|}{$(0.154)$} & \\
\hline & {$[0.017]$} & {$[0.018]$} & \multicolumn{2}{|l|}{$[0.016]$} & \\
\hline \multirow[t]{4}{*}{ Sample } & baseline & $\begin{array}{c}\text { drop common } \\
\text { secondary classes }\end{array}$ & \multicolumn{2}{|l|}{ drop small classes } & \\
\hline & \multicolumn{4}{|c|}{ Panel C: Robustness, alternative weighting } & \\
\hline & & Deper & ent Variable: $\operatorname{In}$ (covered & $\mathrm{yroll}_{\mathrm{jt}}$ ) & \\
\hline & $(1)$ & $(2)$ & (3) & (4) & \\
\hline \multirow[t]{3}{*}{ In $\left(\right.$ baseRate $\left._{j t}\right)$} & -0.293 & -0.210 & -0.241 & -0.197 & \\
\hline & $(0.122)$ & $(0.104)$ & (0.114) & $(0.095)$ & \\
\hline & {$[0.017]$} & {$[0.044]$} & {$[0.036]$} & {$[0.038]$} & \\
\hline Weights & unweighted & $\begin{array}{l}\text { baseline covered } \\
\text { payroll }\end{array}$ & $\begin{array}{l}\text { baseline risk-adjusted } \\
\text { covered payroll }\end{array}$ & baseline premiums & \\
\hline
\end{tabular}

Notes: The table above presents robustness analysis from the difference-in-differences demand estimation outlined in equation 2. The data used in these regressions cover the time period 2006-2011, and each regression includes year fixed effects and classification fixed effects. Each column represents a separate regression, where the estimated coefficients are displayed along with the associated standard errors in parentheses and p-values in brackets. Panel A displays robustness analysis under alternative assumptions on the incidence of changes in workers' compensation premiums. Specifically, these additional specifications repeat the baseline payroll regression replacing the dependent variable with the natural logarithm of normalized covered payroll: $\ln \left(\frac{\text { payroll }_{j t}}{1-\theta \times \text { premium }_{j t}}\right)$, where premium $_{j t}$ represents the mean premium per dollar of payroll for classification $j$ in year $t$ and $\theta$ represents the fraction of premiums shifted to workers in the form of reduced wages. The corresponding assumption on the incidence of premium changes (the value of $\theta$ ) is denoted in each column. Panel B displays robustness analysis using alternative samples: the baseline analysis data (column $1 ; \mathrm{N}=2,064)$, dropping common secondary classifications (column 2; $\mathrm{N}=2,046$ ), and dropping small classifications with less than $\$ 10$ million in mean annual covered payroll (column 3; $\mathrm{N}=1,716$ ). Panel $\mathrm{C}$ displays alternative specifications weighting regressions by the indicated weights. In all panels, robust standard errors are clustered at the classification level. 
Table A9: Robustness: Selection Estimates

\begin{tabular}{|c|c|c|c|c|c|c|c|}
\hline & \multicolumn{3}{|c|}{$\ln \left(\right.$ baseRate $\left._{\mathrm{jt}}\right)$} & \multicolumn{2}{|c|}{ Implied $\Delta \mathrm{Q}: \mathrm{Q}^{\text {optimal }}-\mathrm{Q}^{\mathrm{CE}}$} & \multicolumn{2}{|c|}{$\begin{array}{c}\text { Implied DWL from selection relative } \\
\text { to optimal }\end{array}$} \\
\hline & Est & Std Err & $p$-value & Linear & Const Elasticity & Linear & Const Elasticity \\
\hline & (1) & (2) & (3) & (4) & (5) & (6) & (7) \\
\hline (1) baseline & 0.025 & $(0.265)$ & {$[0.926]$} & 0.015 & 0.018 & 0.00080 & 0.00090 \\
\hline \multicolumn{8}{|l|}{ Alternative Specifications } \\
\hline (2) shifted natural logarithm, $\ln (x+1)$ & 0.030 & (0.244) & [0.901] & 0.018 & 0.023 & 0.00123 & 0.00139 \\
\hline (3) natural logarithm & 0.086 & $(0.192)$ & {$[0.653]$} & 0.057 & 0.076 & 0.01103 & 0.01250 \\
\hline \multicolumn{8}{|l|}{ Alternative Cost Measures } \\
\hline (4) unwinsorized & 0.009 & $(0.280)$ & [0.974] & 0.005 & 0.006 & 0.00011 & 0.00012 \\
\hline (5) winsorize at 99.9 percentile & 0.012 & $(0.275)$ & [0.965] & 0.007 & 0.009 & 0.00019 & 0.00022 \\
\hline (6) winsorize at 98 percentile & 0.028 & (0.258) & [0.914] & 0.016 & 0.020 & 0.00102 & 0.00115 \\
\hline (7) undeveloped losses & 0.034 & (0.259) & {$[0.897]$} & 0.020 & 0.025 & 0.00151 & 0.00170 \\
\hline
\end{tabular}

Notes: The table above presents alternative specifications for the cost regressions. The coefficients reported above are from a differencein-differences specification as outlined in equation 2. These classification-year-level regressions include the following controls: year fixed effects and classification fixed effects. Each row represents a separate regression, where the table displays the estimated coefficient (column 1), standard error (column 2) and p-value (column 3). Robust standard errors are clustered at the classification level. The data used in these regressions cover the time period 2006-2011, where each observation represents a classification-year ( $\mathrm{N}=2,030$ in natural logarithm specification in row 3 and $\mathrm{N}=2,064$ in all other specifications). Unless otherwise noted, the dependent variable is the inverse hyperbolic sine of costs per $\$ 10 \mathrm{~K}$ of risk-adjusted payroll. See Appendix Section $\mathrm{C}$ for more details on risk-adjustment used in this analysis. Columns 4 and 5 report the implied difference in insured quantity, comparing the optimal quantity to the competitive equilibrium under a linear and constant elasticity extrapolation, respectively. Columns 6 and 7 report the implied deadweight loss of selection, comparing the competitive equilibrium to the optimal allocation, based on a linear and constant elasticity extrapolation, respectively. 
Table A10: Selection Estimates: Empirical Cost Curves

\begin{tabular}{|c|c|c|c|c|}
\hline & \multicolumn{2}{|c|}{ Linear } & \multicolumn{2}{|c|}{ Constant Elasticity } \\
\hline & $\begin{array}{l}\text { Est } \\
(1) \\
\end{array}$ & $\begin{array}{c}\text { Std Err } \\
\text { (2) }\end{array}$ & $\begin{array}{l}\text { Est } \\
\text { (3) }\end{array}$ & $\begin{array}{c}\text { Std Err } \\
(4)\end{array}$ \\
\hline \multicolumn{5}{|l|}{ Demand Curve } \\
\hline Constant & 7.1229 & $(1.56)$ & 0.7736 & $(0.21)$ \\
\hline Slope & -7.8431 & $(2.49)$ & -2.2441 & $(0.71)$ \\
\hline \multicolumn{5}{|l|}{ Average Cost Curve } \\
\hline Constant & 1.9478 & $(1.21)$ & 1.7985 & $(0.53)$ \\
\hline Slope & -0.1629 & $(1.93)$ & -0.0555 & $(0.66)$ \\
\hline \multicolumn{5}{|l|}{ Marginal Cost Curve } \\
\hline Constant & 1.9478 & $(1.21)$ & 1.6988 & (1.73) \\
\hline Slope & -0.3258 & $(3.85)$ & -0.0555 & $(0.66)$ \\
\hline
\end{tabular}

Notes: The table above reports the implied linear and constant elasticity parameters for demand as a function of the quantity insured based on the estimates in Table 4 Panel A. In this table, the "constant" and "slope" in the constant elasticity specification $\left(P=A Q^{\beta}\right)$ refer to $A$ and $\beta$, respectively; in the linear specification $(P=A+\beta Q)$, the "constant" and "slope" refer to $A$ and $\beta$, respectively. The table reports bootstrapped standard errors clustered at the classification level, where 1,000 randomly drawn bootstrap samples are used. 
Table A11: Robustness: Welfare Calculations with Empirical Cost Curves

\begin{tabular}{|c|c|c|c|c|}
\hline & \multicolumn{2}{|c|}{ Linear } & \multicolumn{2}{|c|}{ Constant Elasticity } \\
\hline & $\begin{array}{l}\text { Baseline } \\
\text { (1) }\end{array}$ & $\begin{array}{c}\text { Alternative } \\
\text { (2) }\end{array}$ & $\begin{array}{l}\text { Baseline } \\
\text { (3) }\end{array}$ & $\begin{array}{c}\text { Alternative } \\
\text { (4) }\end{array}$ \\
\hline \multicolumn{5}{|l|}{ Counterfactuals } \\
\hline \multicolumn{5}{|l|}{ Quantity (fraction risk-adjusted payroll covered) } \\
\hline Mandate & 1.000 & 1.000 & 1.000 & 1.000 \\
\hline Optimal & 0.673 & 0.688 & 0.679 & 0.698 \\
\hline \multicolumn{5}{|l|}{ Welfare (relative to status quo) } \\
\hline \multicolumn{5}{|l|}{ Mandate } \\
\hline per $\$ 100$ of risk-adjusted payroll & -0.4118 & -0.3513 & -0.1992 & -0.1522 \\
\hline scaled by $\$ 50,000$ & -205.91 & -175.63 & -99.59 & -76.10 \\
\hline$\%$ of mean premium & $-18.8 \%$ & $-16.0 \%$ & $-9.1 \%$ & $-6.9 \%$ \\
\hline \multicolumn{5}{|l|}{ Optimal } \\
\hline per $\$ 100$ of risk-adjusted payroll & 0.0078 & 0.0136 & 0.0085 & 0.0149 \\
\hline scaled by $\$ 50,000$ & 3.91 & 6.81 & 4.24 & 7.45 \\
\hline$\%$ of mean premium & $0.4 \%$ & $0.6 \%$ & $0.4 \%$ & $0.7 \%$ \\
\hline \multicolumn{5}{|c|}{ Subsidy to support optimal allocation--25\% MDWL of taxation } \\
\hline per $\$ 100$ of risk-adjusted payroll & -0.0511 & -0.0676 & -0.0509 & -0.0659 \\
\hline scaled by $\$ 50,000$ & -25.55 & -33.82 & -25.47 & -32.93 \\
\hline$\%$ of mean premium & $-2.3 \%$ & $-3.1 \%$ & $-2.3 \%$ & $-3.0 \%$ \\
\hline
\end{tabular}

Notes: The table above presents alternative welfare calculations that use the implied empirical cost curves based on the elasticities in Table 4 Panel A. Columns 1 and 3 display the baseline welfare estimates for reference. The table reports welfare measured in dollars per $\$ 100$ of risk-adjusted payroll. In addition, the table reports two scaled measures of welfare to ease interpretation: (i) welfare measures scaled by $\$ 50 \mathrm{~K}$, approximately the mean annual earnings for this population and (ii) welfare as a percent of mean premiums observed in the status quo (one measure of the size of the market). See Table 5 and Appendix Section C for further details on the welfare calculations. 